Aus der Abteilung Prothetik

(Komm. Direktor: Priv.-Doz. Dr. med. dent. N. Gersdorff)

im Zentrum Zahn-, Mund- und Kieferheilkunde

der Medizinischen Fakultät der Universität Göttingen

\title{
Einfluss verschiedener Reinigungsmethoden auf die Haftkraft rezementierter implantatgetragener Zirkoniumdioxid-Kronengerüste
}

\section{INAUGURAL-DISSERTATION}

\author{
zur Erlangung des Doktorgrades \\ für Zahnheilkunde
}

der Medizinischen Fakultät

der Georg-August-Universität zu Göttingen

\author{
vorgelegt von \\ Franziska Pohlmeyer \\ aus Itzehoe
}

Göttingen 2013 
Dekan:

I. Berichterstatter/in:

II. Berichterstatter/in:

III. Berichterstatter/in:

Tag der mündlichen Prüfung:
Prof. Dr. rer. nat. H. K. Kroemer

PD Dr. med. dent. N. Gersdorff

Prof. Dr. med. dent. M. Hülsmann

Prof. Dr. med. M. Oppermann 
In Liebe und Dankbarkeit meinen Eltern Heinrich und Aspasia Pohlmeyer gewidmet. 


\section{Inhaltsverzeichnis}

1. EINLEITUNG UND FRAGESTELLUNG

2. LITERATURÜBERSICHT 5

2.1. GeSCHICHTLICHE ENTWICKLUNG DER DENTALEN IMPLANTOLOGIE 5

2.2. EINTEILUNG DER IMPLANTATE

2.2.1. BEDECKUNG 8

2.2.2. LAGE 8

2.2.3. IMPLANTATMATERIAL 8

2.2.4. IMPLANTATFORM 12

$\begin{array}{ll}\text { 2.2.5. IMPLANTATIONSZEITPUNKT } & 13\end{array}$

2.2.6. EINHEILUNG 14

2.3. OSSEOINTEGRATION

2.4. GeschichtLiche ENTWickLUNG Dentaler Keramiken 17

2.5. EINTEILUNG UND WERKSTOFFKUNDLICHE ASPEKTE DENTALER KERAMIKEN 19

2.5.1. SILIKATKERAMISCHE WERKSTOFFE 20

2.5.2. OXIDKERAMISCHE WERKSTOFFE 23

2.6. Dentale CAD/CAM-TeChnologie 27

2.6.1. CAD/CAM IN DER IMPLANTOLOGIE 28

2.7. Allgemeines ZU dentalen Befestigungszementen 29

2.7.1. DENTALZEMENTE UND IMPLANTATGETRAGENE SUPRAKONSTRUKTIONEN 32

2.8. REINIGUNGSMETHODEN 33

2.8.1. GRUNDPRINZIPIEN 33

3. MATERIAL UND METHODE

3.1. Versuchsplanung, Pilotstudie Und Materialien 35

3.2. Herstellung der Probekörper 36

3.1. Herstellung der EinzelzahnKronengerüste 38

3.2. ZEMENTIERUNG

3.3. ReINIGUNGSMEthoden 42

3.4. AbZugsversuch 42 
3.5. MATERIALANALYSE IM RASTERELEKTRONENMIKROSKOP (REM) 44

3.5.1. AufBau des RAStereleKtronenMikROSKOPS REM 46

3.5.2. Präparation der Proben 48

3.6. Statistische Methoden 50

4. ERGEBNISSE $\quad 51$

4.1. Statistische Auswertung Der ERgebnisse 52

4.2. Proben im Rasterelektronenmikroskop 54

4.2.1. TEMPBOnd® NE (KerR,Ratstatt, Deutschland) 54

4.2.2. UNBEHANDELTES REFERENZKÄPPCHEN 55

4.2.3. MANUELL GEREINIGTES KÄPPCHEN 56

4.2.4. Manuelle Reinigung in Kombination mit Ultraschall 57

4.2.5. ReINIGUNG DURCH AUSStrahlen MIT AlUMINIUMdIOXID 58

4.3. ENERGIEDISPERSIVE RÖNTGENSPEKTROSKOPIE (EDX-ANALYSE) 59

4.3.1. TempBOnd® NE (KerR,RAtstatt, Deutschland) 59

4.3.2. UNBEHANDELTES ZIRKONIUMDIOXID-KÄPPCHEN 60

5. DISKUSSION 61

5.1. SCHLUSSFOlgerUNG FÜR DIE PraXIS 69

6. ZUSAMMENFASSUNG $\quad 70$

7. LITERATURVERZEICHNIS $\quad 71$ 


\section{Einleitung und Fragestellung}

Im Rahmen der prothetischen Versorgung zahnloser und teilbezahnter Kiefer, sowie einzelner Zahnlücken, sind osseointegrierte Implantate immer häufiger fester Bestandteil komplexer Therapieverfahren in der heutigen Zahnmedizin und dienen der Verankerung von festsitzendem oder herausnehmbarem Zahnersatz (Spiekermann 1994).

Diese Art der restaurativen Versorgung gewährleistet einen besseren Halt von Totalprothesen und kann als Pfeilervermehrung fungieren. Des Weiteren wirken enossale Implantate der Atrophie zahnloser Kiefer entgegen und schonen im Gegensatz zu parodontal getragenen Versorgungen die Zahnhartsubstanz.

Um die Gefahr einer Fremdkörperreaktion zu minimieren, müssen Werkstoffe für dentale Implantate Eigenschaften, wie beispielsweise eine gute Biokompatibilität, keine toxischen Korrosionsprodukte oder kanzerogenen Wirkungen aufweisen. In den letzten Jahrzehnten hat sich Titan als Werkstoff der Wahl in diesem Bereich etabliert.

Neben den bekannten Vorteilen bei der Verwendung des Titans als Implantatmaterial, wie seiner außerordentlichen Festigkeit und hervorragenden biologischen Verträglichkeit, kann es speziell bei Versorgungen im Frontzahnbereich zu ästhetischen Einbußen kommen. Diese werden in der Regel durch ein Hindurchscheinen des Metallrandes durch das periimplantäre Gewebe hervorgerufen (Köhler 2011, Heydecke et al. 1999).

Die stetig wachsende Forderung nach einem Werkstoff mit vergleichbar guten Materialeigenschaften, sowie einer verbesserten Ästhetik, hat zu einer rasanten Weiterentwicklung im Bereich der dentalen Keramiken geführt. 
Das mit Yttriumoxid (Y-TZP) verstärkte Zirkoniumdioxid als aktuelle Entwicklungsstufe der Hochleistungskeramiken erfüllt diese Forderungen in idealer Weise (Schweiger 2004).

Nicht nur die außerordentlich guten physikalischen Eigenschaften dieses Werkstoffs, wie seine enorme Biegefestigkeit, Härte, Korrosionsbeständigkeit und Biokompatibilität, sprechen für die Hochleistungskeramik, auch die ansprechende Ästhetik, gegeben durch die farbliche Assimilation zu Schmelz und Dentin, sowie eine nachgewiesene verminderte Plaqueakkumulation, machen das Zirkoniumdioxid zu einem qualitativ hochwertigen Werkstoff und zu einer sinnvollen Alternative zum bewährten Titan im Bereich der dentalen Implantologie (Kern 2011a, Fischer et al. 2002). Deshalb ist es nicht nur Gerüstwerkstoff für Kronen- und Brückenrestaurationen, sondern kommt auch bei der Herstellung von Implantatkörpern und Abutments zum Einsatz.

Der Markt dentaler Implantatsysteme hat mit einer derzeitigen Anzahl von etwa 200 unterschiedlichen enossalen Systemen in den letzten Jahren rasant zugenommen. Osseointegrierte Implantate bestehen aus Implantatkörper, Abutment und Suprakonstruktion. Diese Einzelkomponenten müssen als Gesamtgefüge eine gleichmäßige Kraftverteilung gewährleisten, um Fehlbelastungen und somit die Gefahr von Misserfolgen zu vermeiden (Köhler 2011).

Zur Herstellung des Zirkoniumdioxidgerüstes für die prothetische Suprakonstruktion werden immer häufiger digitale dentale Technologien, wie das hochpräzise CAD/CAM Verfahren („Computer-aided-Design“, „Computer-aided-Manufacturing“), angewendet. Dieses ermöglicht neben einer wesentlich präziseren Darstellung der oralen Situation weiterhin eine optimale Passgenauigkeit, besonders im Bereich des marginalen Randspaltes (Kern 2011b). Außerdem birgt die Minimierung der gesamten Arbeitsschritte eine vereinfachte Anfertigung der prothetischen Rekonstruktion (Galosi et al. 2011). 
Die Suprakonstruktion, die den eigentlichen Zahnersatz darstellt, wird entweder auf das Abutment zementiert oder vertikal bzw. horizontal mit diesem verschraubt (Chee et al. 1999, Michalakis et al. 2003).

Der Langzeiterfolg einer implantatgetragenen Restauration wird maßgeblich durch die Befestigung des Zahnersatzes bestimmt. Die optimale Befestigungsart für festsitzenden Zahnersatz auf Implantaten, Zementierung oder Verschraubung, wird in der Literatur immer noch umstritten gehandelt.

Eine zementierte Suprakonstruktion bietet, neben der ansprechenden Ästhetik, eine optimale Gestaltung der Okklusionsfläche. Des Weiteren wird die Gefahr der Entstehung einer Periimplantitis minimiert, da der Zement einen möglichen Spalt zwischen Implantatbasis und Restauration ausfüllt (Keller et al. 1998). Besteht jedoch die Notwendigkeit einer Abnahme oder Reparatur der Krone, so ist eine verschraubte Konstruktion von Vorteil (Torrado et al. 2004). Nachteilig können unter anderem mögliche Schraubenlockerungen mit nachfolgender Besiedlung durch Mikroorganismen, Frakturen der Verblendkeramik, aber auch der erhöhte materielle Aufwand und die erschwerte Handhabung genannt werden (Hebel und Gajjar 1997, Brägger et al. 2005, Wolfart et al. 2006).

Im Bereich der festsitzenden Implantatprothetik stellt die Zementierung in der Regel das Mittel der Wahl dar. Sie ist neben den bisher genannten Aspekten in Herstellung und Handhabung einfacher und preisgünstiger ist. Nicht nur definitve, sondern auch provisorische Dentalzemente erzielen hierbei gute Ergebnisse.

Da durch Bewegungen der Suprakonstruktion auf dem Abutment Pumpbewegungen entstehen, kommt es zum Eintritt vom Speichel in die sogenannten „Microleakages“, den Raum zwischen Abutment und Suprakonstruktion. Dieses kann zur initialen Auflösung des Zementes bis hin zur Dezementierung führen. Es ist in jedem Fall anzustreben, den marginalen Zementspalt so klein wie möglich zu halten, um der Besiedlung von Mikroorganismen und einer damit drohenden Periimplantitis entgegenzuwirken (Kappert und Altvater 1991). 
Ziel dieser in-vitro-Studie ist es, die Haftkraft von rezementierten ZirkoniumdioxidKronengerüsten auf Implantaten zu untersuchen.

Hierbei wurden die unterschiedlichen Einflüsse verschiedener Reinigungsmöglichkeiten untersucht, um nachweislich aufzuzeigen, welche Methode bei rezementierten prothetischen Implantat-Versorgungen ein bestmögliches Ergebnis bei maximaler Retention liefert:

- manuelle Entfernung der Zementreste

- Säuberung durch Ausstrahlung der Suprakonstruktion mit Aluminiumdioxid (Korngröße: $110 \mu \mathrm{m}, 2$ bar, 15s Dauer)

- kombinierte manuelle Säuberung und Ultraschallreinigung (Isopropanolbad $99 \%$ ig). 


\section{Literaturübersicht}

\subsection{Geschichtliche Entwicklung der dentalen Implantologie}

Was versteht man unter dem Begriff Implantologie in der Zahnheilkunde?

Per Definition lässt sich Implantologie als: „Einbringen alloplastischer oder xenogener Materialien" beschreiben, mit dem Ziel eine Basis für prothetische Versorgungen zu schaffen und die Rekonstruktion funktionell, sowie ästhetisch zu verbessern (Koeck und Wagner 2003).

Anhand archäologischer Funde wird deutlich, dass sich die Menschheit, insbesondere die Maya, schon seit Jahrtausenden mit dem Thema "enossale Implantologie" beschäftigen. Bereits im 4. Jahrhundert vor Christus wurden erste Versuche getätigt alloplastische Materialien wie Tierzähne, Steine, Gold oder Holz als Zahnersatz in Alveolen einzubringen. Ein honduranischer Schädel aus der MayaZeit (um 800 n.Chr.) beispielsweise wies ein Obsidian-Implantat im Bereich eines seitlichen unteren Inzisivus auf (Anjard 1981).

1100 n. Chr. empfahl der Spanier Alabucasim erstmals die Transplantation beziehungsweise Replantation von Zähnen als medizinisch vertretbares Vorgehen (Arnaudow und Gerlichs 1972). Dieses Vorgehen wurde über Jahrhunderte hinweg beibehalten.

Mit der fortschreitenden Entwicklung der Naturwissenschaften, speziell auf dem Gebiet der Medizin im 18. und 19. Jahrhundert, kam es zu vielfältigen Versuchen verlorengegangene Zähne durch das Einbringen von Fremdmaterial zu ersetzen.

Diese Sofortimplantationsversuche geschahen entweder unmittelbar (post extractionem) in frischen Extraktionsalveolen, aber auch in künstlich geschaffenen Zahnalveolen.

1891 erweiterte Hartmann diesen Gedanken mit der Idee einen prothetischen Plattenersatz an den alloplastischen Zahnwurzeln zu verschrauben (Perry 1888, Znamensky 1891, Hartmann 1891). 
Strock entwickelte 1939 das erste Implantat mit Gewindeform nach Art einer Holzschraube aus einer Chrom-Kobalt-Molybdän-Legierung (Vitallium). Diese Grundidee wurde in den nächsten 30 Jahren durch viele Autoren aufgegriffen und verbessert. So empfahl der Franzose Scialom 1962 beispielsweise Nadelimplantate, die in den Kieferknochen eingebracht wurden (Strock 1939, Scialom 1962). 1946 zog Formiggini die Aufmerksamkeit auf sich. Nach 12 Jahren konnte er dank einer Heliokolloidalschraube aus Tantal erstmals einen Langzeiterfolg verbunden mit Knochenapposition nachweisen (Formiggini 1947).

Die historische Entwicklung manifestierte sich vor allem in der Wahl der alloplastischen Materialien, der Erweiterung der Indikationsstellung der Therapieformen und der chirurgischen Vorgehensweise (Koeck und Wagner 2003).

Als Linkow 1968 aus Titan gefertigte Blattimplantate vorstellte, gelang inm damit ein weltweiter Durchbruch. Hierbei wurden blattähnliche Metallplatten im Kieferknochen verankert. Abgelöst wurde diese Implantationstechnik zugunsten der Schraubenimplantate, welche sich seit nunmehr über 40 Jahren durchsetzen.

Ein wichtiger Meilenstein in der Entwicklungsgeschichte der Implantologie wurde unabhängig voneinander durch Prof. P.I. Brånemark von der Universität Göteburg und Prof. A. Schröder der Universität Bern gelegt. Beide zeigten, dass enossale Titanimplantate mit direktem Knochen-Implantat-Kontakt, heute als Osseointegration oder funktionelle Ankylose bezeichnet, eine sichere Verankerung für prothetische Rekonstruktionen darstellen (Brånemark et al. 1977, Schroeder et al. 1978, Schroeder et al. 1981).

Während früher Implantate vorwiegend bei zahnlosen Patienten erprobt wurden, finden sie heute immer mehr Gebrauch bei teilbezahnten Patienten mit Freiendsituationen, Einzelzahn- oder Schaltlücken. 


\subsection{Einteilung der Implantate}

Generell bestehen Implantate aus drei Komponenten: einem in den Kieferknochen zu inserierenden Implantatkörper und einem Implantataufbau, dem Abutment, welches mittels einer Abutmentschraube am Implantatkörper fixiert wird und als Basis für die anschließende prothetische Versorgung dient (Steinebrunner et al. 2005). Es gibt jedoch auch einteilige Implantatsysteme, bei denen der enossale Anteil und das in die Mundhöhle ragende Abutment aus einem Stück gefertigt sind. Die Abutments fungieren als Bindeglied zwischen dem Implantatkörper und der Suprakonstruktion und können konfektioniert oder individualisiert vom Hersteller bezogen werden (Bresciano et al. 2005, Michalakis et al. 2003). Die Implantat-AbutmentVerbindungen sind heutzutage vielfältig. Aufzuführen sind zum Beispiel Schraubenkonusverbindungen mit Innenachtkant, konisch gestaltete Verbindungen mit Innenzwölfkant, externe hexagonale Verbindungen, Tube-in-TubeVerankerungen oder polygonprofile Verbindungen.

Die auf dem heutigen Markt verfügbaren Implantatsysteme sind bedingt durch die progressive Entwicklung der Implantationstechnik vielfältig (Ehrl und Müller 1993).

Wagner und Koeck formulieren eine erste allgemeine Einteilung in geschlossene (subgingival einheilende) und offene (transgingival einheilende) Implantate (Wagner und Koeck 2004).

Die Einteilung basiert auf verschiedenen Gesichtspunkten:

- Bedeckung

- Lage

- Implantatmaterial

- Implantatform

- Implantationszeitpunkt

- Einheilung. 


\subsubsection{Bedeckung}

Man unterscheidet offene und geschlossene dentale Implantate. $\mathrm{Zu}$ den Geschlossenen zählen in den Wurzelkanal eingebrachte Implantate, die den Zahn über den Apex hinaus im Knochen fixieren. Auch Implantate zur Alveolarfortsatzerhöhung für eine effektivere prothetische Versorgung gehören in diese Gruppe. Offene Implantate werden in den Kieferknochen eingebracht und haben Kontakt zur Mundhöhle. Durch den Vorgang der Osseointegration wird das Implantat zur festen Basis für prothetische Versorgungen.

\subsection{2. $\underline{\text { Lage }}$}

Je nach Insertionsort oder Lagergewebe werden submuköse, periostale und enossale Implantate unterschieden. Letztere umfassen Blatt-, Nadel-, Zylinder- und die heute vorrangig verwendeten Schraubenimplantate (Strub et al. 1999a).

\subsubsection{Implantatmaterial}

Dentale Implantate bestehen heute vorzugsweise aus Titan oder Keramik. Diese Werkstoffe haben sich gegenüber anderen, wie Stahllegierungen oder Kunststoffen, durchgesetzt, da letztere nicht zur gewünschten Osseointegration nach Brånemark führen.

Weitere wichtige Bewertungsparameter zur Wahl des Implantatmaterials sind:

- Biokompatibilität

- Korrosionsbeständigkeit

- Mechanische Festigkeit

- Stabilität bei Biege- und Torsionsspannung

- Langzeitbeständigkeit

- Sterilisierbarkeit. 


\section{Titan}

Das unedle Leichtmetall reagiert spontan mit atomarem Sauerstoff und bildet so eine passivierende Oxidschicht, in deren Oberfläche sich Calcium- und Phosphat-Ionen durch Absorption einlagern können (Steinemann 1988). Diese Oxidschicht bildet die Grundvoraussetzung für die gute Biokompatibilität und Korrosionsbeständigkeit (Marxkors und Meiners 2005). Die beständige Schutzschicht aus $\mathrm{TiO}_{2}$ (Titandioxid) ist stabil und verhindert einen direkten Kontakt zwischen umgebendem Gewebe und dem Titan selbst (Parr et al. 1985). Vielfach wurde klinisch experimentell nachgewiesen, dass eine Kombination aus Oxidschicht und rauer Implantatoberfläche eine Knochenanlagerung an die Implantatoberfläche begünstigt (Wagner und Al-Nawas 2004). Titan kommt temperaturabhängig in unterschiedlichen Modifikationen vor:

- $\leq 882^{\circ} \mathrm{C}$ : hexagonale $\alpha-F o r m$

- $>882^{\circ} \mathrm{C}$ : kubische $\beta$-Form

Die $\beta$-Phase besitzt jedoch in zahnmedizinischer und speziell implantologischer Sicht die mechanisch günstigeren Eigenschaften.

Weiterhin zeugt es von geringer Dichte $\left(4,5 \mathrm{~g} / \mathrm{cm}^{3}\right)$, hoher Bruchfestigkeit (1000-1200 $\mathrm{MPa}$ ), sowie einer geringen thermischen Leitfähigkeit (Wagner und Al-Nawas 2004). Diese Aspekte sind von großer Bedeutung, weil dentale Implantate beispielsweise als Basis für Brückenkonstruktionen hohen mechanischen Anforderungen genügen müssen. Da Implantate die Aufgabe haben, Kaukräfte aufzunehmen und diese auf den Kieferknochen zu übertragen, basiert die mechanische Belastung vorrangig auf einer Druck- und Biegebelastung. Um die Sicherheit gegenüber einem Ermüdungsbruch gewährleisten zu können, ist ein Kompromiss zwischen Festigkeit, hoher Dehngrenze und plastischer Verformbarkeit unabdingbar (Schwenzer und Ehrenfeld 2009). 
Bis heute wird die Frage der Biokompatibilität und der Korrosionsbeständigkeit des Implantatwerkstoffs Titan diskutiert und untersucht. Wohingegen man 1980 noch die geläufige Aussage traf, Titan sei ein bioinertes Material, welches nicht mit Stoffwechselvorgängen interferiert und somit keine Reaktionen im umliegenden Gewebe auslöst und weiterhin den europäischen Standard für Korrosionsbeständigkeit von metallischen Biomaterialien im Bereich der Zahnmedizin erfüllt $\left(<11 \mu \mathrm{g} \mathrm{cm} \mathrm{cm}^{-2} / \mathrm{Tag}\right)$, zeigen aktuelle Ergebnisse, dass Titan ein korrosives Verhalten zeigen kann ( Schmidt 1992, Steinemann 1980, Abke 2003). Fluoridionen setzen vor allem in Kombination mit einem sauren $\mathrm{pH}-$ Wert nachhaltig die schützende Oxidschicht herab, was schließlich zur Korrosion von Titan führen kann (Toumelin-Chemla et al. 1996).

Auch die Ästhetik ist bei Titan in Frage zu stellen. Zwar wird das Implantat in den Kieferknochen eingebracht und mit einer Suprakonstruktion versorgt, jedoch kommt es vor allem im Frontzahnbereich zu ästhetischen Einbußen, hervorgerufen durch das Durchscheinen des grauen Implantates durch das periimplantäre Gewebe. Weiterhin kann es nach Implantatinsertion durch eine Retraktion des Weichgewebes zu einer unerwünschten Sicht auf den grauen Implantatkopf kommen (Kohal et al. 2003). 


\section{Zirkoniumdioxid}

Die stetig wachsende Forderung nach Ästhetik und makelloser Schönheit spiegelt sich heutzutage auch in der Zahnheilkunde wider: Angelehnt an die „Rot-WeißÄsthetik", fordern Patienten einen natürlichen, kosmetisch einwandfreien Zahnersatz, sowie einen gesunden, harmonischen Zahnfleischverlauf. Bezogen auf ein Oberkieferfrontzahnimplantat beispielsweise ist die Gestaltung einer Implantatgetragenen Versorgung nach den Vorstellungen des Patienten oft eine Herausforderung.

Hier birgt die farbliche Assimilation der Dentalkeramiken zu Schmelz und Dentin einen unabdingbaren Vorteil zur Herstellung einer ästhetisch anspruchsvollen Versorgung. Den Beginn der keramischen Implantatwerkstoffe machte das Aluminiumoxid $\left(\mathrm{Al}_{2} \mathrm{O}_{3}\right)$. Es zeigte einen guten Einheilungsprozess und gesunde Gingivaverhältnisse (Anneroth et al. 1990, Schulte 1983). Die ausgeprägte Sprödigkeit und damit verbundene mangelnde Bruchfestigkeit trugen jedoch dazu bei, dass Implantate aus $\mathrm{Al}_{2} \mathrm{O}_{3}$ nicht neben den Titanimplantaten bestehen konnten (Schlegel et al. 1994, Buser et al. 1998, Wagner und Al-Nawas 2004).

Erst das mit Yttriumoxid verstärkte Zirkoniumdioxid (Y-TZP, „Yttrium stabilized Tetragonal Zirconia Polycristals") stellte eine wirkliche Alternative zum herkömmlichen Titanimplantat und Abutment dar, da es neben bereits bekannten positiven Eigenschaften, wie Biokompatibilität und Ästhetik, ebenfalls die notwendigen physikalischen Eigenschaften, wie z.B. eine große Härte (1200 Vickers), Risszähigkeit und mit 900-1200 MPa eine hohe Biegefestigkeit aufweist (Marx 1993, Piconi et al. 1998). 
Zusammengefasst zeigen Zirkoniumdioxidimplantate eine Vielfalt interessanter Vorteile (Volz 2005).

Abschließend zeigen sich in Tab. 1 Implantatwerkstoffe im Vergleich zu Referenzwerkstoffen, sowie Schmelz und Dentin (Marx und Bieniek 1998).

\begin{tabular}{|c|c|c|c|c|}
\hline Materialien & $\begin{array}{l}\text { Bruchzähigkeit } \\
\left(\mathrm{Mpam}^{1 / 2}\right)\end{array}$ & $\begin{array}{l}\text { Dehngrenze } \\
\left(\mathrm{Rp}_{0,2}(\mathrm{Mpa})\right)\end{array}$ & $\begin{array}{l}\text { E-Modul } \\
\text { (Gpa) }\end{array}$ & $\begin{array}{l}\text { Härte } \\
\text { (HB, HV) }\end{array}$ \\
\hline $\begin{array}{l}\text { Titan } \\
\text { (unlegiert) }\end{array}$ & 77 & 580 & 100 & HB 200 \\
\hline TiAl6V4 & 72 & 1160 & 105 & HB 300 \\
\hline $\begin{array}{l}\mathrm{Al}_{2} \mathrm{O}_{3} \\
\text { polykristallin }\end{array}$ & $2,8-6$ & $160-600$ & $300-410$ & HV 1500-1930 \\
\hline $\begin{array}{l}\mathrm{ZrO}_{2} \\
\text { (teilstabilisiert) }\end{array}$ & $4,6-15$ & $350-1400$ & 220 & HV 700-1700 \\
\hline Schmelz & $0,7-1,3$ & 35 & 84 & HK 340 \\
\hline Dentin & 3,8 & 60 & $15-20$ & HB $60-70$ \\
\hline Komposit & $1,0-1,5$ & $17-41$ & $5-25$ & HB 15-40 \\
\hline Stahl & $>100$ & $1000-2000$ & $200-300$ & HB 170-350 \\
\hline
\end{tabular}

Tabelle 1: Mechanische Kennwerte alloplastischer Materialien und Referenzmaterialien (Marx und Bieniek 1998).

\subsubsection{Implantatform}

In der modernen Implantologie finden sich überwiegend rotationssymetrische Implantate in Form von Zylinderimplantaten, Schraubenimplantaten, stufenförmigen Implantaten und konischen Implantaten (Koeck und Wagner 2003). Extensionsimplantate, wie beispielsweise das Blattimplantat, welches sein Hauptanwendungsgebiet bei Patienten mit reduziertem Knochenangebot hat, finden dank moderner Augmentationsverfahren hingegen heute kaum noch Verwendung (Al-Nawas et al. 2000). 
Das Merkmal der Rotationssymmetrie dient einer stabilen Implantatverankerung im Kieferknochen, was als Ziel der chirurgischen Aufbereitung gilt (Spiessl 1989). Aufgrund der verminderten Mikrobewegungen durch die Rotationssymmetrie der Implantate, sowie der verbesserten Primärstabilität, werden vor allem die Schraubenformen propagiert (Al-Nawas et al. 2006).

\subsubsection{Implantationszeitpunkt}

Bezüglich des Zeitpunktes der Implantatinsertion unterscheidet man zwischen der Sofortimplantation, der verzögerten Sofortimplantation und der klassischen Spätimplantation.

Von einer verzögerten Sofortimplantation spricht man beim Einbringen des Implantates vor der knöchernen Ausheilung der Extraktionsalveole etwa sechs bis acht Wochen nach Extraktion.

Bei der Sofortimplantation erfolgt die Insertion in der gleichen Sitzung wie die Zahnextraktion. Voraussetzung sind hierbei die Entzündungsfreiheit der Alveole sowie keine wesentlichen Knochendefekte, vor allem im Bereich der fazialen Knochenfacette. Als Vorteile sind bei diesem Verfahren der reduzierte Behandlungsstress für den Patienten, die verkürzte Behandlungsdauer und das minimierte Operationstrauma zu nennen. Auch der Kieferatrophie wird durch eine sofortige Insertion entgegengewirkt.

Weiterhin gewährleistet die Sofortimplantation den Erhalt der Rot-Weiß-Ästhetik, da der Gingivaverlauf durch das minimalinvasive Vorgehen erhalten bleibt und dieses Verfahren somit Kieferkamm- und Weichgewebs-erhaltend wirkt. Nachteilig kann hier das erschwerte Handling und das erhöhte Risiko eines Implantatverlustes genannt werden. Die Sofortimplantation kann speziell bei einwurzeligen Zähnen ein gutes Konzept darstellen, sollte jedoch besonders bei der Gefahr eines entzündlichen Prozesses zugunsten anderer Techniken zurückstehen. 
Die Spätimplantation als klassisches Verfahren erfolgt nach vollständiger knöcherner Ausheilung der Extraktionsalveole, was in der Regel eine Dauer von drei bis vier Monaten in Anspruch nimmt.

Obwohl der optimale Zeitpunkt der Implantatinsertion noch immer umstritten gehandelt wird, stellt diese Methode weiterhin das Standardverfahren dar, da Vorteile wie ein sicheres Knochenangebot, eine exakte Planung des Eingriffs, sowie eine Erleichterung von Augmentationsverfahren gegenüber den Nachteilen, wie einer verlängerten Behandlungsdauer, sowie einer beginnenden Atrophie des Kieferknochens überwiegen. Im Frontzahnbereich ist aus ästhetischer Sicht eine Spätimplantation kritisch zu sehen. Hier bietet es sich an, zeitnah nach Extraktion eine Sofortversorgung durchzuführen (Esposito et al. 2006, De Rouck et al. 2008, Bhola et al. 2008).

\subsubsection{Einheilung}

Hier unterscheidet man zwischen der offenen (einphasigen) und geschlossenen (zweiphasigen) Einheilung.

Bei der geschlossenen oder auch subgingivalen Einheilung wird nach der Insertion der vorher präparierte Schleimhautlappen über das enossale Implantat gelegt und mit der gegenüberliegenden Schleimhaut fest vernäht, um eine möglichst keimfreie Einheilung des Implantats gewährleisten zu können (Brånemark et al. 1969). Vor der anschließenden prothetischen Versorgung muss das Implantat in einer zweiten Sitzung zunächst freigelegt werden. Dieses zeitintensivere Verfahren wird, vor allem bei Ersatz von mehreren Zähnen, sowie bei Augmentations- oder Transplantationsverfahren angewendet (Buser und von Arx 2000, Dahlin et al. 1991).

Bei offenen Systemen heilt das Implantat transmukosal ein. Eine folgende Freilegungsoperation entfällt somit. Die Erfolgschancen beider Einheilungsmethoden sind vergleichbar (Abrahamsson et al. 1996). 
Die Einheilungsdauer wird in der Literatur mit 5-6 Monaten für den Oberkiefer und 3 Monaten für den Unterkiefer angegeben (Brånemark et al. 1977).

Nach Implantatinsertion kommt es nach Bildung eines Blutkoagulums durch Granulationsgewebe zu einer Fremdkörperreaktion am Implantat (Thomson et al. 1999).

Zur Stabilisierung des Implantates entwickelt sich durch Anlagerung von Geflechtknochen und Sklerosierungsvorgänge mit der Zeit eine lamelläre Knochenstruktur rund um das Implantat (Büchter et al. 2003). Die abschließende prothetische Versorgung muss exakt geplant sein, da eine Fehl- oder Überbelastung zur Resorption des periimplantären Knochens und somit zum Implantatverlust führen kann. Weiterhin muss eine adäquate Mundhygiene gewährleistet sein, um die Gefahr einer Periimplantitis zu vermindern.

\subsection{Osseointegration}

Der Begriff der Osseointegration wurde 1969 erstmals durch Brånemark definiert. Er beschreibt die Implantateinheilung als funktionellen und strukturellen Verbund von Implantatoberfläche und umgebendem Knochen gemäß einer funktionellen Ankylose (Brånemark et al. 1969).

Grundlage einer erfolgreichen Osseointegration ist die Bildung einer mechanischen Einheit zwischen Implantat, Implantatlager und Knochen. Nur so ist das Implantat in der Lage, die einwirkenden Kaukräfte in idealer Weise auf den Knochen zu übertragen. Die Reaktion des Knochengewebes orientiert sich anhand der einwirkenden Kräfte. So erkannten Brånemark et al. 1969, dass die Ausrichtung der Havers'schen Kanäle der Richtung der auf das Implantat wirkenden Kräfte folgt. Die Einheilung des Implantates basiert letztlich auf einer posttraumatischen Gewebsneubildung, welche durch das Implantatmaterial positiv oder negativ beeinflusst wird (Kohal et al. 2004). Eine gelungene Osseointegration wird maßgeblich durch die Makro- und Mikroretention des Implantatkörpers bestimmt. 
Die Makroretention fungiert als mechanische Verankerung des Implantates im Kieferknochen, bewirkt dessen Stabilität und wird heutzutage vor allem durch die Schraubenwindungen des Implantatkörpers bestimmt. Dieses führt zum Erreichen der gewünschten Primärstabilität, der sofortigen mechanischen Stabilität nach dem Einbringen. Weiterhin fungieren die Windungen als Oberflächenvergrößerung, wodurch sie dem Knochen eine größere Kontaktfläche zum Anwachsen bieten (Buchs et al. 2001). Die Mikroretention ist elementarer Bestandteil der gewünschten Bioadhäsion (Bowers et al. 1992, Cochran 1999). Sie ist das Resultat der Oberflächenspannung des Implantatmaterials und dessen benetzender Flüssigkeit, in diesem Falle Blut. Die molekularen Eiweißbestandteile des Blutes bilden einen Angriffspunkt zellulärer Gewebskomponenten. In vielen experimentellen Studien wurde nachweislich aufgezeigt, dass raue Implantatoberflächen eine bessere Verankerung im Knochen erzielen als glatte. Diese Oberflächenmodifikation kann mechanisch, ablativ oder additiv erfolgen (Buser et al. 1992, Wagner und Al-Nawas 2004).

Zu den ablativen Verfahren zählen beispielsweise Aluminiumoxidbestrahlung oder Säureätzung. Bei den additiven Verfahren werden zusätzliche Schichten, wie eine Titanplasmaspritzschicht oder eine Hydroxylapatitschicht auf die Oberfläche aufgetragen. All diese Verfahren dienen der Erhöhung der Mikrorauigkeit, was eine positive Beeinflussung der Proliferation von "Osteoblast-like-Cells" und der Produktion von Zytokinen und Wachstumsfaktoren nach sich zieht (Kieswetter et al. 1996, Ramires et al. 2003, Schneider et al. 2003).

Makro- und Mikroretention dienen zusammenfassend der biomechanischen Bindung und sorgen für eine effektivere, schnellere Einheilung und eine erhöhte Stabilität des Implantatkörpers. 


\subsection{Geschichtliche Entwicklung dentaler Keramiken}

Die Bezeichnung Keramik stammt vom griechischen Wort "keramos" ab und umfasst all diejenigen anorganischen Rohstoffe, die aus pulverisierten Erden geformt und durch ein anschließendes Brennverfahren ausgehärtet werden. Die heutigen dentalkeramischen Massen basieren auf Porzellan und Glasurmaterialien.

Nachdem es Böttcher 1708 gelungen war, Porzellan unter Verwendung von Kaolin herzustellen, unternahmen Guillemeau und Fauchard zu Beginn des 18. Jahrhunderts erstmalig den Versuch, Keramik im zahnmedizinischen Bereich einzusetzen.

Die erste wirklich erfolgreiche Anwendung von Keramik in der Zahnheilkunde ist auf den Apotheker Duchâteau zurückzuführen. Er ließ sich 1774 eine komplette Prothese aus Porzellan brennen. Die industrielle Fertigung künstlicher, aber möglichst naturgetreuer Zähne ließ nicht lange auf sich warten. Mitte des 19. Jahrhunderts begannen die amerikanischen Zahnfabriken S.W. Stockton und S.S. White Corporation mit der Herstellung künstlicher Zähne (Eichner und Kappert 1996, Reuling und Siebert 1989, Strub et al. 1999b).

Schon im 18. Jahrhundert war nicht nur der Ersatz verlorengegangener Zähne, sondern auch dessen natürliches Aussehen für die Menschen von großer Bedeutung. Erste Verfahren zur Herstellung vollkeramischer Kronen wie beispielsweise das Aufbrennen von Feldspatkeramik auf einen mit Platinfolie abgedeckten Zahnstumpf wurden 1896 vorgestellt. Da diese Kronen jedoch zu fragil waren, wurden Untersuchungen zur Festigkeitssteigerung vorgenommen (Kappert und Krah 2001, Strub et al. 1999b). 
1905 stellte Charles Herne Land erstmals eine individuelle Mantelkrone aus keramischen Massen vor, die sogenannte Jacketkrone (Eichner 1979). Bis zur Entwicklung metallkeramischer Systeme 1962 durch die Firma Vita-Zahnfabrik und Degussa beziehungsweise 1966 durch DeTrey und Heraeus, waren die Jacketkronen trotz der relativ hohen Frakturanfälligkeit und des beschränkten klinischen Anwendungsbereichs die einzige festsitzende ästhetisch ansprechende Restaurationsmöglichkeit für den Frontzahnbereich (Eichner und Kappert 1996, Kappert und Krah 2001).

Die Metallkeramik ermöglichte erstmals ästhetische und belastbare Versorgungen auch im Seitenzahnbereich und findet bis heute weltweiten Einsatz. Dieser Erfolg drängte die Vollkeramik vorerst in den Hintergrund, bis McLean und Hughes 1965 die Frakturanfälligkeit durch das Einbringen von Aluminiumoxidpartikeln als Verstärkung der Keramik verbesserte. Weiterhin entwickelten sich zu gleicher Zeit vollkeramische Verbundsysteme mit einem keramischen Grundgerüst sowie einer keramischen Verblendung mit höherer Transluzenz.

Dank Optimierung der Herstellungsverfahren von Keramikrestaurationen haben Ästhetik und Stabilität vollkeramischer Sytseme in den 1980er und 1990er Jahren immer größere Fortschritte erzielt. Durch den Einsatz von aluminiumoxid- und zirkoniumdioxid-verstärkten Keramiken wurde nun auch die vollkeramische prothetische Versorgung im kaubelasteten Seitenzahngebiet möglich, was zu einer Erweiterung des Indikationsspektrums führte (Eichner und Kappert 1996).

Neben der klassischen Sintertechnologie überschwemmten bald Immer neuere Herstellungsverfahren, wie Guss-, Press- und Fräsverfahren den Markt. Durch die Entwicklung gießbarer Glaskeramiken wurden keramische Einlagefüllungen realisierbar. Doch erst die durch die Firma Ivoclar (Schaan-Liechtenstein) entwickelte pressbare, leuzitverstärkte Keramik IPS-Empress ${ }^{\circledR}$ und deren Nachfolger Empress $2 \AA$ machten gepresste vollkeramische Inlays, Teilkronen aber auch Vollkronen zu einem Standardverfahren der keramischen Restaurationsverfahren (Fenske et al. 1999, Kappert und Krah 2001, Wohlwend und Schärer 1990). 
Mit der Entwicklung der Oxidkeramiken wurde 1989 eine erfolgversprechende Bruchstabilität generiert: Die Firma Vita Zahnfabrik (Bad Säckingen) stellte die glasinfiltrierte Aluminiumoxidkeramik In-Ceram® vor, mit der nun auch ästhetisch hochwertige Frontzahnbrücken sowie stabile Seitenzahnversorgungen realisierbar wurden (Chong et al. 2002, Kappert und Altvater 1991, Mörmann und Bindl 2001, Schüller und Hennicke 1985).

Der aktuell höchste Entwicklungsstand der Keramiken in der Zahnheilkunde basiert auf Zirkoniumdioxid $\left(\mathrm{ZrO}_{2}\right)$. Dieses Material erfüllt alle nötigen und wünschenswerten mechanischen Eigenschaften und ermöglicht somit eine adäquate vollkeramische Brückenversorgung im Seitenzahnbereich sowie jede andere Form von festsitzendem Zahnersatz.

Komplexe, computergesteuerte Fräsmaschinen (CAD/CAM-Systeme) ermöglichen einen passgenaue Konstruktion, vor allem im Problembereich des marginalen Randspaltes (Clauss 2002, Filser et al. 2002, Luthardt et al. 2001, Rinke und Jenatschke 2001, Sturzenegger et al. 2000).

\subsection{Einteilung und werkstoffkundliche Aspekte dentaler Keramiken}

Die Dentalkeramiken leiten sich zwar vom Porzellan ab, unterscheiden sich jedoch heutzutage bezüglich ihrer Zusammensetzung. Wie in Abbildung 2 ersichtlich, lassen sie sich nach ihrer chemischen Zusammensetzung in zwei Hauptgruppen unterteilen: die mehrphasigen Silikatkeramiken, die einen hohen Glasanteil aufweisen und die einphasigen Oxidkeramiken mit keinem oder einem geringeren Glasanteil (Abb. 2) (Marxkors und Meiners 2005). 


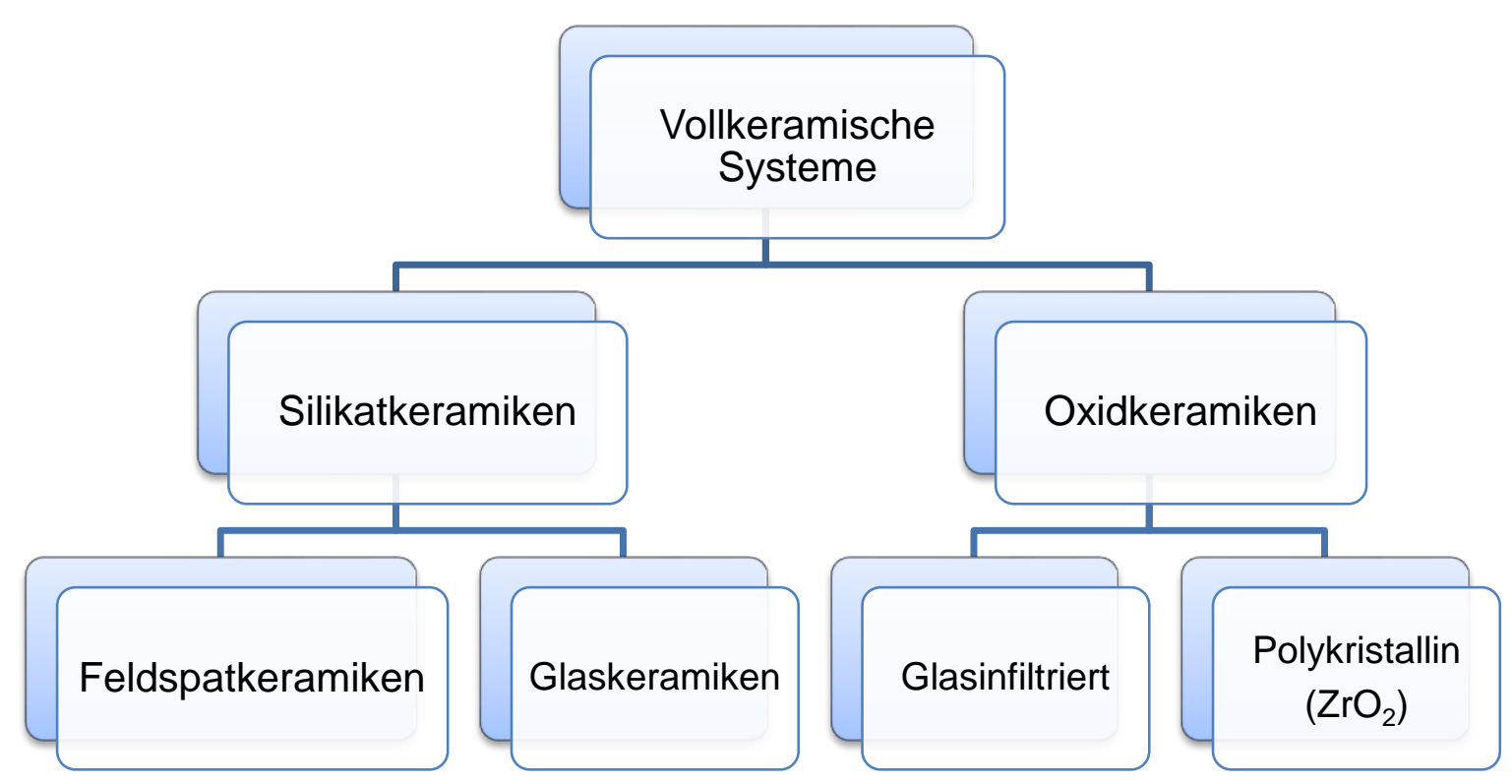

Abb. 2: Einteilung vollkeramischer Systeme nach werkstoffkundlicher Zusammensetzung.

\subsubsection{Silikatkeramische Werkstoffe}

\section{Feldspatkeramik}

Die Silikatkeramiken Feldspat- und Glaskeramiken bestehen aus drei Hauptbestandteilen:

60-80 Gew. \%: Feldspat

15-25 Gew. \%: Quarz

0-5 Gew. \%: Kaolin

10 Gew. \%: Füllstoffe und andere Zusätze.

Diese pulverförmigen Basiskomponenten werden in den erforderlichen Verhältnissen gemischt und anschließend gebrannt. Als thermische Vorbehandlung dient dieses einer Senkung der Schmelztemperatur sowie der Beeinflussung von Transparenz und den mechanischen Eigenschaften. Silikatkeramiken besitzen eine glasigamorphe Phase, in die kristalline Partikel eingefügt werden. 
Das Aluminiumsilikat Kaolin (Tonerde) als kleinster Bestandteil verleiht der Keramik Plastizität, Formbarkeit und durch den Brand Formbeständigkeit. Weiterhin bewirkt es in Kombination mit Feldspat durch die Bildung von Mulitkristallen einen Lichtstreuungseffekt und ist somit unabdingbar für die Opazität des Materials.

Feldspat als Mischkristallsystem besteht vorwiegend aus Kalifeldspat (Orthoklas), Natronfeldspat (Albit) und Kalkfeldspat (Anorthit) (Eichner und Kappert 1996, Reuling und Siebert 1989, Strub et al. 1999b). Während des Brennvorganges entstehen kristalline Einschlüsse in der gläsernen Feldspatmatrix, bestehend aus Leuzit (GeisGerstorfer 1996). Da sich Leuzit erst bei $1540^{\circ} \mathrm{C}$ löst, garantiert es der dentalkeramischen Schmelze eine gewisse Standfestigkeit und wirkt sich des Weiteren positiv auf die Festigkeitseigenschaften der Keramik aus, indem es unter anderem Rissausbreitungen entgegenwirkt (Geis-Gerstorfer 1996, Schwickerath 1994).

Quarz (Kieselsäure) ist ein Siliziumdioxid $\left(\mathrm{SiO}_{2}\right)$, liegt in kristalliner Form vor und wird in keramischen Massen als Magerungsmittel verwendet. Mit einem Schmelzpunkt zwischen $1400^{\circ} \mathrm{C}$ und $1600^{\circ} \mathrm{C}$ beeinflusst es das thermische Verhalten der Keramik, indem es zu einer reduzierten Sinterschwindung führt (Nakamura et al. 2000, Klink 2006). Dieses thermovolumetrische Verhalten basiert auf einer temperaturabhängigen Gitterumwandlung: Je nach Modifikation der Kristallstruktur unterscheidet man Quarz ( $\alpha$ und $\beta$ ), Tridymit ( $\alpha, \beta$ und $y$ ) und Cristobalit ( $\alpha$ und $\beta$ ) (Eichner und Kappert 1996, Reuling und Siebert 1989).

Neben den drei Hauptbestandteilen werden weiterhin Flussmittel (Kaliumphosphat, Kaliumkarbonat, Natriumkarbonat, Borax, Bleioxid, Kaliumoxid, Magnesiumoxid) zur Reduktion der Brenntemperatur beigemischt. Weitere Zusätze wie Metalloxide, seltene Erden und hochschmelzende feste Oxide des Siliziums, Aluminiums, Zirkoniums, Leuzit, Glimmer und Hydroxylapatit beeinflussen die Farbgebung, die Fluoreszenz, sowie die Bruchfestigkeit (Eichner und Kappert 1996). 


\section{Glaskeramik}

Glaskeramiken sind Werkstoffe, die ihre Eigenschaften durch Kristallisation aus einem Glaszustand heraus erhalten (Kappert und Krah 2001). Ausgangspunkt stellt ein Glas dar, das über eine spezielle thermische Behandlung zu einer Glasmatrix führt, in die Kristalle eingebettet sind. Endprodukt ist also ein mehrphasiges Produkt aus Kristallen und Glas: die Glaskeramik (Wissenschaftliche Dokumentation 1997).

Das Kristallwachstum geht von so genannten Kristallisationszentren aus. Während dieses Kristallisationsprozesses kommt es durch Einlagerung von feinen Kristallen zu einer Festigkeitssteigerung, die durch möglichst kleine Kristalle in großer Menge und Dichte gesteigert werden kann (Hahn und Löst 1992).

Die Kristalle bergen einen weiteren Vorteil. Entsteht ein Riss, so wird dieser an der Kristalloberfläche gestoppt oder umgeleitet, was eine Verlangsamung des Risswachstums zur Folge hat. Durch die Oberflächenstruktur der Kristalle wird eine Lichtstreuung ermöglicht, die der Keramik eine gewisse Transluzenz verleiht (Kappert und Krah 2001).

Ausschlaggebend für die keramischen Eigenschaften ist die gleichmäßige Verteilung der Kristalle, die man durch Zugabe kristallisationskeimbildender Zusätze oder Katalysatoren erreicht (Strub et al. 1999b). Glaskeramiken können mittels Guss- oder Pressverfahren hergestellt werden. Das Gussverfahren basiert auf dem „Lost-Wax“Prinzip. Die aufgewachste Restauration hinterlässt nach Austreibung des Wachses eine Hohlform, in welcher die Keramik anschließend hineingegossen oder hineingepresst wird (Starling et al. 1986, Strub et al. 1983). 


\subsubsection{Oxidkeramische Werkstoffe}

Oxidkeramiken sind einphasige Werkstoffe und besitzen neben einer kleinen Glasphase zu über 90\% Metalloxide. Da die Metalle sehr unedel sind und ihr Oxidationspotential somit sehr hoch ist, sind die Oxide sehr stabil. Aufgrund der besonders hohen Festigkeit der oxidkeramischen Werkstoffe gegenüber herkömmlichen Dentalkeramiken werden sie auch als Hochleistungskeramiken bezeichnet, da sie die Herstellung von Restaurationen ermöglichen, die großen Belastungen ausgesetzt sind (Rinke und Jenatschke 2001).

Hauptvertreter dieser Gruppe sind je nach Art der Metalloxide: Aluminiumoxid-, Magnesiumoxid-, Zirkoniumdioxid-, Titandioxid- und Spinellkeramiken (Hahn und Löst 1992, Pospiech 2002, Strub et al. 1999b). Aluminiumoxid- und Zirkoniumdioxidkeramiken werden entweder als Infiltrationskeramiken oder als Gerüstkeramik in der CAD/CAM-Technologie angewendet (Pröbster 2001). In der Zahnheilkunde lassen sich glasinfiltrierte- und polykristalline Oxidkeramiken unterscheiden.

\section{Glasinfiltrierte Oxidkeramik}

Glasinfiltrierte Oxidkeramiken bestehen vorwiegend aus oxidkeramischen Mikropartikeln, die mit einem lanthanhaltigen Glas infiltriert werden, wodurch praktisch eine Porenfreiheit resultiert (Marxkors und Meiners 2005). Aufgrund des höheren Anteils der Glasphase weisen glasinfiltrierte Oxidkeramiken jedoch auch geringere Festigkeitswerte auf als polykristalline Oxidkeramiken (Manicone et al. 2007, Wohlwend et al. 1996).

Bei der Herstellung wird ein poröses, vorgesintertes Aluminiumoxid-Gerüst durch einen speziellen Glasinfiltrationsbrand mit einem mehrkomponentigen Spezialglas infiltriert und nach Bearbeitung durch eine weitere Glasinfiltration mit einer niedrigviskösen Suspension aus lanthanhaltigem Glaspulver und Wasser zu seiner endgültigen Härte gebracht (Bindl und Mörmann 2002, Chong et al. 2002, Eichner und Kappert 1996, Kurbart und Reichel 2001). Da dieses Verfahren ohne Sinterschrumpfung erfolgt, resultiert eine deutlich verbesserte Passgenauigkeit 
(Kappert und Krah 2001). Opazität und Bruchfestigkeit des Gerüstes werden durch einen möglichst hohen Anteil an Aluminiumoxid-Kristallen erreicht. Die anschließende Verblendung erfolgt mittels Feldspatkeramik (Strub et al. 1999b).

\section{Polykristalline Oxidkeramiken}

Zu dieser Gruppe der Oxidkeramiken zählen Aluminium- und Zirkoniumdioxid, die sich durch ihre besonders hohe Festigkeit von den übrigen Gruppen abheben. Grund für diese nennenswerte Festigkeitssteigerung und damit verbundene Bruchzähigkeit und Biegebruchfestigkeit ist der nicht vorhandene Glasanteil. Vor allem das dicht gesinterte Zirkoniumdioxid mit einer Festigkeit von über $1000 \mathrm{MPa}$ und einer Risszähigkeit von 5-10 MPa/m weist besonders gute Werte auf (Göbel et al. 1998, Luthardt et al. 2001, Suttor et al. 2001).

Neben den ausgezeichneten mechanischen Eigenschaften der Zirkoniumdioxidkeramik weist sie, wie alle Keramiken, weiterhin eine besonders hohe Biokompatibilität auf, welche bereits in vielen Studien nachgewiesen wurde (Luthardt et al. 1998, Luthardt und Musil 1997, Suttor 2001).

Das Zirkoniumdioxid als besonders feste Strukturkeramik ist in der aktuellen Zahnheilkunde die Keramik mit den besten Materialeigenschaften (Schweiger 2004). Reines Zirkoniumdioxid unterliegt, abhängig von der Temperatur, verschiedenen Phasentransformationen. Bezüglich der Kristallform werden die drei Modifikationen: monoklin, tetragonal und kubisch unterschieden. Wie in Abb. 3 ersichtlich liegt unterhalb einer Temperatur von $1250^{\circ} \mathrm{C}$ die monokline Gitterstruktur vor, das Baddeleyit. Beim weiteren Temperaturanstieg kommt es zur Transformationsverfestigung und somit zur Umwandlung in die tetragonale Phase, die bis $2370^{\circ} \mathrm{C}$ bestehen bleibt. Zwischen $2370^{\circ} \mathrm{C}$ und $2680^{\circ} \mathrm{C}$, was dem Schmelzpunkt entspricht, liegt das $\mathrm{ZrO}_{2}$ als kubische Kristallstruktur vor. 


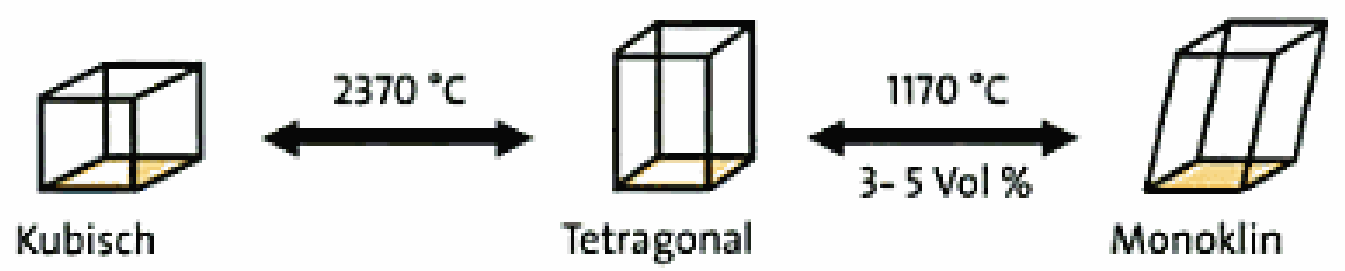

Abb. 3: Phasentransformation von Zirkoniumdioxid (aus: „Oxidkeramiken und CAD/CAM-Technologien“, Tinschert et al. 2007, S. 8)

Bei der Umwandlung von der tetragonalen zur monoklinen Phase kommt es zu einer Volumenvergrößerung von 3-5\%. Diese Volumenvergrößerung führt bei reinem Zirkoniumdioxid während der Abkühlung zu Rissbildungen, steigert jedoch auch dessen Festigkeit.

Oxide, wie Magnesiumoxid, Calciumoxid, Yttriumoxid und Cereoxid unterbinden die kritische Phasentransformation, stabilisieren so die tetragonale Kristallphase und nutzen somit den eigentlich negativen Volumenzuwachs zu einer erwünschten Festigkeitssteigerung (Pospiech et al. 2004, Weber und Rieger 2001). Vor allem das mit Yttriumoxid verstärkte Zirkoniumdioxid (Y-TPZ, „Yttrium-stabilised Tetragonal Zirconia Polycrystals) spielt im Bereich dentaler Keramiken eine zentrale Rolle, da es bedingt durch sein feinkörniges, dichtes und belastbares Gefüge die gewünschten Eigenschaften mit sich bringt.

Wird das Y-TPZ im Bereich eines Risses durch äußere Belastung einer hohen Zugspannung ausgesetzt, so findet, wie in Abbildung 4 ersichtlich, bedingt durch den reduzierten Druck eine erneute Umwandlung in die monokline Phase statt, was eine Volumenzunahme von 3-5\% an der Rissspitze mit sich zieht. Diese Volumenexpansion komprimiert somit die Rissflanken und führt letztlich zu einer Schwächung der Rissausbreitung (Guazzato et al. 2005). 

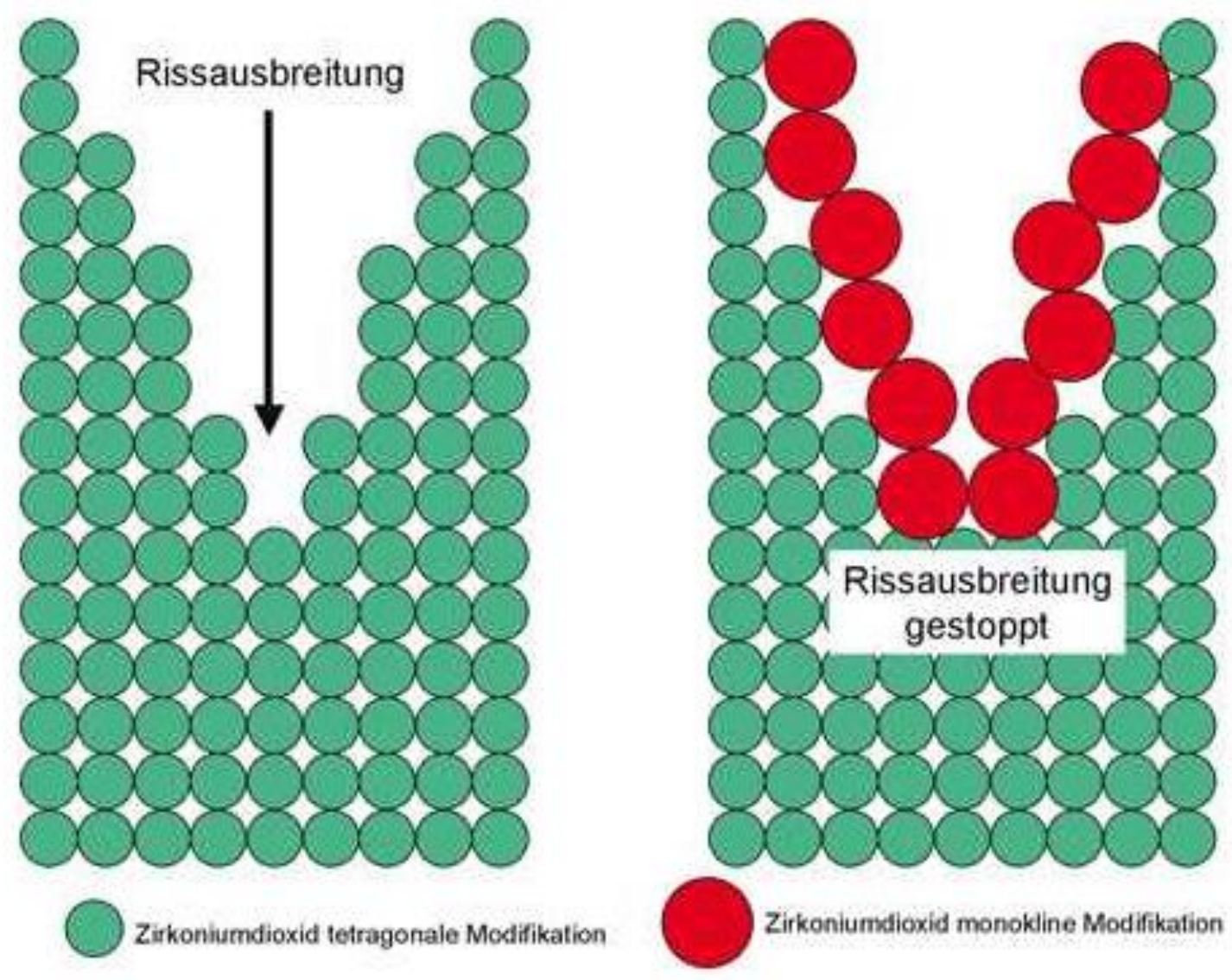

Abb. 4: Phasenumwandlung bei Rissbildung (Strietzel und Lahl 2007, S. 60)

Durch ein Nachverdichten des $\mathrm{ZrO}_{2}$ bei bis $z u 1500^{\circ} \mathrm{C}$ und $500-2000$ bar entsteht das sogenannte gehippte Zirkoniumdioxid (HIP = „hot isostatic pressing“). Dieser Prozess führt zu einer verminderten Porosität mit der Folge reduzierter Defekte der Materialoberfläche und $\mathrm{zu}$ einer deutlich erhöhten Dichte $\left(6,2 \mathrm{~g} / \mathrm{cm}^{3}\right)$. Diese Nachbearbeitung, sowie eine anschließende biomechanische Druckbelastung steigern die hydrothermale Beständigkeit, die Transluzenz und Festigkeit des Werkstoffes (1500MPa), sowie dessen Lebenserwartung (Kern 2004).

Auch bei der CAD/CAM-Fertigung bietet Zirkoniumdioxid Vorteile. Individuell gefertigte keramische Abutments ermöglichen eine Lichttransmission in den Gingivasulkus und lassen so besonders im Frontzahnbereich ästhetisch einwandfreie Restaurationen zu (Wüstefeld und von Blanckenburg 2007). 


\subsection{Dentale CAD/CAM-Technologie}

Der Einsatz von CAD/CAM-Systemen in Zahnmedizin und Zahntechnik ist fester Bestandteil im Herstellungsprozess für Zahnersatz geworden. Die dentale CAD/CAM-Technologie unterliegt somit einer enormen Entwicklung und stellt sich momentan als das innovativste Segment der Zahnmedizin dar. Der Markt und die Technik entwickeln sich fortschreitend weiter.

Mit dem stetig wachsenden Anspruch auf ästhetisch hochwertigen Zahnersatz wurden neben den unterschiedlichen Keramiken auch deren Verarbeitungsmöglichkeiten weiterentwickelt. Dieser Trend spiegelt sich vor allem in der CAD/CAM-Technologie wider, deren Entwicklung sich innerhalb der letzten Jahre stark beschleunigt hat (Luthardt et al. 2001). Die Anzahl der auf dem Markt gebotenen Systeme hat sich ebenso wie das Anwendungsspektrum enorm erhöht (Neumeier 2010).

CAD/CAM steht für "Computer-aided-Design“ (CAD) und "Computer-aidedManufacturing" (CAM). Dieses digitale System besteht aus drei Komponenten: einem intraoralen Scanner, einer Konstruktionssoftware und einer Fertigungseinheit (Beuer et al. 2008). Nach dem optischen Abtasten der oralen Situation, wird die Restauration am Computer mittels einer speziellen Konstruktionssoftware erstellt und anschließend aus einem industriell gefertigtem Material Rohling herausgefräst. Die computergestützte Herstellung der Restauration (digital workflow) kann entweder in einem zentralen Fertigungszentrum, im Dentallabor (,labside“-Fertigung) oder in der Praxis (,chairside“-Fertigung) erfolgen (Güth et al. 2009).

Während die CAD/CAM-gestützten Fertigungsverfahren noch vor einiger Zeit vor allem auf Fertigung von Zirkoniumdioxid-Gerüsten ausgelegt waren, lassen sich derzeit neben den oxidischen Hochleistungskeramiken auch Infiltrationskeramiken und Glaskeramiken durch CAD/CAM-Maschinen bearbeiten (Beuer et al. 2008). 
Die dentalen CAD/CAM-Verfahren bieten viele Vorteile. Industrielle Herstellungsprozesse sichern eine homogene Materialqualität und Präszision. Durch den Einsatz von Scannern und Computern fallen neben den manuellen Bearbeitungsschritten auch potentielle Fehlerquellen weg, sodass ein passgenauerer, qualitativ und ästhetisch hochwertigerer Zahnersatz resultiert.

Weiterhin können mit diesen Verfahren Werkstoffe verarbeitet werden, die mittels konventioneller Fertigungstechniken kaum oder nur schwer bearbeitet werden konnten, wie beispielsweise das Zirkoniumdioxid (Strietzel und Lahl 2007). Auch hinsichtlich der klinischen und ökonomischen Wertigkeit stellt sich CAD/CAMgefertigter Zahnersatz als gute Alternative zu konventionellen direkten und indirekten Restaurationen dar (Mörmann und Attin 2008).

Insgesamt werden durch den Einsatz der CAD/CAM-Systeme die Arbeitsschritte minimiert und die Herstellung prothetischer Rekonstruktionen vereinfacht.

\subsection{1. $\quad$ CAD/CAM in der Implantologie}

Durch CAD/CAM-Verfahren hergestellte individualisierte Implantatabutments und Suprakonstruktionen können die ungünstige Angulierung, sowie die ungenügende Abstützung der periimplantären Weichgewebe von herkömmlich hergestellten konfektionierten Abutments ausgleichen (Galosi et al. 2011).

Auch die Ästhetik profitiert von den CAD/CAM-gestützten Fertigungsverfahren. Speziell im Frontzahnbereich kam es bei Versorgungen immer wieder zu ästhetischen Einbußen. Individuell gefertigte keramische Abutments ermöglichen heutzutage eine Lichttransmission in den Gingivasulkus und lassen so besonders ästhetisch einwandfreie Restaurationen zu (Wüstefeld und von Blanckenburg 2007). 
Um einen langfristig erfolgreichen Zahnersatz zu schaffen bedarf es vor allem bei mehrgliedrig implantatgetragenen Restaurationen einer genauen Planung und Passgenauigkeit. Aus den biomechanische Faktoren resultieren immense Kräfte, die bei schlecht sitzenden Versorgungen einen Misserfolg garantieren und im schlimmsten Fall eine Gerüstfraktur mit sich ziehen (Lee et al. 2008, Beuer et al. 2008).

\subsection{Allgemeines zu dentalen Befestigungszementen}

Dentalzemente fungieren in der Zahnmedizin in erster Linie als provisorische oder definitive Füllungswerkstoffe, als Isolatoren zwischen Füllungsmaterial und Zahn und dienen der Befestigung von Zahnersatz. Sie bestehen aus einem basisch bis amphoterem Pulver und einer sauren wässrigen Flüssigkeit. Die Basis des Pulvers sind Metalloxide, die gebrannt und anschließend zermahlen werden. Die Flüssigkeit enthält eine Säure, wodurch sich bei der Reaktion beider Ausgangskomponenten Salze bilden und das Gemisch erstarrt (Marxkors und Meiners 2005). Neben der individuellen Zusammensetzung der Zementtypen werden die mechanischen Eigenschaften weiterhin durch das Mischungsverhältnis von Pulver und Flüssigkeit beeinflusst (Marxkors und Meiners 2005). Dentalzemente unterliegen beim Aushärten einer Abbindekontraktion welche jedoch aufgrund der dünnen Schichtdicke vernachlässigt werden kann. Der Abbindeprozess verläuft im sauren Milieu und entspricht einem exothermen Vorgang.

Grundsätzlich besteht die Möglichkeit, die Restauration definitiv oder provisorisch einzugliedern. Welche Methode sinnvoller ist, wird heute noch widersprüchlich diskutiert und muss individuell beurteilt werden. Die Festigkeit von Zirkoniumdioxidgerüsten erlaubt zwar eine provisorische Befestigung, jedoch werden diese provisorisch zementierten Versorgungen oft vergessen, wobei es durch Auswaschungen des Zementes zur Sekundärkaries beziehungsweise bei implantatgetragenen Konstruktionen zu einer Periimplantitis kommen kann. Weiterhin kann es beim Entfernen der provisorisch befestigten Versorgung zur definitiven Eingliederung zu Schäden an der Verblendkeramik kommen. 
Man unterscheidet bei den Dentalzementen konventionelle Zemente, die über eine mikromechanische Verankerung der Zementkörner Retention schaffen, von neueren adhäsiven Zementen, die über Bildung langkettiger Moleküle einen chemischen Verbund zur Zahnhartsubstanz eingehen. Der adhäsive Verbund wird durch Säureätztechnik erreicht. Abbildung 5 zeigt eine Übersicht der Dentalzemente.

$$
\text { Pulver (basisch) }
$$

\section{Zinkoxid}

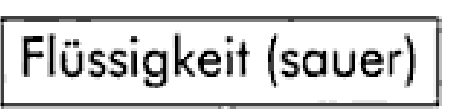

\section{Zement}

Zinkoxidphosphatzement

Carboxylatzement

verdünnte

Polyacrylsäure

Flüssigkeit:

Eugenolöl
Zinkoxid-

Eugenol-Zement fluorhaltiges

Aluminium-Silikatglas
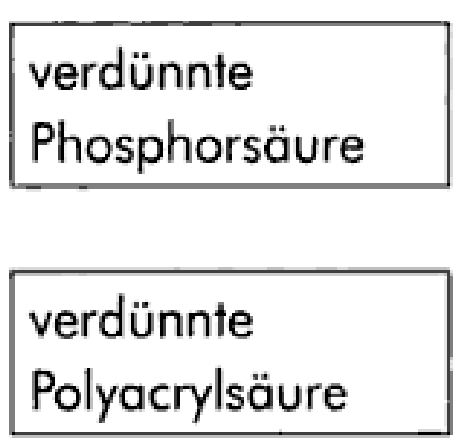

\section{Silikatzement}

Glas-lonomer-

Zement

Abb.5.: Übersicht der Dentalzemente (Caesar und Ernst 2007, S. 294) 


\section{Zinkoxidphosphatzement}

Das Pulver dieses Zementes besteht vor allem aus Zinkoxid. Zusätze wie beispielsweise Magnesiumoxid oder Siliziumdioxid erhöhen die Festigkeit und die Mundbeständigkeit. Die Phosphorsäure wird mit Zusätzen wie Zink und Aluminium versehen. Dieses vermindert die Reaktionsgeschwindigkeit und es resultiert eine verlängerte Verarbeitungszeit. Durch den hohen Säureanteil entsteht nach dem Anmischen ein pH-Wert von 1,6-3,6, was bei zu dünnem Anmischen zu Pulpairritationen führen kann. Sie werden vorwiegend als povisorische Zemente verwendet.

\section{Carboxylatzement}

Die Zusammensetzung des Pulvers entspricht in etwa der des Zinkoxidphosphatzementes. Die Flüssigkeit, ein Polymer der Acrylsäure, weist verhältnismäßig große Säuremoleküle auf, wodurch die Säurediffusion in die Dentinkanälchen eingeschränkt wird und somit zu einer verbesserten Pulpaverträglichkeit führt. Die Haftkraft am Dentin oder am Schmelz ist gegenüber der des Zinkoxidphosphatzementes erhöht, die Mundbeständigkeit verringert.

\section{Zinkoxid-Eugenolzement}

Dieser Zementtyp findet vorwiegend als provisorischer Befestigungszement Verwendung, da die Härte, sowie die Mundbeständigkeit gering sind. Anstelle einer Säure, bildet Eugenolöl den Hauptbestandteil der Flüssigkeit. Das Eugenol bildet mit dem Zink aus dem Pulver ein Chelatkomplex.

\section{Silikatzement}

Auch hier findet sich Phosphorsäure als Hauptbestandteil der Flüssigkeit. In Kombination mit Siliziumdioxid und Aluminiumoxid als Basis des Pulvers ergibt sich ein gering löslicher, halbtransparenter Zement, der die geringe Toxizität des Zinkoxidphosphatzementes mit besseren mechanischen Eigenschaften kombiniert. 


\section{Glasionomerzement}

Hauptbestandteile sind Acrylsäure und Silikatglas. Diese Kombination schafft einen festen, mundbeständigen, transluzenten und fluoridhaltigen Werkstoff mit hohen Adhäsionseigenschaften (Marxkors und Meiners 2005, Caesar und Ernst 2007, Tinschert 2002).

\subsubsection{Dentalzemente und implantatgetragene Suprakonstruktionen}

Wird implantatgetragener Zahnersatz zementiert, so wird der Spalt zwischen Implantatbasis und Restauration mit Zement aufgefüllt. Dieses beugt einer bakteriellen Besiedlung und der Gefahr einer damit einhergehenden Periimplantitis vor.

Die Wahl des Befestigungszementes, provisorisch oder defintiv, wird in der Literatur umstritten gehandelt. Besteht Bedarf die prothetische Versorgung abzunehmen, so erscheint ein provisorischer Zement von Vorteil. Klinische Studien zeigen jedoch, dass die Retention dieser Zemente im Gegensatz zu definitiven Zementen oft unbefriedigende Ergebnisse liefern (Bernal et al. 2003, Michalakis et al. 2003). Auch die Entfernung der Zementreste gestaltet sich bei einigen Zementtypen schwierig (Agar et al. 1997, Rapley et al. 1990).

Entscheidend für die Langlebigkeit des Implantates ist unter anderem die Stabilität der Suprakonstruktion auf dem Abutment. Durch Kaubelastungen wird das System enormen Kräften ausgesetzt, wodurch es zu Bewegungen zwischen Abutment und prothetischer Versorgung und somit zum Transport von Mikroorganismen in den Zementspalt kommen kann. Im schlimmsten Fall führt dieses über die Resorption des periimplantären Knochens bis hin zum Implantatverlust (Zipprich et al. 2007). 
Seit Jahren wird die provisorische Befestigung von Restaurationen aus Metalllegierungen auf Implantaten empfohlen, obwohl es nur wenige klinische Studien dazu gibt (Heinemann et al. 2006, Michalakis et al. 2003, Pan et al. 2007). Im Falle von Versorgungen aus Zirkoniumdioxid ist noch nicht erwiesen, dass temporäre Befestigungen auf Implantaten, langfristig betrachtet, genauso erfolgreich sind wie bei metall-basierten Suprakonstruktionen. In-vitro-Studien zeigen, dass permanent und temporär zementierte Zirkoniumdioxid-Kronen die Kausimulation in gleichem Maße gut überstehen, die anschließend ermittelte Bruchfestigkeit bei den provisorisch eingegliederten Kronen jedoch nur halb so groß war (Plein et al. 2007).

Um eine hohe Retentionskraft zu erzielen, sollte neben den Zementeigenschaften auch das Design der Abutments, deren Oberflächenbeschaffenheit sowie die Innenrauigkeit der Suprakonstruktion nicht vernachlässigt werden. Das Zusammenspiel dieser Parameter erklärt auch den Widerspruch einiger Studien, die die Retention verschiedener Zemente auf Titanabutments untersuchten (Kaar et al. 2002, Mansor et al. 2002, Michalakis et al. 2003, Squier et al. 2001).

\subsection{Reinigungsmethoden}

\subsubsection{Grundprinzipien}

Kontrovers wird heutzutage der Einfluss verschiedener Reinigungsmethoden auf die Retentionskraft von Zirkoniumdioxid-Kronen diskutiert.

Ziel der Oberflächenbearbeitung ist die Reinigung von Zementresten um bei Rezementierung bestmögliche Retentionswerte wiederzuerlangen. Es existiert eine Vielzahl unterschiedlicher Reinigungsmethoden. Sie reichen von manueller Reinigung, über Sandstrahl- und Ätzverfahren, bis hin zu Ultraschallbädern und Ausbrennverfahren. In der vorliegenden Arbeit wurden die manuelle Reinigung, die Reinigung durch Sandstrahlen mit Aluminiumoxidpartikeln, sowie eine Kombination aus manueller- und Ultraschallreinigung untersucht. 
Um optimale Ergebnisse zu erzielen, wird in der Literatur in der Regel Aluminiumoxid $\left(\mathrm{Al}_{2} \mathrm{O}_{3}\right)$ als Strahlmittel mit einer durchschnittlichen Korngröße von $100 \mu \mathrm{m}$ empfohlen. Es sollte in einem Abstand von 2-10 mm für eine Dauer von 10-15 Sekunden bei einem Druck von 1,5-2,5 bar appliziert werden. In der Literatur wird jedoch selbst das Abstrahlen kontrovers diskutiert. Einige Firmen raten vorsorglich von dieser Art der Säuberung ab. Da durch mechanische Überbeanspruchung mehr Energie zugeführt wird, kann es zu Schädigungen am Kristallgitter des Zirkoniumdioxid-Käppchens kommen (Frankenberger et al. 2000, Kern et al. 2010, Niedermeier et al. 1998). 


\section{Material und Methode}

\subsection{Versuchsplanung, Pilotstudie und Materialien}

Die Versuche der vorliegenden Studie wurden so geplant, dass der Einfluss der drei Parameter (manuelle Säuberung, manuelle Säuberung in Kombination mit Reinigung im Ultraschallbad und Reinigung durch Ausstrahlen) sowie ein Referenzversuch an unbehandelten Zirkoniumdioxid-Käppchen 13 mal pro Versuchsreihe untersucht wurde.

Zur Ermittlung der Parameter für die Abzugsversuche, die Reinigungsmethoden, sowie die Einstelldaten der Universalprüfmaschine Zwick Z007 (Zwick, Ulm) wurde den eigentlichen Versuchen eine Pilotstudie von 10 Zirkoniumdioxid-Käppchen vorgeschaltet. In der Serie wurde zum einen das Design der Käppchen festgelegt. Die gestalteten seitlichen Ausläufer zur Aufnahme der Abzugskralle wurden auf ihre Effizienz hin getestet. Es zeigte sich anhand der Pilotserie, dass die seitlichen Ausläufer und die daraus resultierenden Unterschnitte größer gestaltet werden mussten, da sich die Abzugskralle zum Teil schief unter den Ausläufern verkeilte oder bei zu geringer Ausprägung ohne jeglichen Kraftaufwand über die Ausläufer hinüber glitt.

Die Materialien der in-vitro-Studie wurden anhand der Vorgehensweise der Implantologie in der Praxis ausgewählt. Aufgrund der Aktualität wurde die Kombination von Implantaten aus Titan und Suprakonstruktionen aus Zirkoniumdioxid untersucht. In diesem Zuge fiel die Entscheidung des Befestigungszementes auf den handelsüblichen provisorischen Zement TempBond® NE der Firma Kerr (Ratstatt, Deutschland), der als Goldstandard der provisorischen Zemente gilt (siehe Kapitel 3.3.). Das in der vorliegenden Studie verwendete Schraubenimplantatsystem ANKYLOS® der Firma Dentsply Friadent (Mannheim, Deutschland) verfolgt ein speziell konisches Verbindungsprinzip und erscheint als zweiteiliges Implantat. 


\subsection{Herstellung der Probekörper}

Um die Abzugsversuche an der Universalprüfmaschine Zwick Z007 (Zwick, Ulm) durchführen zu können, wurden die Ankylos-Implantate (Dentsply Friadent, Mannheim, Deutschland) zur Herstellung der Prüfkörper (wie in Abbildung 6 gezeigt) in Autopolymerisat (Palavit G, Heraeus Kulzer, Hanau, Deutschland) gesockelt. Zur Gewährleistung eines achsgerechten Einbringens der Implantate, wurden diese in einem Parallelometer befestigt und anschließend in den noch nicht auspolymerisierten Kunststoff der Sockelform abgesenkt (siehe Abbildung 7).

Die T-förmige, nach zwei Seiten offene Sockelform wurde zur Herstellung der Prüfkörper zwischen zwei Metallplatten befestigt, sodass beide offenen Seiten verschlossen wurden. Nach Einbringen des Palavit $\mathrm{G}$ und Absenken des Implantats wurden die auspolymerisierten Probekörper mit konfektionierten Titan-Abutments (Höhe: 7,5 mm, Konuswinkel: 5,7 ${ }^{\circ}$ ) mit Hilfe eines Schraubendrehers bei einem definierten Drehmoment von $15 \mathrm{Ncm}$ manuell bestückt.

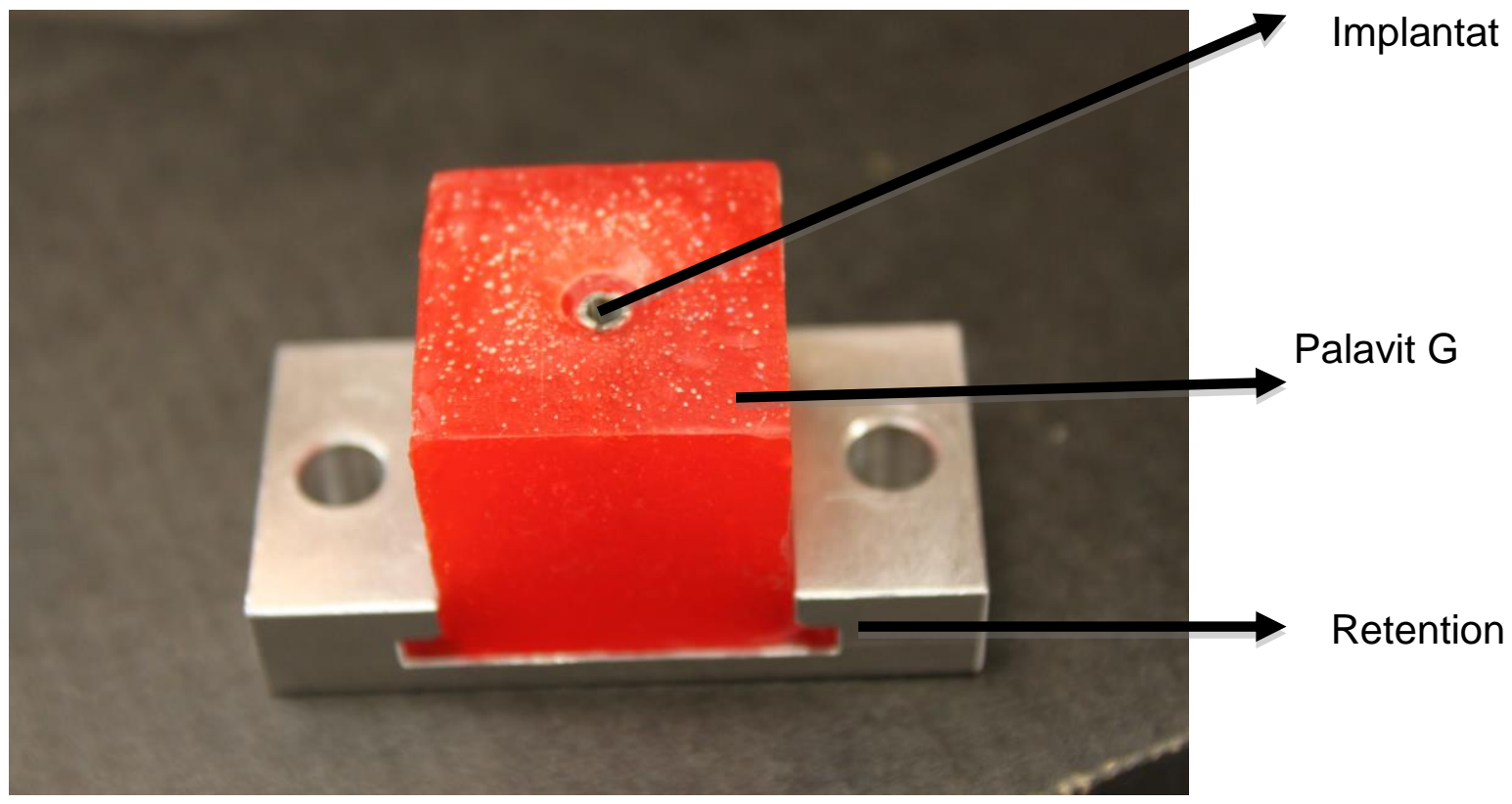

Abb. 6: Prüfkörper aus Palavit G mit bereits eingelassenem Implantat 


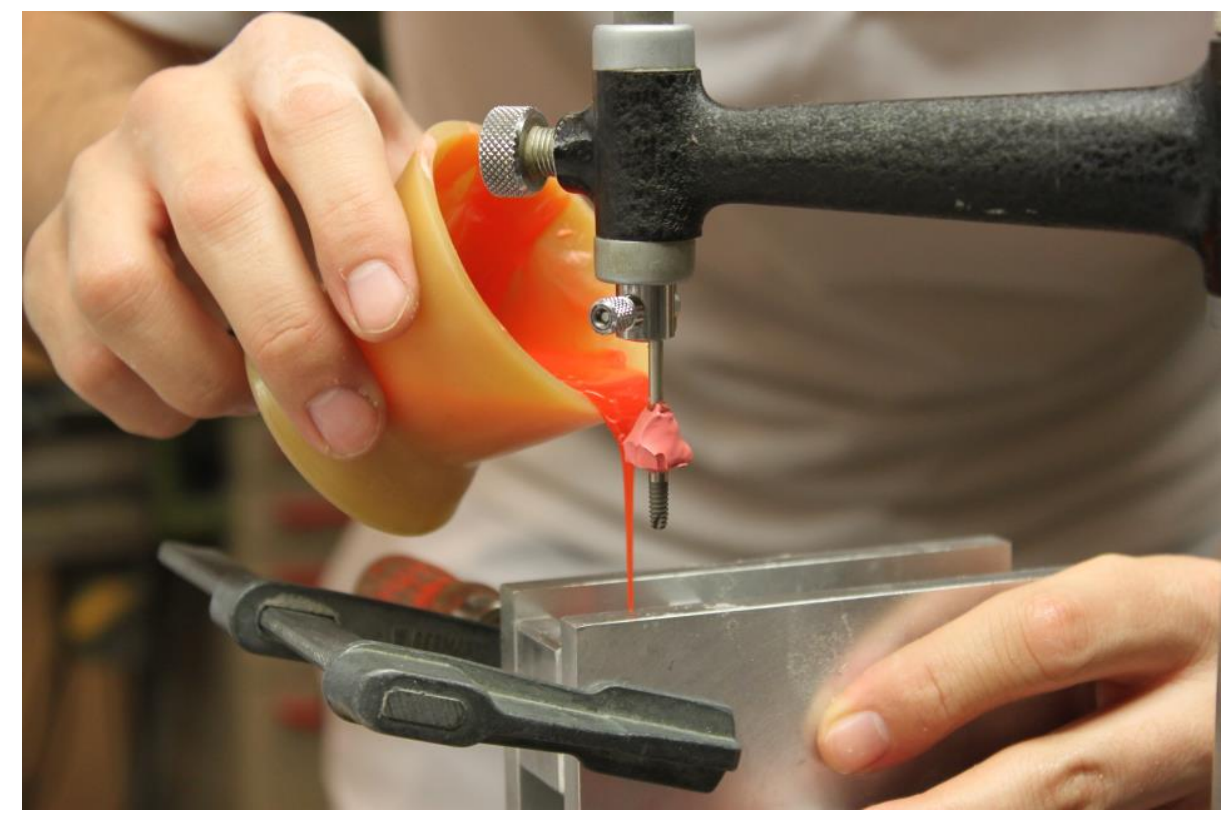

Abb. 7 a): Ausgießen der Hohlform mit Palavit G

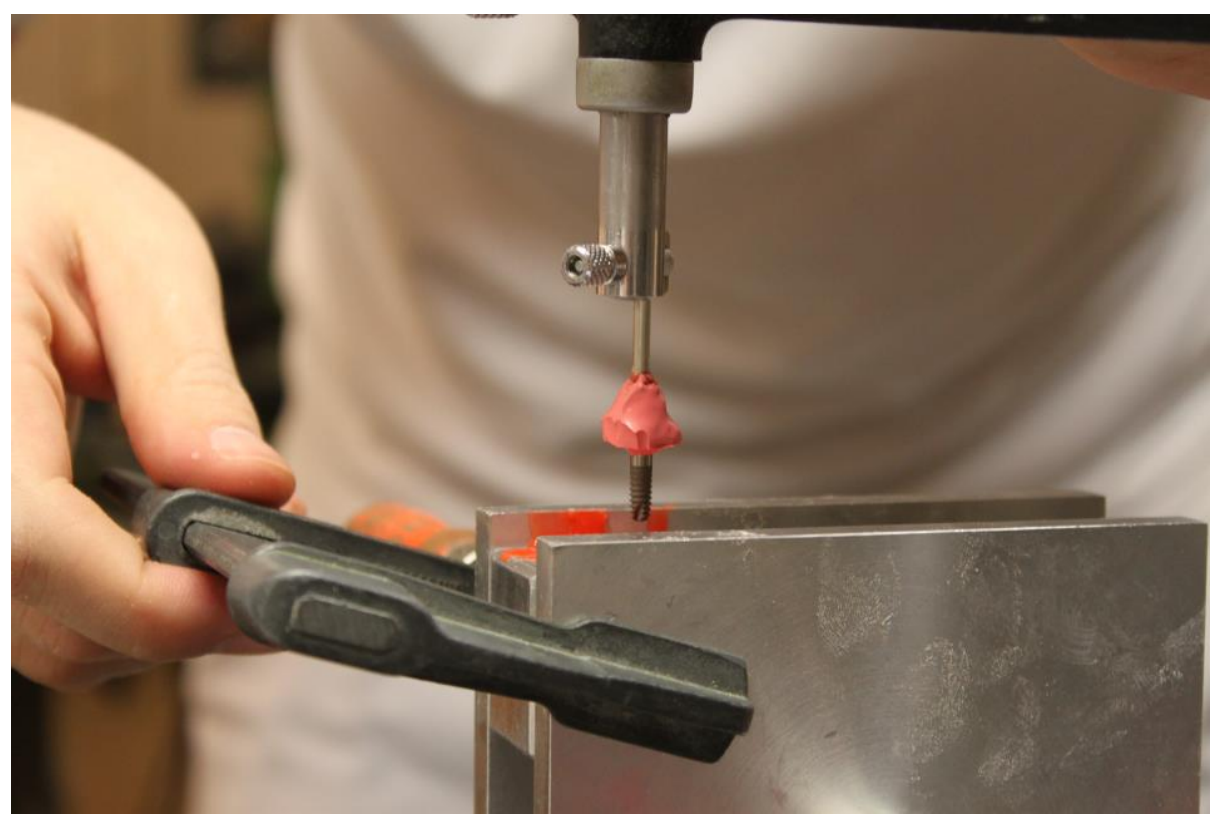

Abb. 7 b): Inserieren des Implantats in das noch flüssige Palavit G 


\subsection{Herstellung der Einzelzahnkronengerüste}

Die Abutments wurden mit Hilfe des Cercon® eye Scanner der Firma DeguDent (Hanau) (siehe Abbildung 8) einem Scanprozess unterzogen. Hierfür wurden die Abutments mit den bereits gesockelten Implantaten bei einem definiertem Drehmoment von $15 \mathrm{Ncm}$ verschraubt, dünn mit Scan-Puder bedeckt und ausgeblockt. Die Scaneinheit erkennt das zu scannende Objekt, indem eine Laserlinie das rotierende Objekt erfasst. Zwei Matrixkameras zeichnen hierbei den räumlichen Verlauf der Laserlinie auf und ermöglichen über dieses Laserschnittverfahren die Erfassung der Daten. Weiterhin existiert eine dritte Kamera, welche ein Vorschaubild liefert und der Zuordnung von Referenzpunkten während des Scanvorganges dient. Entsprechend des aktiven Triangulationsverfahrens entsteht ein detailgetreues, dreidimensionales Bild des Scanobjektes auf dem Monitor (Hellwig et al. 2010).

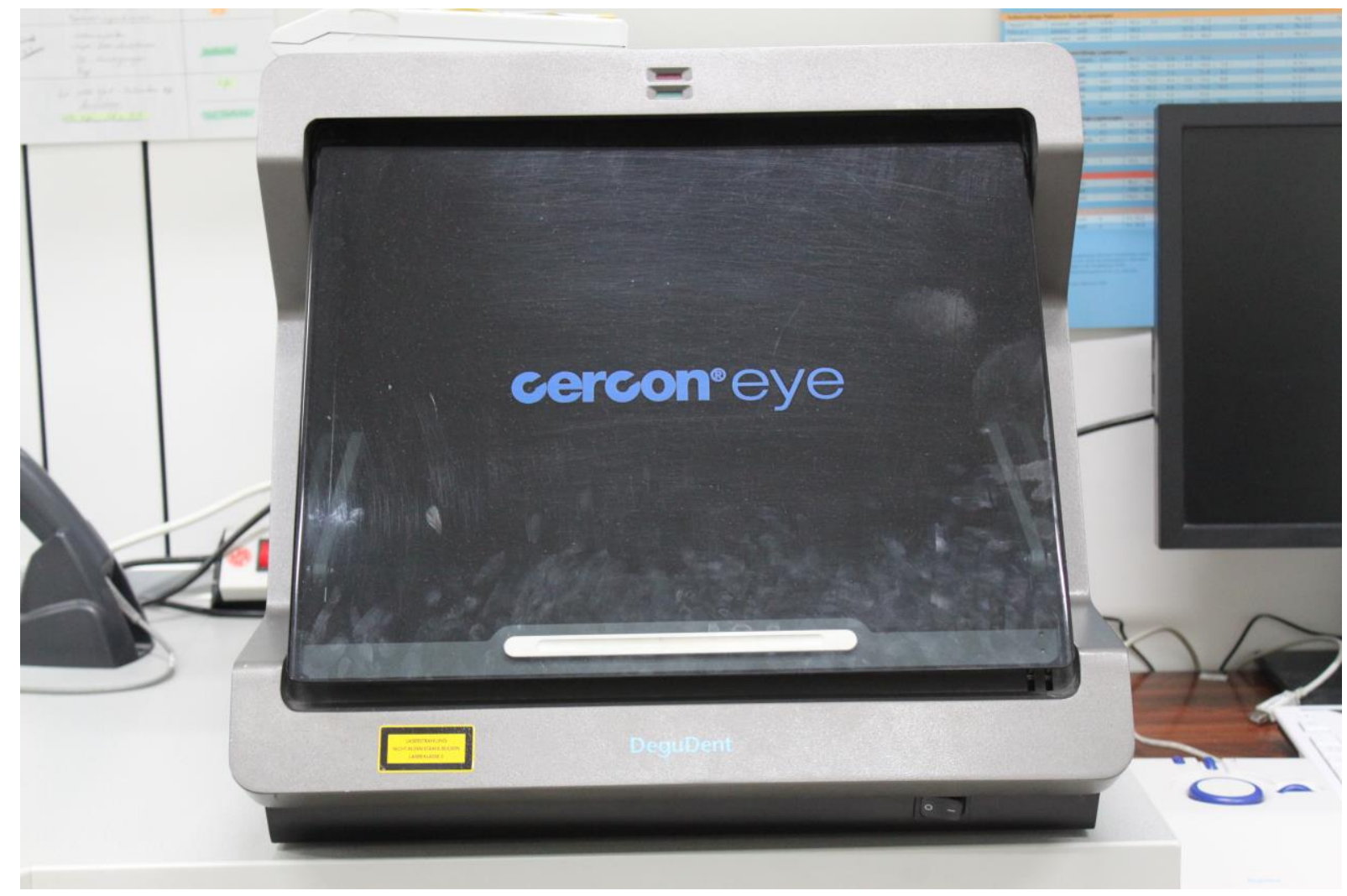

Abb. 8: Cercon® eye Scanner der Firma DeguDent (Hanau) 
Mittels der CAD-Software Cercon® art erfolgte nach abgeschlossenem Scanprozess die digitale Modellation der Zirkoniumdioxid-Käppchen. Die Parameter der Kronengerüste betrugen $10 \mu \mathrm{m}$ für den Zementspalt, 0,5 mm für die Käppchenstärke und $70 \%$ für die Spacerfläche. Zur Aufnahme in die Abzugsvorrichtung und zur Gewährleistung eines korrekten axialen vertikalen Abzuges wurden seitliche Ausläufer modelliert, mit dem Ziel, einen Unterschnitt für das Ansetzen der Abzugskralle zu erzeugen. Die Befestigungselemente zur Aufnahme des Prüfkörpers in die Zwick Universalprüfmaschine wurden eigens für die Versuche der vorliegenden Studie angefertigt und durch Steck- und Schraubverbindungen spielfrei miteinander verbunden. Abbildung 9 zeigt die Gesamtkonstruktion zur Befestigung in der Universalprüfmaschine.

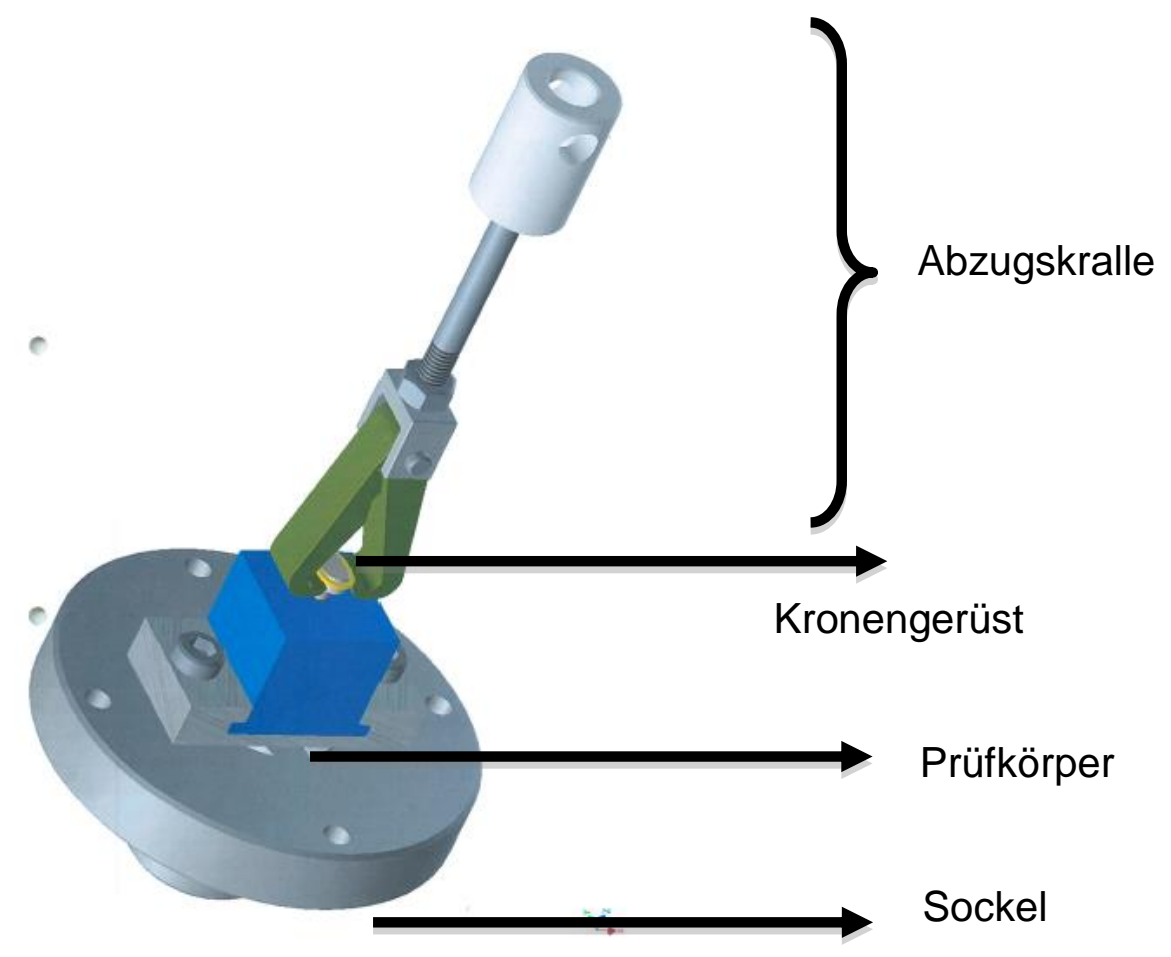

Abb. 9: Konstruktionszeichnung

Nach abgeschlossener Modellation wurde der Datensatz an das Labor der Firma DeguDent (Hanau) weitergeleitet, wo die Käppchen aus Zirkondiumdioxid-Blöcken (Cercon base@) herausgefräst wurden.

Abschließend erfolgte die Zementierung der Käppchen auf den Abutments. Um eventuelle isolierende Rückstände in der Suprakonstruktion zu entfernen wurden 
diese vor der Zementierung mit Alkohol gereinigt. 


\subsection{Zementierung}

Für die vorliegende Studie wurde der handelsübliche provisorische Befestigungszement TempBond® NE der Firma Kerr (Ratstatt, Deutschland) verwendet.

TempBond® NE ist ein selbsthärtender eugenolfreier Zement auf Zinkoxid-Basis, der zur Befestigung von provisorischen Kronen, Brücken oder Bissschienen, sowie zur provisorischen Befestigung von Langzeitrestaurationen geeignet ist. Da Rückstände eugenolhaltiger Produkte bei defintiver Befestigung inhibierend auf die Polymerisation von methacrylat-basierten Dentinadhäsiven, sowie auf die Abbindereaktion von Befestigungskompositen wirken, wurde in der vorliegenden Studie für den erhöhten klinischen Nutzen TempBond® NE verwendet (Schwartz et al. 1992, Woody und Davis 1992).

Die Suprakonstruktionen wurden vor der Zementierung mit Propanol entfettet. Nach Lufttrocknung wurden die Zirkoniumdioxid-Käppchen mit einem Einwegpinsel dünn und gleichmäßig mit dem Zement bestrichen und mit manuellem Anpressdruck bis zum merkbaren „Anziehen“ des Zementes auf dem Prüfkörper gehalten. Die Anmischung des Dentalzementes erfolgte gemäß der Herstellerangaben. Es wurden je ein gleich dimensionierter Strang Basispaste und Katalysatorpaste auf einem Anmischblock mit Hilfe eines Zementspatels zügig miteinander vermischt, bis eine homogene Masse entstanden ist. Überschüssige Zementreste am Kronenrand wurden mit Hilfe eines Heidemann-Spatels entfernt und die Proben wurden 24 Stunden bei Raumtemperatur getrocknet. 


\subsection{Reinigungsmethoden}

In der vorliegenden Studie wurden folgende Reinigungsmöglichkeiten untersucht:

- manuelle Reinigung

- manuelle Reinigung in Kombination mit Ultraschallreinigung

- Reinigung durch Ausstrahlen mit $\mathrm{Al}_{2} \mathrm{O}_{3}$.

Die manuelle Reinigung wurde mit Hilfe eines Heidemann-Spatels durchgeführt. Bei der kombinierten manuellen Reinigung mit dem Ultraschallbad wurden die Kronengerüste 15 Minuten in einem $99 \%$ igen Isopropanolbad bei $30^{\circ} \mathrm{C}$ gesäubert. Die Käppchen der dritten Versuchsreihe wurden mit Aluminiumdioxid (110 $\mu \mathrm{m}$-Korn, 2 bar, 15 s Dauer) ausgestrahlt.

\subsection{Abzugsversuch}

Die Abzugsversuche wurden unter folgenden Parametern durchgeführt:

- Vorkraft: $20 \mathrm{~N}$

- Vorkraftgeschwindigkeit: $50 \mathrm{~mm} / \mathrm{min}$

- Prüfgeschwindigkeit: $5 \mathrm{~mm} / \mathrm{min}$.

Die Auswertung der Versuche und die Aufzeichnung der Kraft-Dehnungs-Diagramme erfolgte durch die Software "testXpert" (Zwick, Ulm) Je Versuchsreihe wurden 13 Prüfkörper einem Abzugsversuch unterzogen. Nach dem Einspannen der Prüfkörper in die Abzugsvorrichtung, wurden die Versuche nacheinander mit den oben erwähnten Einstellungskriterien den Abzugsversuchen bis zur Dezementierung der Suprakonstruktionen unterzogen (Abbildung 10). 

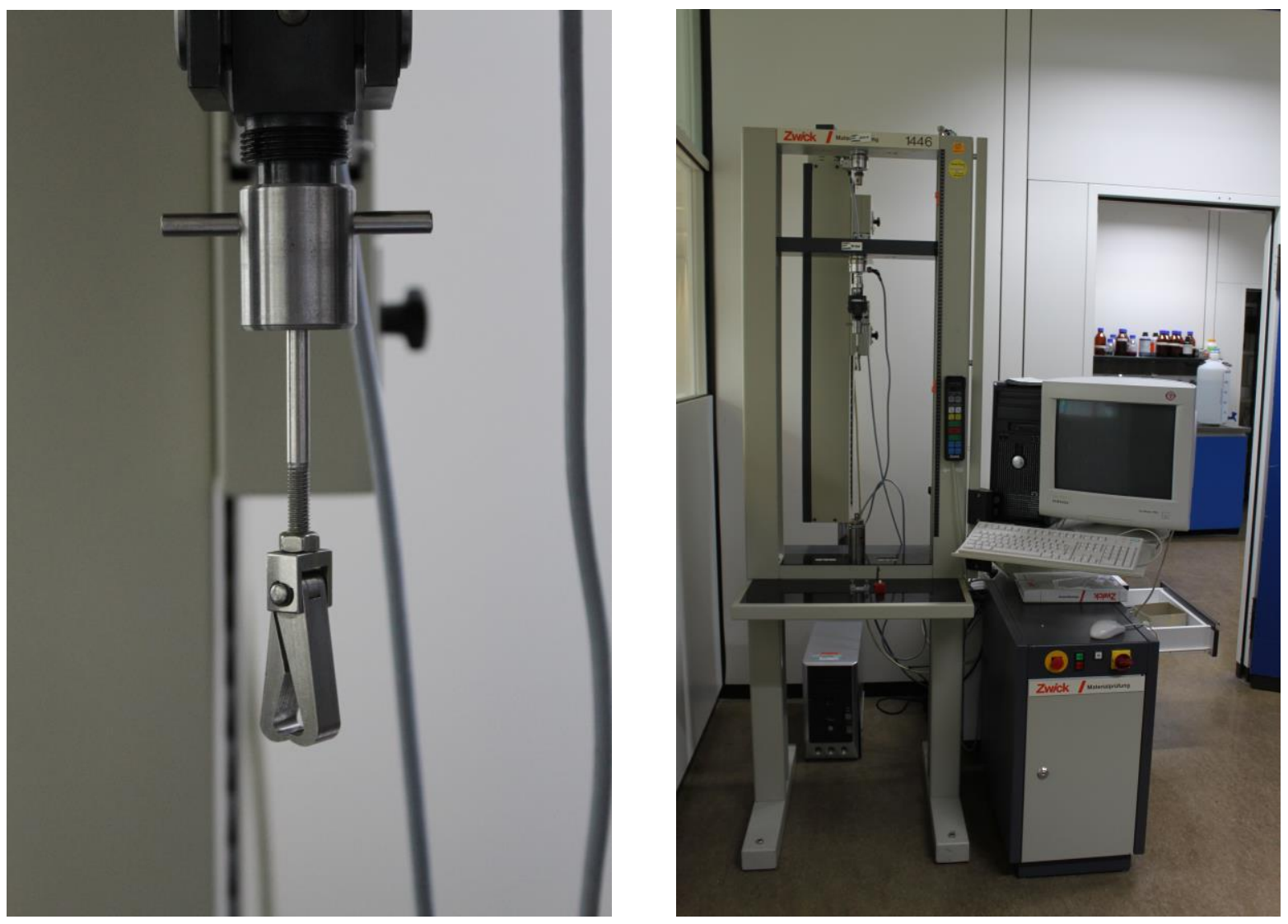

Abb.10: a) Abzugskralle,

b) Zwick Universalprüfmaschine 


\subsection{Materialanalyse im Rasterelektronenmikroskop (REM)}

Die Rasterelektronenmikroskopie dient der Darstellung mikromorphologischer Oberflächenbeschaffenheiten. Gleichzeitig können im mikroskopischen Bereich chemische Untersuchungen bezüglich der Zusammensetzung von Materialien erfolgen.

In Zusammenarbeit mit Frau Dr. Techmer der Abteilung Kristallographie des Geozentrums der Georg-August-Universität Göttingen, wurde pro Reinigungsmethode je eine Zirkoniumdioxid-Suprakonstruktion, sowie eine Zementprobe im Rasterelektronenmikroskop (Quanta 200 von FEI, Hillsboro, Oregon USA) einer chemischen und strukturellen Oberflächenanalyse unterzogen. Zur besseren Darstellung etwaiger Oberflächenveränderungen nach erfolgter Reinigung wurde ein neues, unbehandeltes Zirkoniumdioxid-Käppchen als Referenzmaterial hinzugezogen.

Bei der Rasterelektronenmikroskopie wird die Oberfläche der Probenkörper von einem fokussierten Primärelektronenstrahl bei unterschiedlichen Anregungsspannungen in der Form eines Rasters punktförmig überstrichen und die entstehenden Wechselwirkungen des Primärelektronenstrahles mit den obersten Schichten der Oberfläche aufgezeichnet. Der Elektronenstrahl wird gerade entlang einer Oberfläche geführt, kehrt zu seinem Ausgangspunkt zurück und wird durch ein Standardinkrement nach unten versetzt. Dieser Vorgang wiederholt sich so oft, bis die gesamte Oberfläche vollständig abgerastert worden ist. Die Punktdichte innerhalb der Rasterung und damit die Auflösung der rasterelektronischen Aufnahme ist stufenweise einstellbar. Bei diesem Abrasterverfahren werden verschiedene Signalarten generiert, die chemische und topographische Aussagen über eine Probenoberfläche zulassen. Bei der Rasterelektronenmikroskopie werden vor allem rückgestreute Elektronen und Sekundärelektronen verwendet. Diese Sekundärelektronen, die aus der Probe emittieren, werden von einem Sekundärelektronendetektor registriert. 
Das REM ist in der Lage hochaufgelöste topographische Abbildungen bis in den Nanometerbereich zu liefern (Skoog und Leary 1996). Rückgestreute Elektronen, die ebenfalls aus den oberen Lagen der Probe entstammen, geben relative Massenkontraste der Probe wieder und weisen so auf eventuelle heterogene chemische Zusammensetzungen der Probe an der betreffenden Stelle hin.

Weiterhin wurde das integrierte System der Energiedispersiven Röntgenspektroskopie, die EDX-Analyse (Energy-Dispersive-X-Ray Analyses) eingesetzt. Dieses Verfahren ermöglicht an Ort und Stelle eine Analyse der Energie von emittierten Röntgenquanten an einer Probenlokalität und somit eine Messung der chemischen Zusammensetzung unterschiedlicher Materialien. Das Messverfahren beruht auf der Wechselwirkung zwischen den Primärelektronen des Elektronenstrahls und den Elektronenhüllen der Probenatome. Diese Wechselwirkung führt zur Tiefenionisation der Atome und dadurch zur Emission von Röntgenstrahlen. Nach dem Moseley'schem Gesetz hängt die Energie der Röntgenstrahlen von der Ordnungszahl der Atome ab, sodass anhand der charakteristischen Röntgenspektren die chemische Zusammensetzung der Probe ermittelt werden kann (Raether 1957). Die Auswertung der Energie der Röntgenemission erfolgt in den sogenannten EDX-Spektren. Diese geben Auskunft über die Signalintensität („counts per second“ als Maß für die Zählstatistik) in Abhängigkeit der Energie der Röntgenquanten und bestehen aus der unspezifischen Bremsstrahlung als Untergrundspektrum und den für die chemische Analytik wichtigen, charakteristischen, elementspezifischen Peaks. Die energetische Lage des charakteristischen Linienspektrums wird für die qualitative Analyse verwendet und die Intensität des Spektrums für die quantitative Analyse. 


\subsubsection{Aufbau des Rasterelektronenmikroskops REM}

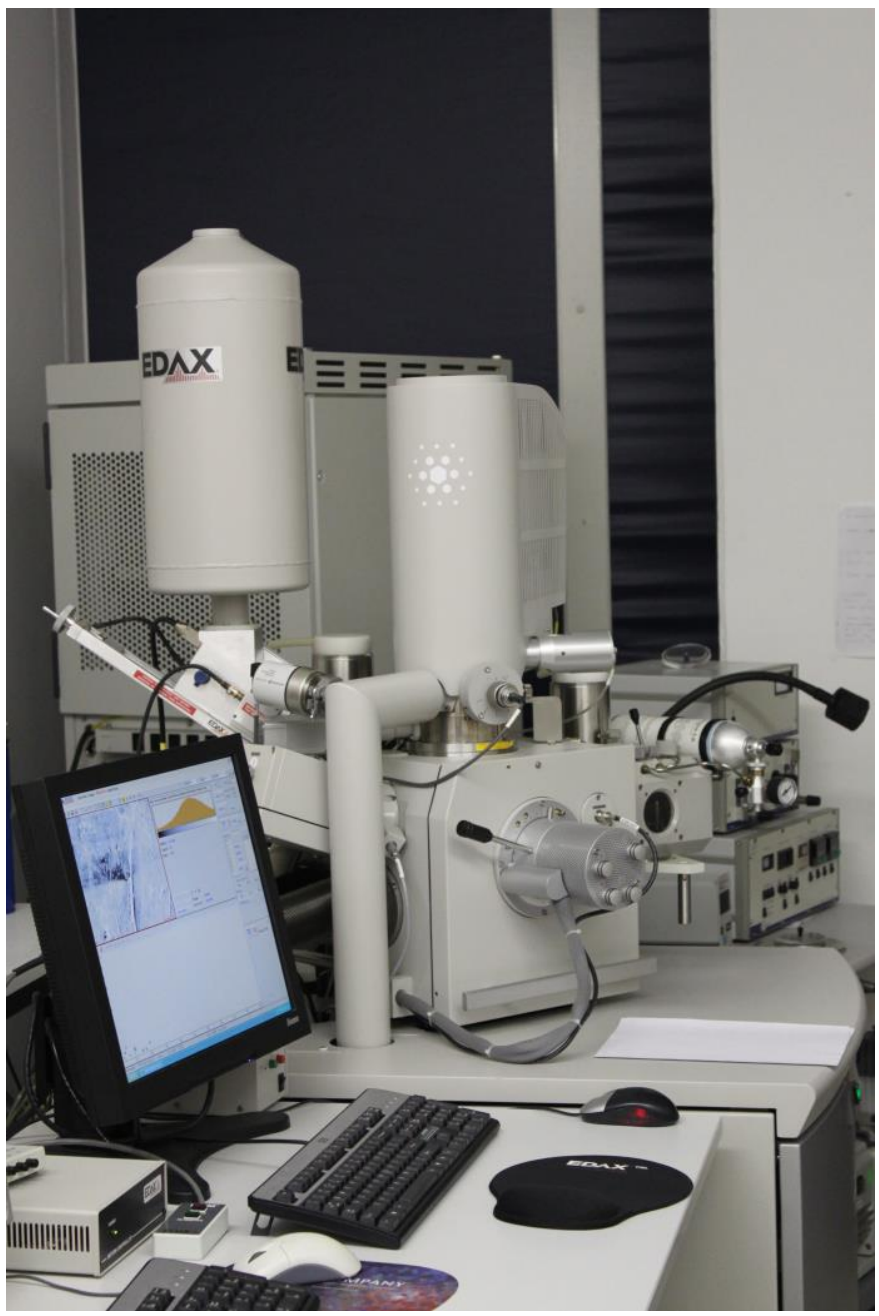

Abb. 11: Rasterelektronenmikroskop Quanta 200, Firma FEI (Hillsboro, Oregon USA)

Das in Abbildung 11 gezeigte Rasterelektronenmikroskop besteht aus verschiedenen Komponenten: Strahlerzeuger, Linsensystem, Ablenkelemente, Detektoren und einem Bilderfassungssystem. Um Wechselwirkungen des Primärelektronenstrahles mit Atomen und Molekülen in der Luft zu vermeiden, findet der komplette Mikroskopiervorgang im Hochvakuum von 10-6 mbar statt. 
An der Wolframglühkathode werden Elektronen freigesetzt und durch eine Spannung von 1-30 kV zu der auf dem Nullpotential liegenden Anode hin beschleunigt. Durch einen zusätzlichen Wehneltzylinder um die Kathode entsteht durch ein noch negativeres elektrisches Potential eine negative Raumladungswolke, woraus ein stabiler Emissionsstrahl resultiert. Die Elektronenstrahllenkung basiert auf elektromagnetischen Linsen. Diese fokussieren den Elektronenstrahl auf einen Durchmesser von ungefähr $5 \mathrm{~nm}$. Der Abrastervorgang wird durch Ablenkspulen realisiert, die den gebündelten Strahl zeilenweise über die Probe führen, wodurch Sekundärelektronen freigesetzt werden. Diese werden von einem schräg oberhalb der Probe liegendem Sekundärelektronendetektor erkannt. Durch die schräge Anordnung erscheinen dem Detektor zugewandte Bereiche heller als weiter abgewandt liegende, wodurch die Plastizität der Objekte entsteht. Die elektrischen Signale werden abschließend auf einen Monitor übertragen (Heine 2003, von Ardenne et al. 2005).

Neben der hohen Auflösung, zeichnet sich die Rasterelektronenmikroskopie vor allem dadurch aus, dass eine etwa 100 fach höhere Tiefenschärfe gegenüber einem Lichtmikroskop erreicht werden kann (Raether 1957). 


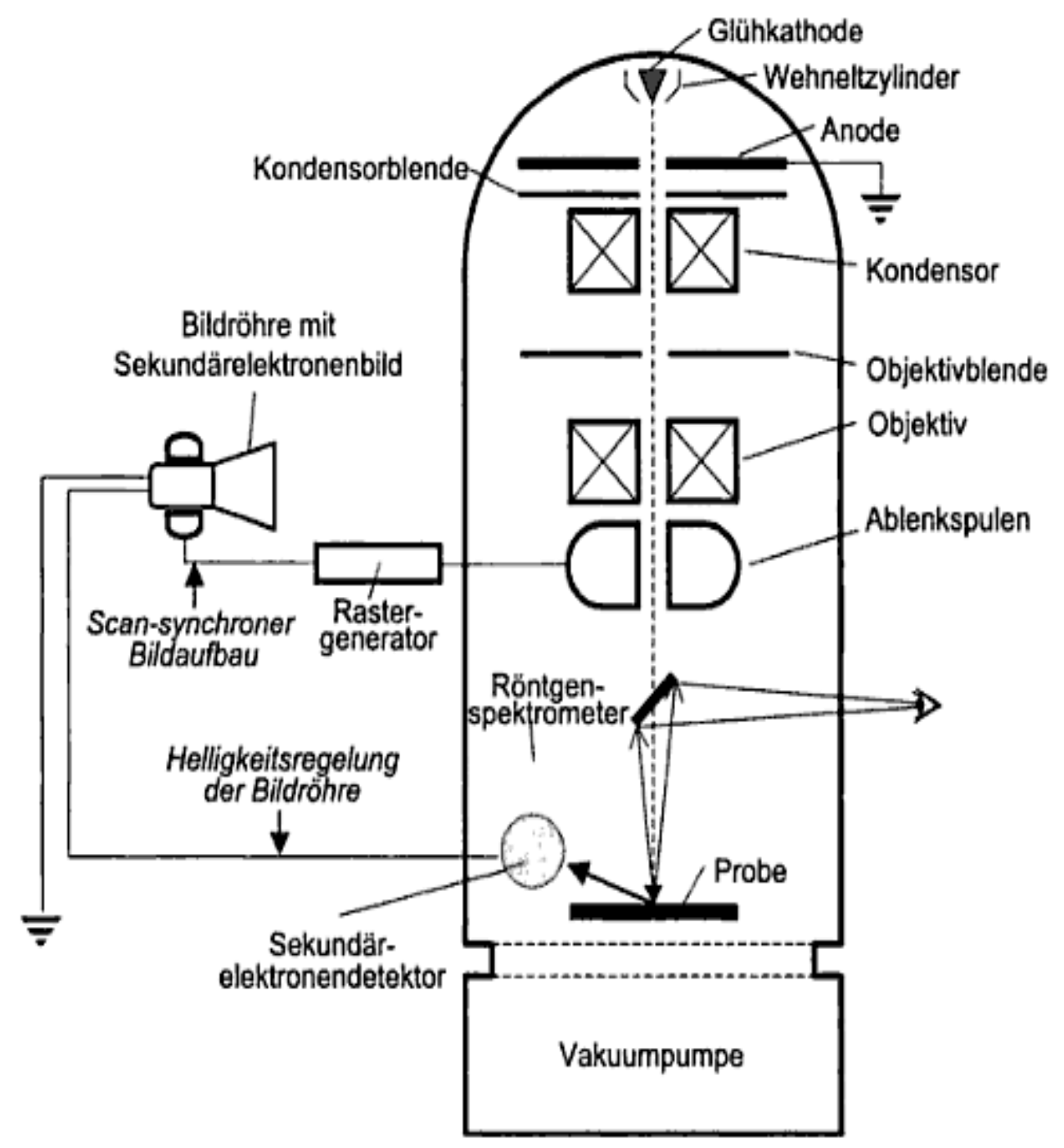

Abb. 12: Schematischer Aufbau Rasterelektronenmikroskop (Heine 2003, S. 88)

\subsubsection{Präparation der Proben}

Um eine Probe im Rasterelektronenmikroskop untersuchen zu können, muss diese gut leitend und trocken sein. Die Bedingung der Leitfähigkeit wurde dadurch realisiert, dass die Zirkoniumdioxid-Käppchen auf eine mit Kohlenstoff bedampfte Folie geklebt wurden. Zur Vermeidung der Kontamination der Probenoberfläche wurde die Probenpräparation mit Handschuhen durchgeführt. 
Die zu untersuchende Zementprobe TempBond® NE der Firma Kerr (Ratstatt, Deutschland) wurde vor dem Mikroskopiervorgang 24 Stunden getrocknet, um durch Schrumpfungsprozesse entstehende Artefakte durch das Herauslösen von $\mathrm{OH}$ Gruppen im Hochvakuum zu vermeiden. Abbildung 13 zeigt die Probenkörper in der Probenkammer.

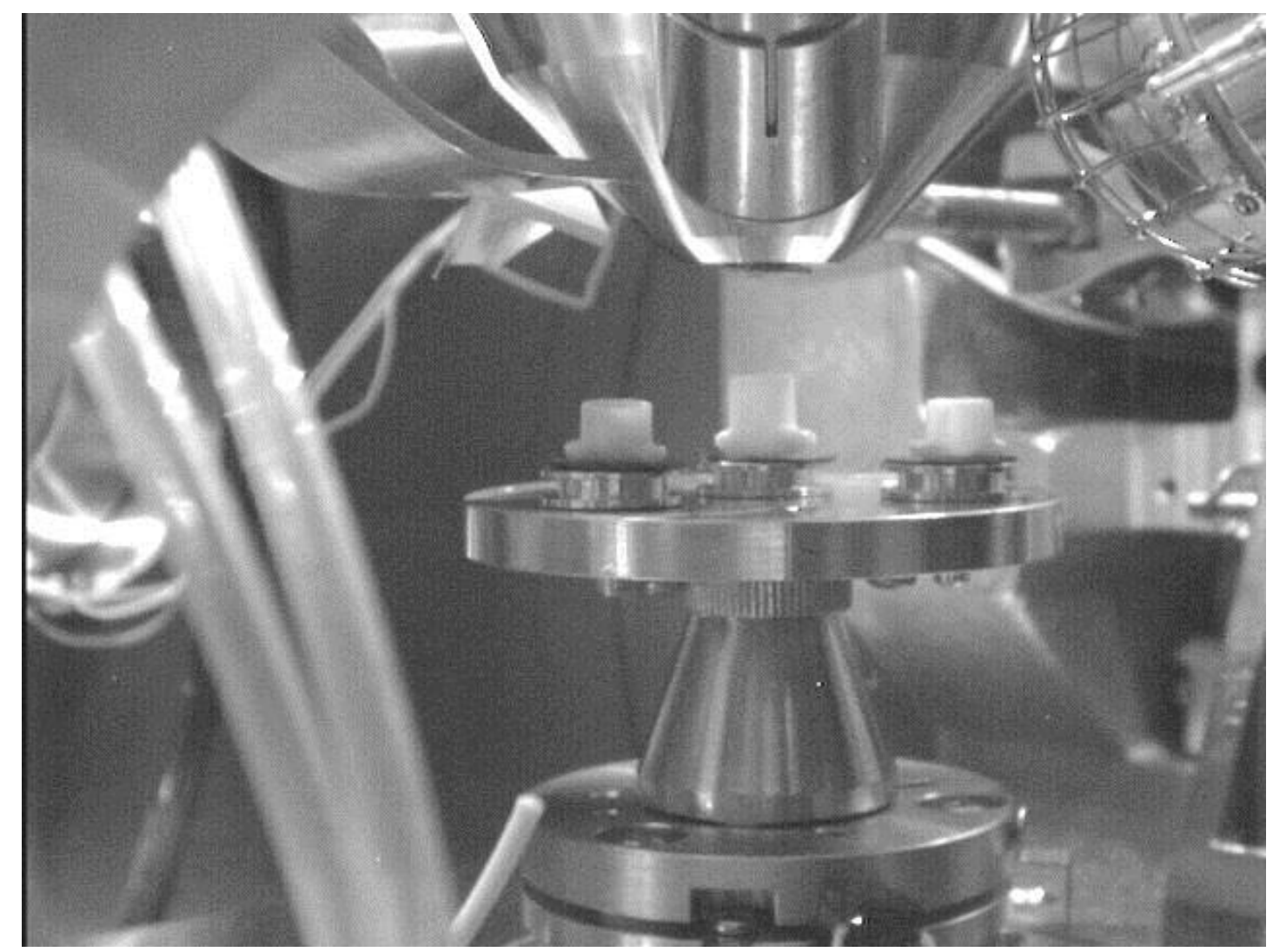

Abb. 13: Probenkammer des Rasterelektronenmikroskops mit den zu untersuchenden Proben 


\subsection{Statistische Methoden}

Da es sich bei dem untersuchten Endpunkt um eine metrische Größe handelt, wurde ein parametrisches Modell verwendet. Um die Einflüsse der verschiedenen Faktoren zu untersuchen wurde eine einfaktorielle Varianzanalyse durchgeführt. Die Varianz wurde hierbei für jede Faktorenstufenkombination separat geschätzt (Varianzheterogenes Modell). In der vorliegenden Studie musste für Post-Hoc Vergleiche zur Einhaltung des multiplen Niveaus mit Hilfe der Dunett-Prozedur adjustiert werden. Die Graphiken (siehe 4.1.) zeigen die zur Hauptanalyse gehörigen Mittelwerte mit ihren 95\%-Konfidenzintervallen.

Die Auswertungen erfolgten mit Hilfe der Software SAS 9.2. (Copyright, SAS Institute Inc. SAS and all other SAS Institute Inc. product or service names are registered trademarks or trademarks of SAS Institute Inc., Cary, NC, USA). 


\section{Ergebnisse}

Die höchste Retentionskraft von 129,28 N (Mittelwert: 90,08 N) konnte bei der manuellen Reinigung in Kombination mit Ultraschall beobachtet werden. Allerdings zeigte diese Messreihe auch die höchste Standardabweichung (23,39 N), die sich jedoch noch im statistisch vertretbaren Bereich befindet. Die niedrigste Haftkraft ließ sich bei der manuellen Säuberung feststellen. Der Mittelwert lag hier bei 48,87 N. Die Messreihe der ausgestrahlten Käppchen ergab einen Mittelwert von 56,85 N. Das unbehandelte Referenzkäppchen zeigte im Mittel eine Retentionskraft von 79,35 N.

\begin{tabular}{|l|l|l|l|l|}
\hline Abutment & Referenzkäppchen, & Manuell, N & $\begin{array}{l}\text { Manuell + } \\
\text { Ultraschall, N }\end{array}$ & $\begin{array}{l}\text { Ausstrahlung, } \\
\text { N }\end{array}$ \\
\hline $\mathbf{1}$ & 85,08 & 41,64 & 101,78 & 70,12 \\
\hline $\mathbf{2}$ & 50,36 & 38,73 & 90,08 & 71,66 \\
\hline $\mathbf{3}$ & 62,83 & 33,66 & 99,25 & 71,60 \\
\hline $\mathbf{4}$ & 94,44 & 48,87 & 123,26 & 51,37 \\
\hline $\mathbf{5}$ & 65,48 & 43,05 & 76,33 & 71,66 \\
\hline $\mathbf{6}$ & 88,74 & 69,93 & 87,18 & 45,20 \\
\hline $\mathbf{7}$ & 85,23 & 79,29 & 65,04 & 44,49 \\
\hline $\mathbf{8}$ & 61,67 & 42,17 & 92,87 & 44,54 \\
\hline $\mathbf{9}$ & 102,92 & 69,05 & 70,73 & 53,20 \\
\hline $\mathbf{1 0}$ & 79,35 & 39,07 & 129,28 & 56,65 \\
\hline $\mathbf{1 1}$ & 111,93 & 76,92 & 57,72 & 90,82 \\
\hline $\mathbf{1 2}$ & 77,50 & 62,79 & 120,68 & 75,5 \\
\hline $\mathbf{1 3}$ & 56,35 & 66,46 & 67,13 & 56,85 \\
\hline $\mathbf{N}$ & 13 & 13 & 13 & 13 \\
\hline Minimum & 50,36 & 33,66 & 57,72 & 44,49 \\
\hline Median & 79,35 & 48,87 & 90,08 & 56,85 \\
\hline Maximum & 111,93 & 79,29 & 129,28 & 90,82 \\
\hline $\mathbf{S}$ & 18,58 & 16,28 & 23,39 & 14,40 \\
\hline $\mathbf{V}$ & 23,64 & 29,73 & 25,74 & 23,31 \\
\hline $\bar{x}$ & 78,61 & 54,74 & 90,87 & 61,80 \\
\hline & & & & \\
\hline
\end{tabular}

Abb. 14: Auflistung aller Ergebnisse 


\subsection{Statistische Auswertung der Ergebnisse}

In Zusammenarbeit mit Frau Dr. Lange der Abteilung Medizinische Statistik an der Georg-August-Universität Göttingen erfolgte die statistische Auswertung der Ergebnisse der vorliegenden Studie.

\begin{tabular}{|l|l|r|r|r|}
\hline Effect & Reinigungsmethode & Estimate & Lower & Upper \\
\hline Reinigungsmethode & Referenzkäppchen & 78.6062 & 68.2435 & 88.9688 \\
\hline Reinigungsmethode & ausgestrahlt & 61.8200 & 53.7768 & 69.8632 \\
\hline Reinigungsmethode & manuell & 54.7408 & 45.6639 & 63.8176 \\
\hline Reinigungsmethode & manuell + Ultraschallbad & 90.8746 & 77.8283 & 103.92 \\
\hline
\end{tabular}

$\mathrm{N}$

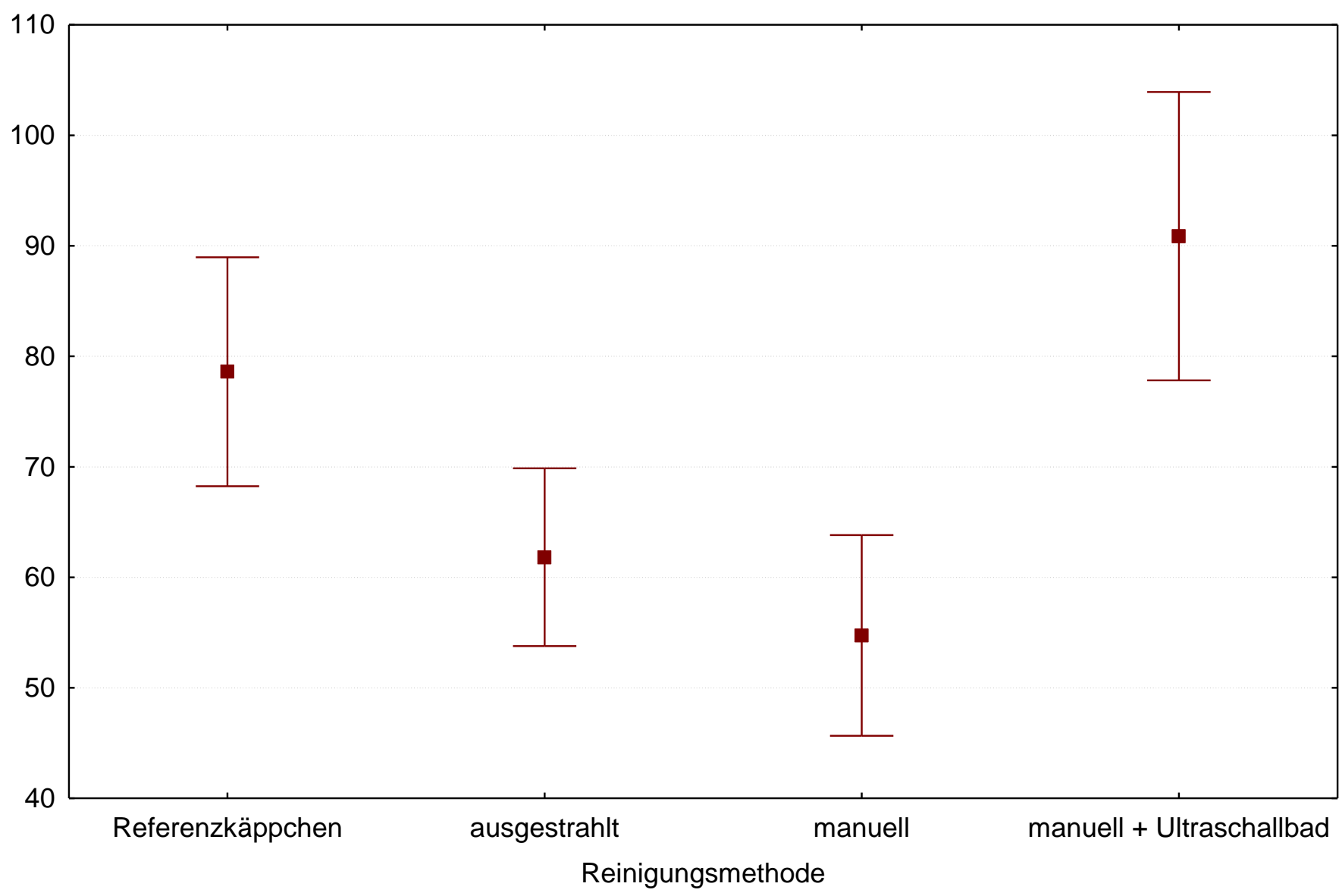

Abb. 15: tabellarische und graphische Darstellung der Mittelwerte der Gruppen mit 95\%-Konfidenzintervallen 


\begin{tabular}{|l|r|r|r|r|r|}
\hline Effect & Num DF & Den DF & Chi-Square & F Value & Pr $>$ F \\
\hline Reinigungsmethode & 3 & 48 & 27.62 & 9.21 & $<.0001$ \\
\hline
\end{tabular}

Abb. 16: Analyse mittels einfaktorieller Varianzanalyse

Es zeigte sich ein signifikanter Einfluss der Reinigungsmethode auf die erforderliche Kraft $(p<0.001)$. Zur weiteren Untersuchung dieses Einflusses werden Post-Hoc Vergleiche gegen die Kontrollgruppe (Referenzkäppchen) durchgeführt. Hierbei wird zur Kontrolle des multiplen Niveaus der Dunett-Test verwendet.

\begin{tabular}{|l|l|l|l|c|}
\hline Effect & Reinigungsmethode & Reinigungsmethode & Estimate & Adj P \\
\hline Reinigungsmethode & ausgestrahlt & Referenzkäppchen & -16.7862 & $\mathbf{0 . 0 3 4 8}$ \\
\hline Reinigungsmethode & manuell & Referenzkäppchen & -23.8654 & $\mathbf{0 . 0 0 3 0}$ \\
\hline Reinigungsmethode & $\begin{array}{l}\text { manuell+ } \\
\text { Ultraschallbad }\end{array}$ & Referenzkäppchen & 12.2685 & 0.3224 \\
\hline
\end{tabular}

Abb. 17: Post-Hoc Vergleiche gegen die Referenzkäppchen

\begin{tabular}{|c|c|c|c|c|c|}
\hline Differenz $z^{2}$ & Reinigungsmethode & Estimate & Adjustment & Lower & Upper \\
\hline Reinigungsmethode & ausgestrahlt & -16.7862 & Dunnett & 29.9040 & -3.6683 \\
\hline Reinigungsmethode & manuell & -23.8654 & Dunnett & 37.6412 & 10.0895 \\
\hline Reinigungsmethode & $\begin{array}{l}\text { manuell } \\
\text { Ultraschallbad }\end{array}$ & 12.2685 & Dunnett & -4.3926 & 28.9295 \\
\hline
\end{tabular}

Abb. 18: adjustierte Konfidenzintervalle

2 von der jeweiligen Reinigungsmethode wird der Mittelwert der Referenzmessung abgezogen, sodass Werte kleiner 0 bedeuten, dass bei der entsprechenenden Reinigungsmethode kleinere Werte als beim Referenzkäppchen gemessen wurden. 
Während die Reinigungsmethoden: ausgestrahlt und manuell zu signifikant schlechteren Ergebnissen als das Referenzkäppchen führen (ausgestrahlt: $\mathrm{p}=0.0345,95 \% \mathrm{KI}(-29.9,-3.66)$, manuell: $\mathrm{p}=0.0030,95 \% \mathrm{KI}(-37.64,-10.08))$, zeigt sich zwischen dem Referenzkäppchen und der Reinigungsmethode: manuell + Ultraschall kein signifikanter Unterschied mehr $(\mathrm{p}=0.3224,95 \% \mathrm{KI}(-4.39,28.92))$.

\subsection{Proben im Rasterelektronenmikroskop}

\subsection{1. $\quad \underline{\text { TempBond® NE (Kerr,Ratstatt, Deutschland) }}$}

Die Zementprobe weist ein heterogenes Mikrogefüge mit blasenartigen Strukturen auf. Diese können durch das Herauslösen von OH-Gruppen aus den oberen Probenlagen durch den im Hochvakuum stattfindenden Mikroskopiervorgang entstanden sein.
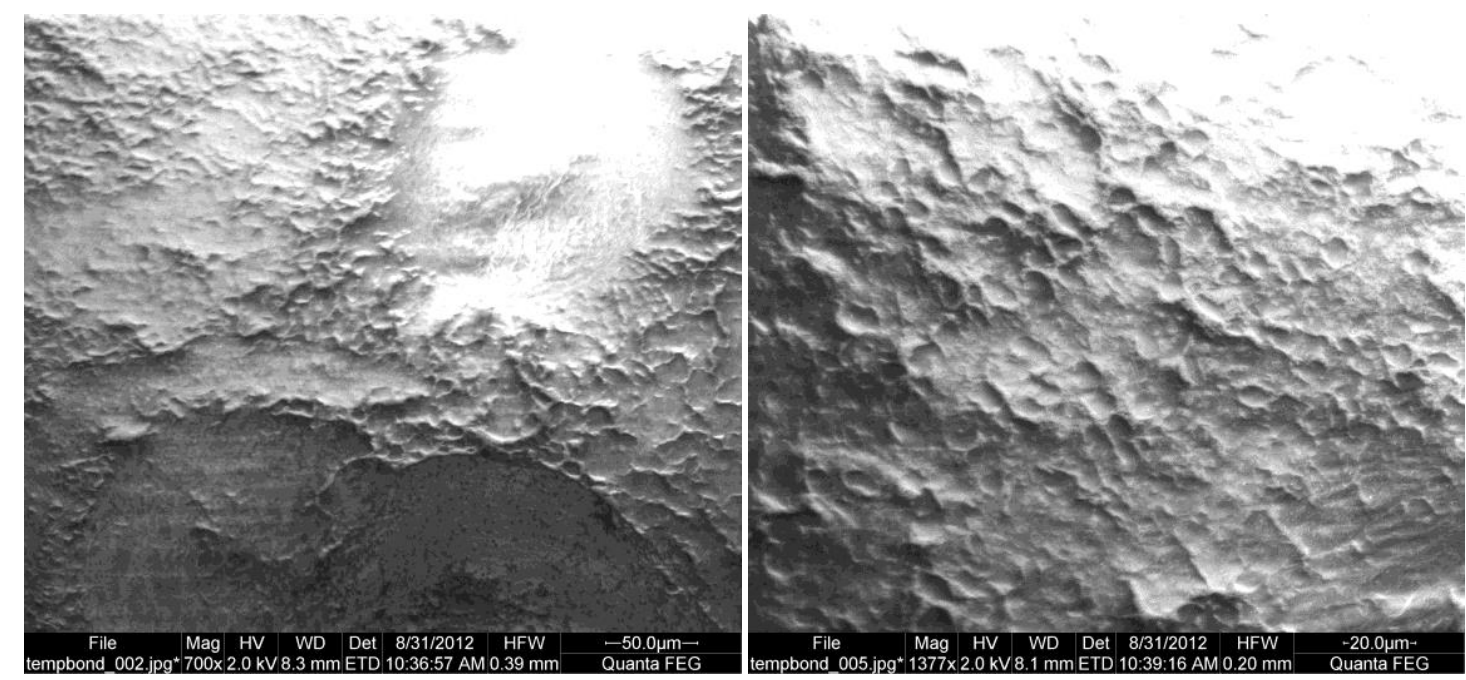

Abb. 19: a) Oberfläche der Zementprobe TempBond® NE

19: b) Detailaufnahme der Probenoberfläche bei höherer Vergrößerung zur Darstellung der blasenartigen Strukturen 


\subsubsection{Unbehandeltes Referenzkäppchen}

Die Übersichtsaufnahmen der unbehandelten Referenzkäppchen zeigen deutliche Schleifrauigkeiten, wobei die dabei entstandenen topographischen Strukturen nahezu parallel zueinander verlaufen. Die am Boden deutlich werdenden heterogenen Phasen sind auf unterschiedliche chemische Zusammensetzungen zurückzuführen. Weiterhin finden sich im Randbereich der Probe einzelne Kristallite, die auf eventuell nicht aufgeschmolzenes Ausgangsmaterial hindeuten können.
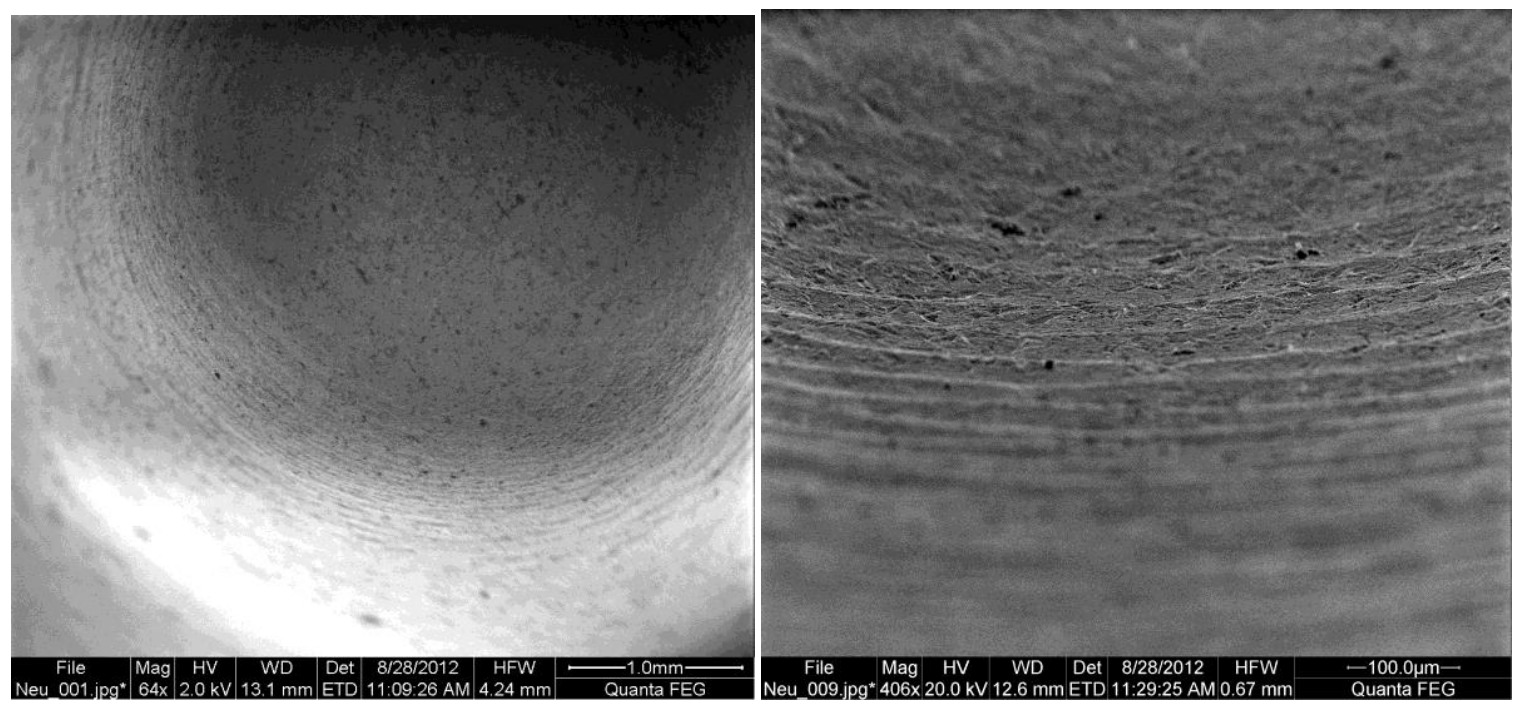

Abb. 20: a) Schleifrauigkeiten des Zirkoniumdioxid-Käppchens

20: b) Detailaufnahme der Schleifrauhigkeiten des Referenzkäppchens
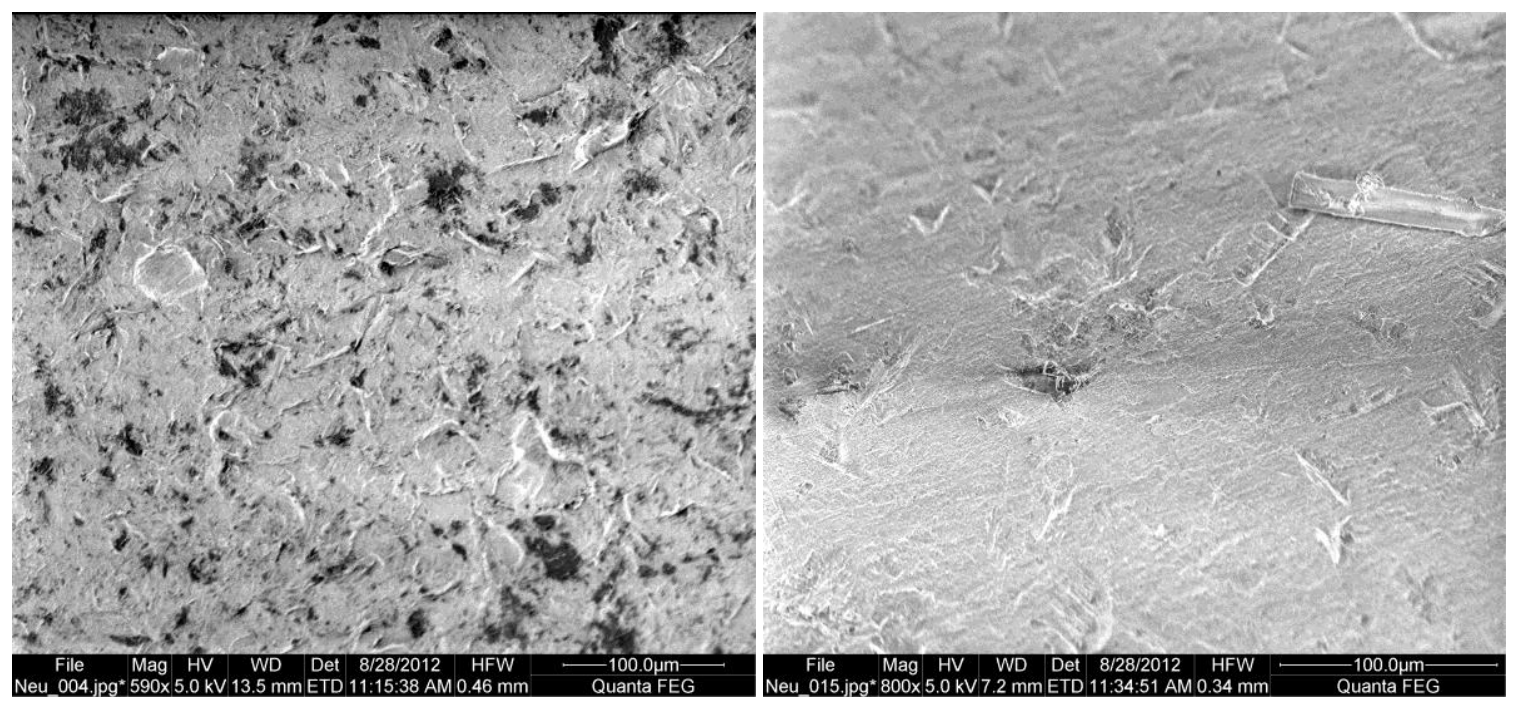

Abb. 21: a) Heterogene Phasen am Boden der Referenzkäppchen

21: b) vereinzelte Kristallite und Verunreinigung im Randbereich der Probe 


\subsubsection{Manuell gereinigtes Käppchen}

Bei der manuell bearbeiteten Probe sind deutliche Zementreste erkennbar, welche die Matrix homogener erscheinen lassen. Auf der Käppchenoberfläche sind weiterhin deutliche „Kratzspuren“ der manuellen Reinigung zu sehen. Sie verlaufen nicht parallel zueinander, sondern zeichnen sich durch irregulär verteilte Untiefen in der Oberfläche aus, die durchaus topographische Unebenheiten im zehnfachen $\mu \mathrm{m}$ Bereich haben.
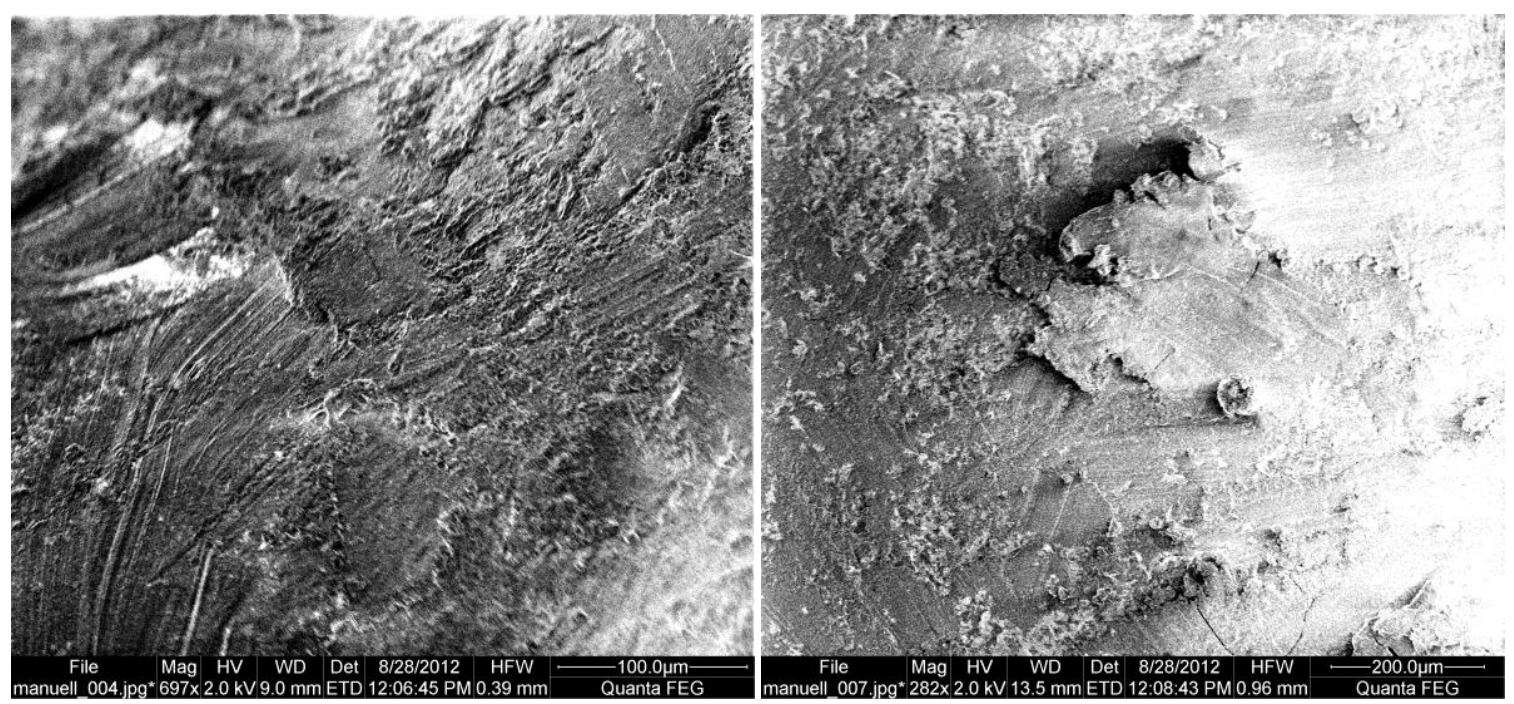

Abb. 22: a) Bearbeitungsspuren durch manuelle Reinigung der Käppchenoberfläche 22: b) Zementreste in der manuell bearbeiteten Probe 


\subsubsection{Manuelle Reinigung in Kombination mit Ultraschall}

Die Probenoberfläche erscheint im Vergleich zu dem unbehandelten Referenzkäppchen homogener. Topographische Untiefen sind weniger stark vorhanden, als in der manuell bearbeiteten Probe (s. 4.1.3.). Die Anwendung eines Ultraschallbades reinigt die Probenoberfläche gänzlich von Zementresten, glättet oberflächliche Inhomogenitäten und präpariert in der Matrix befindliche Kristallite heraus. Rauhigkeitsstrukturen in der Oberfläche liegen hier im einfachen $\mu \mathrm{m}$-Bereich.
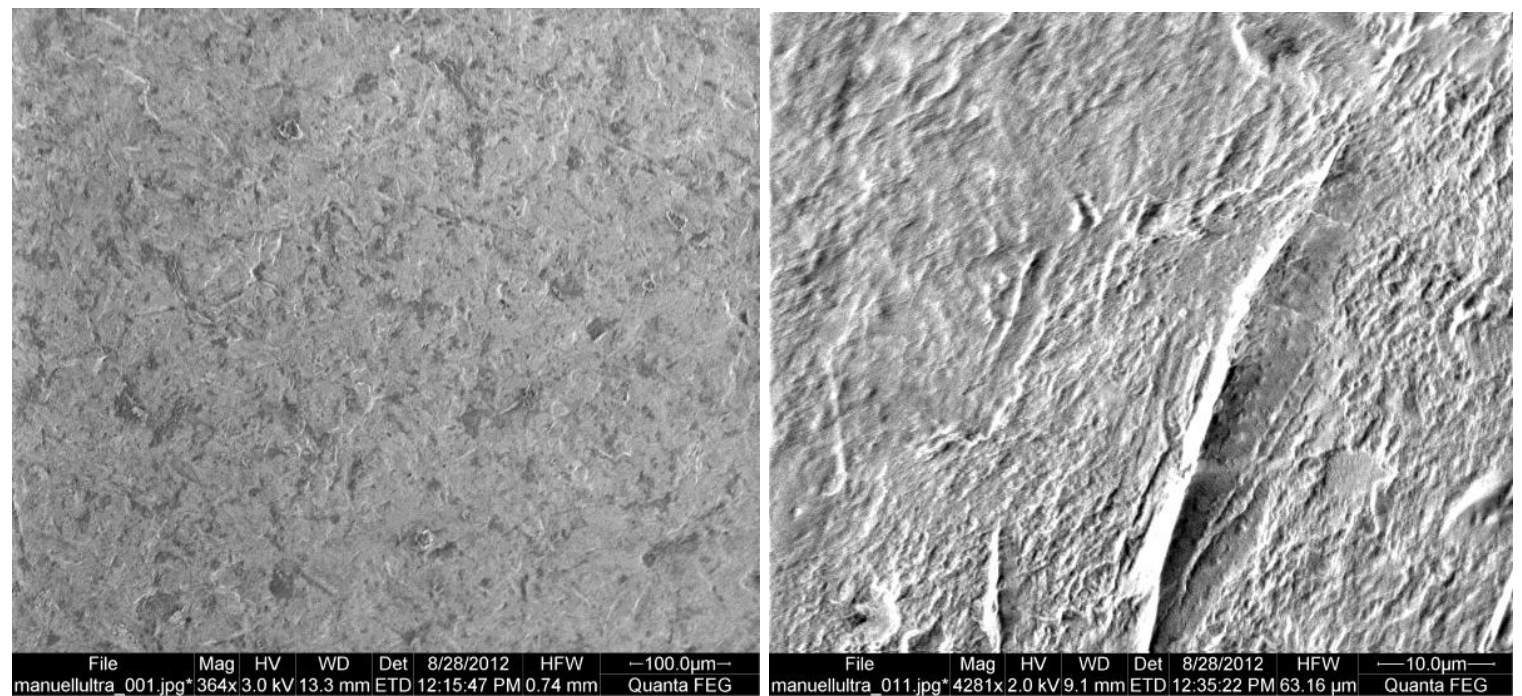

Abb. 23: a) Probenoberfläche nach manueller Reinigung und Ultraschallbad 23: b) Detailaufnahme mit herauspräparierten Kristalliten 


\subsubsection{Reinigung durch Ausstrahlen mit Aluminiumdioxid}

Im Übersichtsbild wird deutlich, dass das Ausstrahlen zu einer effizienten Zementrestbeseitigung geführt hat. Die Probenoberfläche ist tendenziell homogen und eben mit leichten Rauhigkeiten. Erst bei höheren Vergrößerungsaufnahmen wird eine leichte Inhomogenität der Matrix ersichtlich.
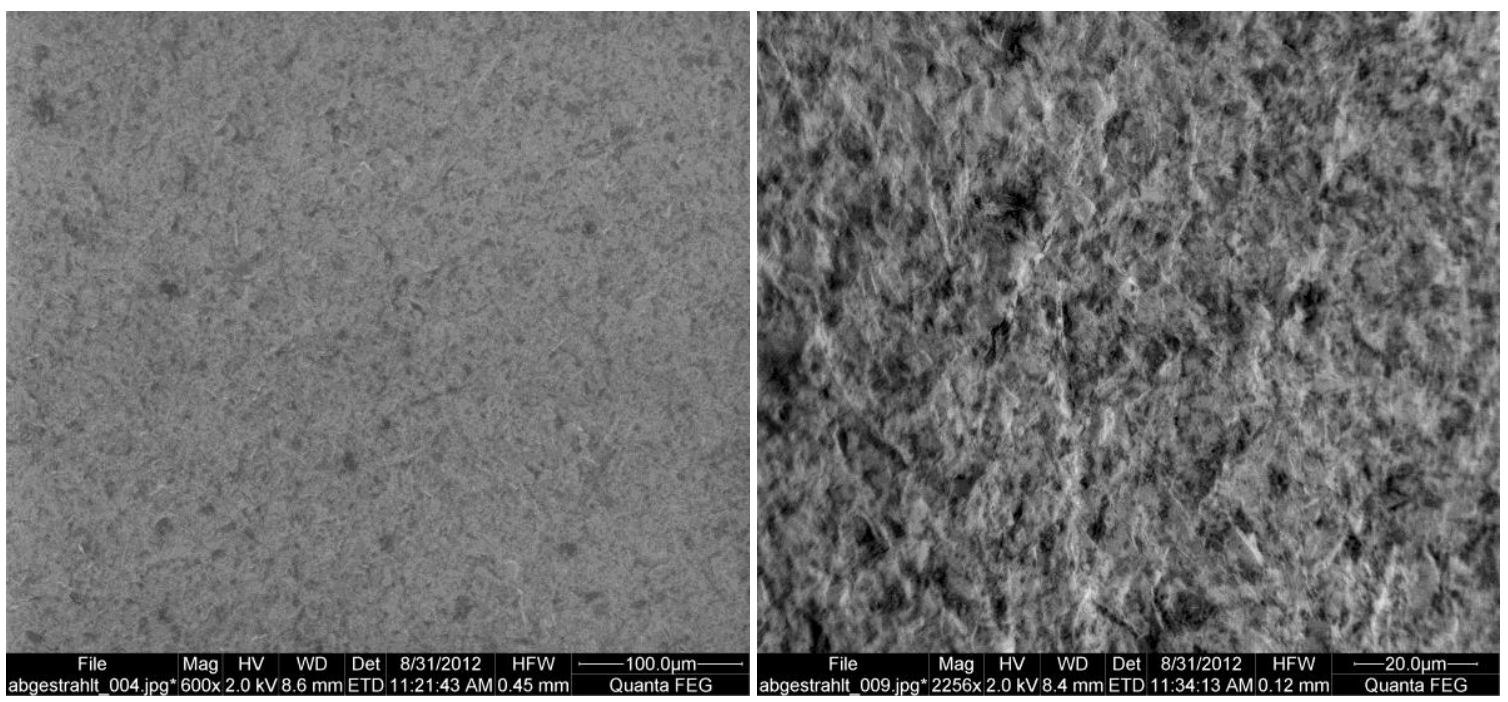

Abb. 24: a) Übersichtsaufnahme des mit Aluminiumdioxid ausgestrahlten Zirkoniumdioxid-Käppchens

24: b) Detailaufnahme der Probenoberfläche mit leichten Inhomogenitäten 


\subsection{Energiedispersive Röntgenspektroskopie (EDX-Analyse)}

Die röntgenographische EDX-Analyse erlaubt eine schnelle chemische Elementbestimmung im Zuge von Materialanalysen. Die Auswertung erfolgt anhand von EDX-Spektren, die die Signalintensität in Abhängigkeit der Energie der Röntgenquanten darstellen. Die erkennbaren Peaks sind elementspezifisch und müssen sorgfältig auf eventuelle Überlagerungen anderer Elemente untersucht werden.

\subsubsection{TempBond® NE (Kerr,Ratstatt, Deutschland)}

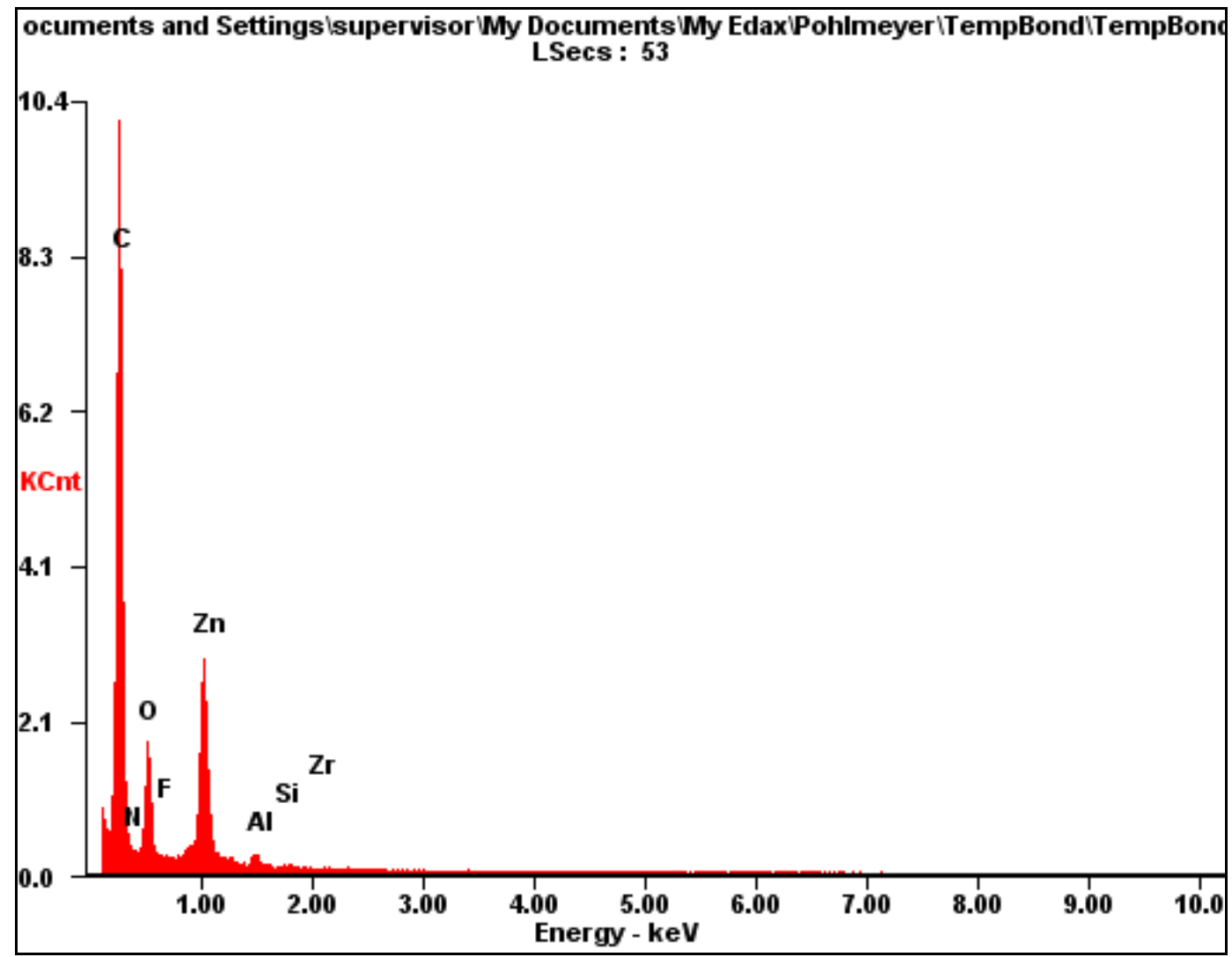

Abb. 25: EDX-Analyse der Zementprobe

Die qualitative EDX-Analyse zeigt als Hauptbestandteile Kohlenstoff, Zink, Sauerstoff, Fluor und Aluminium sowie Silicium in kleinerer Menge. TempBond® NE ist ein selbsthärtender eugenolfreier Zement auf Zinkoxid-Basis, was auch die EDXAnalyse durch einen entsprechen deutlichen Zn-Peak hervorbringt. 


\subsubsection{Unbehandeltes Zirkoniumdioxid-Käppchen}

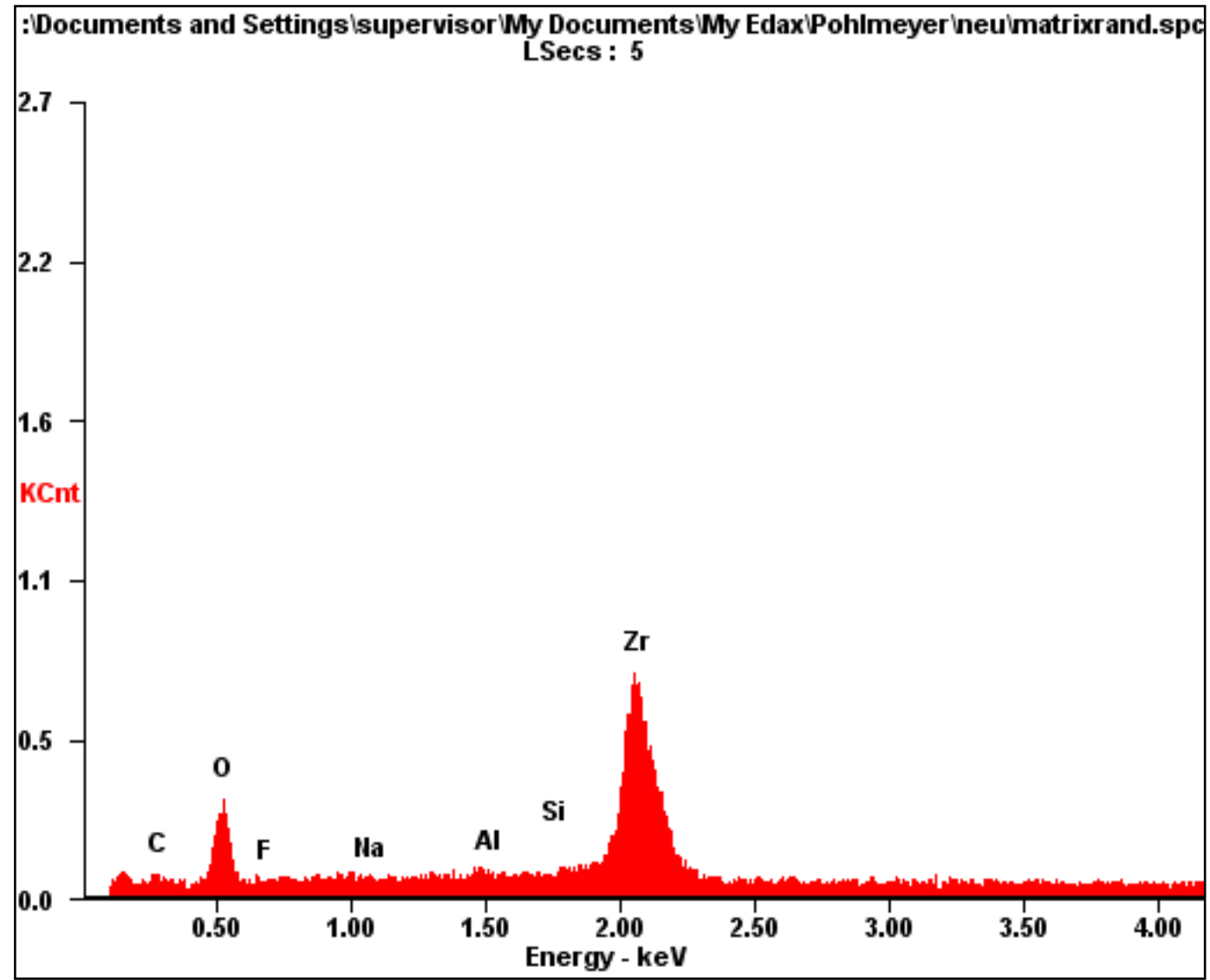

Abb. 26: EDX-Analyse des unbehandelten Zirkoniumdioxid-Käppchens

Wie erwartet waren in der vorliegenden Probe vor allem Zirkonium und Sauerstoff, aber auch Kohlenstoff, Fluor und Aluminium in geringeren Mengen nachweisbar. 


\section{Diskussion}

Anliegen der vorliegenden Studie war die Bewertung verschiedener Reinigungsmethoden hinsichtlich des Einflusses auf die Haftkraft rezementierter implantatgetragener Suprakonstruktionen aus Zirkoniumdioxid. Die unterschiedlichen Reinigungsmethoden zeigten nicht in allen Fällen statistisch signifikante Unterschiede. Da nicht alle Ergebnisse erklärbar waren, wurden aus jeder Gruppe je eine Probe im Rasterelektronenmikroskop genauer untersucht.

Die statistische Auswertung erfolgte mit Hilfe von Post-Hoc Vergleichen und einem Signifikanzniveau von 5\%. Ein direkter Vergleich der Ergebnisse der vorliegenden Untersuchung mit ähnlichen Studien ist aufgrund der unterschiedlichen Versuchsdurchführungen und der verwendeten Materialien erschwert.

Wie erwartet zeigte die manuelle Säuberung hinsichtlich der erreichten Retention bei Wiederbefestigung (im Mittel: 48,87 N) im Vergleich zum Referenzkäppchen (im Mittel: 79,35 N) ein signifikant schlechteres Ergebnis. Betrachtet man die Probe der manuellen Reinigung im Rasterelektronenmikroskop wird deutlich, dass die manuelle Methode nicht ausreicht, um die Zementreste gänzlich zu beseitigen (vergleiche Kapitel 4.2.3.). Dieses spiegelt sich auch bei Betrachtung der Ergebnisse wider: Zurückgebliebene, bereits ausgehärtete Zementreste scheinen die Friktion, die auf Verkeilung der Zementpartikel im Zementspalt basiert, zu stören und somit einen suffizienten Haftverbund zwischen Abutment und Suprakonstruktion zu inhibieren.

Die Reinigungsmethode durch Ausstrahlen des Käppchens mit Aluminiumdioxid (110 $\mu \mathrm{m}$-Korn, 2 bar, 15s Dauer) führte ebenfalls zu einem signifikant schlechteren Ergebnis (im Mittel: 56,85 N) verglichen zum Referenzkäppchen. Da nach dem Ausstrahlen klinisch keine Zementreste mehr ersichtlich waren, wurde bei dieser Reinigungsmethode ein positiveres Ergebnis erwartet. Auch die Analyse im Rasterelektronenmikroskop zeigte eine saubere Probenoberfläche (vergleiche Kapitel 4.2.4.). Der negative Einfluss des Ausstrahlens könnte sich durch einen Abtrag und einer damit einhergehenden Glättung des Zirkoniumdioxids durch die Aluminiumdioxidkörner erklären. 
Durch eine Glättung der Materialoberfläche steht den Zementpartikeln eine reduzierte Oberflächenrauhigkeit und dadurch eine verminderte Verkeilungsmöglichkeit zur Verfügung, woraus letztlich eine geringere Retentionskraft resultieren könnte. Weiterhin könnte die Glättung auch durch das Druck-bedingte "Hineinpressen“ kleinster Zementüberreste in die Poren der Zirkoniumdioxid-Oberfläche resultieren.

Trotz vielfacher klinischer Anwendung wird das Ausstrahlen von Zirkoniumdioxidgerüsten in der Literatur generell umstritten diskutiert, da nicht ausgeschlossen werden kann, dass durch die mechanische Überbeanspruchung beim Ausstrahlvorgang Energie in das Kristallgitter eingebracht wird, wodurch das Risiko einer Verschiebung des Wärmeausdehnungskoeffizienten und damit einer Schädigung des Kristallgitters resultiert (Kern et al. 2010).

Obwohl die Kombination aus manueller Säuberung und Ultraschallbad im Mittel eine Haftkraft von 90,68 N und das Referenzkäppchen von 79,35 N aufweist zeigte sich hier kein statistisch signifikanter Unterschied. Die Probendarstellung im Rasterelektronenmikroskop im Kapitel 4.2.5. verdeutlicht, dass das Ultraschallbad neben der Reinigung der Zementreste dazu führt, dass einzelne Kristallite im Zirkoniumdioxid herauspräpariert werden. Dieses lässt die Annahme zu, dass die dadurch entstandene Materialoberfläche den Zementkörnern eine gute Retentionsfläche bietet, wodurch die Haftkraft positiv beeinflusst würde.

Vergleicht man lediglich die Ergebnisse der drei Reinigungsmethoden miteinander, wird deutlich, dass die Kombination aus manueller Säuberung und dem Ultraschallbad zu signifikant besseren Ergebnissen führt, als die alleinige manuelle Säuberung oder die Reinigung durch Ausstrahlen der Suprakonstruktion. Es wäre interessant in weiterführenden Studien zu untersuchen, welche Auswirkungen die alleinige Ultraschallreinigung oder weitere Reinigungsmöglichkeiten wie beispielsweise die Verwendung von Phosphorsäure oder das vorsichtige Ausbrennen der Suprakonstruktion auf die Haftkraft haben. Ebenso die Untersuchung der Einflüsse verschiedener Säuberungsmethoden bezüglich neuerer semipermanenter Befestigungszemente speziell für den Gebrauch an Implantaten wäre ein interessanter Ansatzpunkt für weitere Studien. 
Die in der vorliegenden in-vitro-Studie untersuchten Reinigungsmthoden wurden im Rahmen der vorgeschalteten Pilotstudie gezielt ausgewählt (vergleiche Kapitel 3.1.).

Einer Studie von Rinke et al. zufolge, die sich mit der klinischen Bewährung von Einzelzahnimplantaten im Unterkiefer-Molarenbereich beschäftigt, zeigt sich ein verminderter Retentionsverlust provisorisch zementierter Kronen, bei vorheriger Aufrauung des Abutments mit einem grobkörnigen Diamanten (Rinke et al. 2008). Hier stellt sich nun die Frage, ob die Effektivität der Reinigungsmethoden davon abhängt, ob die Oberfläche des Abutments oder die der Suprakonstruktion bearbeitet wird. Zur Klärung dieser Fragestellung wären weitere Studien von Vorteil um eine generelle Empfehlung zur Handhabung in der Praxis aussprechen zu können.

Die Versuchsanordnung der vorliegenden Studie, sowie die Anwendung der ZwickMaterialprüfmaschine, entspricht den nationalen und internationalen Standards werkstoffkundlicher Untersuchungen und wurde in anderen Studien in ähnlicher Weise angewendet (Scheuner 2002). Die Erfassung der Abzugskräfte sollte möglichst objektiv erfolgen. Eine Reproduzierbarkeit der Rahmenbedingungen während der Abzugsversuche kann am besten mit einer computergesteuerten Universalprüfmaschine realisiert werden, wie es auch in verschiedenen Studien belegt ist (Attia und Kern 2011, Yang et al. 2010, Aggstaller et al. 2006).

Die Fallzahl der Studie wurde unter zwei Gesichtspunkten festgelegt. Zum einen ist eine möglichst hohe Fallzahl wünschenswert, um reproduzierbare und statistisch auswertbare Ergebnisse zu erlangen. Zum anderen müssen alle Schritte des Vorgehens und der Oberflächenbearbeitung berücksichtigt und identisch durchgeführt werden. Um einen Kompromiss zwischen beiden Aspekten einzugehen, wurde im Zusammenarbeit mit der medizinischen Statistik der Universität Göttingen mittels einer Power-Analyse die Fallzahl von 13 je Versuchsreihe (13 unbehandelte Referenzkäppchen, 13 manuell gesäuberte Käppchen, 13 manuell gesäuberte Käppchen mit zusätzlichem Ultraschallbad und 13 ausgestrahlte Käppchen) festgelegt. Die Standardabweichung der Abzugsversuche lag bei allen Versuchsreihen in einem statistisch vertretbaren Bereich zwischen 14,40 N und $23,39 \mathrm{~N}$. 
Ein grundsätzliches Problem bei der Durchführung klinischer Studien mit dem Ziel der Beurteilung eines Therapieerfolges in der Zahnmedizin sind die Schwierigkeiten, gleiche Ausgangsvoraussetzungen wie im klinischen Alltag zu schaffen. Die vorliegende Arbeit ist eine in-vitro-Studie. Die Objektivität der Ergebnisse bei in-vivoSituationen kann nur als näherungsweise angenommen werden, da die durchgeführten in-vitro-Versuche lediglich eine technisch machbare Annäherung an klinische Situationen sind (Geurtsen 1990).

In der vorliegenden Studie wurde der Einfluss verschiedener Reinigungsmöglichkeiten auf die Retentionskraft rezementierter, implantatgetragener Zirkoniumdioxid-Kronengerüsten untersucht.

Die Zirkoniumdioxid-Suprakonstruktionen wurden durch das CAD/CAM Verfahren hergestellt (vergleiche Kapitel 3.2.). Neben der Reduktion der Arbeitsschritte, der vereinfachten Herstellung präziser, prothetischer Rekonstruktionen und sonstigen Vorteilen der CAD/CAM Technologie, dürfen mögliche Fehlerquellen bei Anwendung des Verfahrens nicht außer Acht gelassen werden. Zur Gewährleistung einer präzisen, passgenauen Restauration, müssen diese Fehlerquellen möglichst minimiert werden. Da die Daten zwischen den einzelnen Verfahrenskomponenten (Digitalisiergerät, CAD-Software, Fertigung) transportiert werden müssen, kann es durch die Datenverarbeitung- und Interpretation zu Einzelfehlern kommen, die sich während des gesamten Verfahrens aufsummieren können. Die Messungenauigkeit von Digitalisiergeräten sollte unter $40 \mu \mathrm{m}$ liegen. Derzeitig eingesetzte Geräte erreichen in der Regel Messfehler von +/- $15 \mu \mathrm{m}$. Die CAD-Software bietet für den Anwender heutzutage eine Vielzahl an Eingriffsmöglichkeiten bei dem Gestaltungsprozess, was zwangsläufig auch potentielle Fehlerquellen mit sich bringt. Speziell nicht erfahrene Anwender sollten aus diesem Grund auf eine vereinfachte CAD-Software zurückgreifen um derartige Fehler zu vermeiden (Quaas und Rudolph 2007).

Bei genauerer Betrachtung im Rasterelektronenmikroskop wurde deutlich, dass selbst neue, unbenutzte Zirkoniumdioxid-Käppchen Verunreinigungen aufweisen, die klinisch nicht ersichtlich sind, jedoch den Haftverbund zwischen Abutment und Suprakonstruktion negativ beeinflussen könnten (vergleiche Kapitel 4.2.2.). 
Die CAD/CAM-gefrästen Kronengerüste wurden auf den konfektionierten Abutments zementiert. Das Anmischen des Befestigungszementes erfolgte gemäß Herstellerangaben manuell, wie es auch in klinischen Situationen der Fall ist. Eine exakt gleich große Portionierung der Basis- und der Katalysatorpaste konnte jedoch nicht gewährleistet werden, was einen Einfluss auf die Retentionskraft des Zementes haben kann. Weiterhin haben auch die Raumtemperatur, sowie unvermeidbare Lufteinschlüsse Einfluss auf die letztendliche Haftkraft. Schon kleine Varianzen können die Retentionswerte beeinflussen.

Der in der vorliegenden Studie verwendete provisorische Zement TempBond® NE der Firma Kerr erzeugt Retention vorwiegend durch Verkeilung der Zementpartikel nach dem Aushärten, was die Parallelverschiebung benachbarter Oberflächen beeinträchtigt. Die Retentionswirkung beruht demnach auf einer mikromechanischen Verankerung (Marxkors und Meiners 2005). Sie wird durch die Dicke des Zementfilms und somit durch den gewählten Zementspalt beeinflusst. Ein dünner Zementfilm vermindert die Gefahr von Rissen im Zementgefüge (Mendelin 2002). Der kleinste zu erreichende Zementspalt ist abhängig von der Korngröße des verwendeten Befestigungszementes, wodurch die durchschnittliche Zementfilmdicke bei 10-25 $\mu \mathrm{m}$ liegt. Dieser Wert sollte demzufolge bei der Einstellung des Zementspaltes während der digitalen Modulation der Suprakonstruktion nicht unterschritten werden, da dann eine ausreichende Friktion sowie ein guter Zementabfluss nicht mehr gewährleistet werden kann (Porsche 1961). Die in der vorliegenden Studie verwendeten Kronengerüste wurden mit einem Zementspalt von $10 \mu \mathrm{m}$ gefertigt.

In der Mundhöhle sind die Restaurationen einer 100\%igen Luftfeuchtigkeit und ständig wechselnden Temperaturen ausgesetzt, was aufgrund der unterschiedlichen Ausdehnungskoeffizienten der verwendeten Materialien zu erheblichen Spannungen an den Grenzflächen führt. Die entstehenden Spannungen können das Zementgefüge und somit die Retentionskraft des Zementes vermindern. In einigen vorangegangenen Studien wurde aus diesem Grund ein Kausimulator in den Versuch mit einbezogen. Hierbei lagern die Proben in einem $37^{\circ} \mathrm{C}$ warmen Wasserbad und wurden zyklischen Belastungen von etwa $100 \mathrm{Nm}$ ausgesetzt. Eine 
weitere Möglichkeit zur Simulation der künstlichen Alterung ist die Verwendung eines Thermocyclers. Diese bestehen in der Regel aus zwei unterschiedlich temperierten, mit destilliertem Wasser gefüllten Wasserbädern $\left(1-5^{\circ} \mathrm{C}, 55^{\circ} \mathrm{C}\right)$ und werden von den Proben in einer individuellen Anzahl von Zyklen durchlaufen. Durch die schlagartigen Temperaturänderungen werden die wechselnden Temperaturen in der Mundhöhle sehr realitätsnah simuliert. In der Literatur zeigen sich hinsichtlich künstlicher Alterungsprozesse paradoxerweise stark divergierende Einflüsse auf die Haftkraft. Wie zu erwarten, kam es in einigen Studien durch die thermale Belastung zu Mikrodefekten im Zementgefüge und somit zu einer Reduktion der Haftkraft (Baldissara et al. 1998). Mendelin untersuchte die Retention von Kronen in Abhängigkeit von Stumpfhöhe und Befestigungszement und konnte einen auffälligen Anstieg der Retention nach Thermocycling nachweisen (Mendelin 2002). Die Vergleichbarkeit der verschiedenen Studien ist jedoch schwierig, da die unterschiedlichen Versuchsaufbauten, sowie die verwendeten Materialien und Zemente unterschiedlich durch das Thermocycling beeinflusst wurden.

Drei der vier Versuchsreihen der vorliegenden Studie wurden vor erneuter Rezementierung durch verschiedene Reinigungsmethoden von Zementresten gesäubert. Die manuelle Säuberung wurde mit Hilfe eines Heidemann-Spatels durchgeführt. Trotz sorgfältiger Bearbeitung der Kroneninnenfläche konnten die Zementreste nicht restlos entfernt werden. Die verbliebenen Zementspuren variierten in Menge und Lokalisation bei den 13 Kronengerüsten, was einen Einflussfaktor auf die erzielten Retentionswerte darstellt. In der zweiten Versuchsreihe wurden die manuell gereinigten Käppchen einer anschließenden Ultraschallreinigung in einem 99\%igen Isopropanolbad unterzogen. In vorangegangenen Studien wurden Keramikkronen für 3 Minuten ultraschallgereinigt. Diese Reinigung folgte jedoch einer vorherigen Abstrahlung des Kronengerüsts mit Aluminumoxid (Attia und Kern 2011, Attia et al. 2011). In der vorliegenden Studie wurden die Kronengerüste hingegen nach manueller Bearbeitung ultraschallgereinigt. Aufgrund dessen wurde eine Verweildauer der Käppchen im Isopropanolbad von 15 Minuten festgelegt. Nach Trocknung der Kronengerüste waren klinisch keine Zementreste mehr erkennbar. Die dritte Reinigungsmethode stellte das Ausstrahlen der Kroneninnenfläche mit Aluminiumdioxid dar. Auch in dieser Versuchsreihe waren nach dem Abstrahlvorgang keine Zementreste mehr ersichtlich. 
Nach Fertigstellung der Probenkörper wurden diese den Abzugsversuchen unterzogen. Bei der Versuchsdurchführung wurde auf eine axiale Abzugskomponente geachtet. Durch diesen Aufbau, wird ein direkter Vergleich auch von verschiedenen Zementen ermöglicht (Finger 2000). Man darf jedoch nicht außer Acht lassen, dass in der Praxis neben der Zugkraft auch extraaxiale, vertikale und horizontale Kräfte wirken (Kirchoff 1978). Eine Vielzahl von Studien haben den physiologischen Kauvorgang bis heute untersucht (Körber und Ludwig 1983, Schwickerath 1976). Die in der Literatur angegebenen Werte bezüglich der Kaukraft variieren stark, da die individuellen Zusammenhänge des orofazialen Systems in seiner Komplexizität schwierig zu erfassen sind. So werden durchschnittliche Kaukräfte im Seitenzahngebiet von $20 \mathrm{~N}$ bis $120 \mathrm{~N}$ angegeben, wobei die Werte bei Parafunktionen sogar bis auf knapp $1200 \mathrm{~N}$ ansteigen können (Ferrario et al. 2004, Jäger et al. 1989, Jent et al. 1979, Schindler et al. 1998). Dementsprechend wurden die Einstelldaten der Zwick Universalprüfmaschine der Literatur vorangegangener Studien entnommen. Zum Vorspannen der Abzugsvorrichtung wurde mit einer Geschwindigkeit von $50 \mathrm{~mm} / \mathrm{min}$ bis zu einem Zug von $20 \mathrm{~N}$ gezogen. Ab diesem Zug begann der Abzugsversuch mit einer Prüfgeschwindigkeit von $5 \mathrm{~mm} / \mathrm{min}$ bis zur Dezementierung des Zirkoniumdioxid-Käppchens. Da die CAD/CAM-gefrästen Kronen hinsichtlich der Größe der Kontaktoberfläche zwischen Abutment und Kroneninnenflächen identisch waren, konnte die Berechnung und Einbeziehung der Oberfläche vernachlässigt werden, sodass die Auswertung der Ergebnisse in Newton (N) erfolgte (Kley 2010).

Der Versuchsablauf ließ bei den einzelnen Messungen keine Unterschiede erkennen. Es wurde bei jedem Versuch die gleiche Einspannvorrichtung verwendet um die Prüfkörper in der Abzugsvorrichtung zu fixieren. Durch Nummerierung der Suprakonsruktionen wurde gewährleistet, dass negative Einflüsse auf die Retentionskraft, wie beispielsweise eventuelle Verunreinigungen oder nicht sichtbare Produktionsmängel an den unbehandelten Käppchen im weiteren Verlauf der Untersuchung nachvollzogen werden konnten. 
Zur genaueren Untersuchung der Proben, speziell des Befestigungszementes, wurde im Zuge der Rasterelektronenmikrospie eine Energiedispersive Röntgenspektroskopie (EDX-Analyse) durchgeführt. Durch das kombinierte REMEDX Verfahren wird eine chemische Elementanalyse kleinster Probenpartikel im $\mu \mathrm{m}$ Bereich ermöglicht. Die EDX-Analyse basiert auf quantitativen und qualitativen Analysen der Energie von Röntgenquanten, die durch die Wechselwirkung des Primärelektronenstrahls mit der Probe entstehen. Inhomogene Proben, uneinheitliche Parameter (Beschleunigungsspannung, Zählraten („Counts per Second“, Arbeitsabstand etc.) und unsachgemäße Probenpräparation können Fehler bei der chemischen Analyse verursachen.

Weiterhin sollte man beachten, dass es zu Überlagerungen einzelner Peaks im charakteristischen Röntgenspektrum kommen kann, wenn in einer Probe emittierte Röntgenquanten aus unterschiedlichen Atomschalen verschiedener Elemente im gleichen Energiebereich liegen. Grundsätzlich sind mit der verwendeten EDXAnalytik Elemente mit einer Ordnungszahl größer 4 nachweisbar. Je niedriger jedoch die Ordnungszahl, desto schlechter ist die Nachweisgrenze und desto ungenauer die Aussagekraft der Analyse. Die Nachweisempfindlichkeit steigt also mit zunehmender Ordnungszahl an, da die Wahrscheinlichkeit der Aussendung charakteristischer Röntgenstrahlung, sowie deren Durchdringungsfähigkeit, mit der Atommasse zunehmen. Daraus resultiert, dass der Nachweis von Elementen wie Kohlenstoff oder Sauerstoff in geringer Konzentration quantitativ als unsicher zu betrachten ist. Weitere Unstimmigkeiten können auftreten, wenn die Analyse bei großen Vergrößerungen oder einer hohen Beschleunigungsspannung durchgeführt werden. Ist das Wechselwirkungsvolumen der Probe, in dem die charakteristischen Röntgenstrahlen entstehen, größer als der zu analysierende Ausschnitt, so kann es zu einer Mischanalyse des Analysegebietes und der Umgebung kommen. Nicht zu vernachlässigen ist weiterhin die sekundäre Röntgenfluoreszenz. Diese entsteht durch Interaktion mit Bauteilen der Probenkammer oder des Probentellers und kann vom Detektor fälschlicherweise mit ausgewertet werden. 
Die Materialanalyse des Zementes TempBond® NE (Kerr, Ratstatt, Deutschland) zeigte bei der EDX-Analyse keine auffälligen oder sicherheitsgefährdenden Bestandteile. Die durch die Analyse gefundenen Elemente sind im Sicherheitsblatt des Produktes aufgeführt. Es stellt sich jedoch die Frage, ob weitere Analysen wie zum Beispiel die Röntgenfluoreszenzanalyse (RFA), die Neutronenaktivierungsanalyse (NAA) oder die ICP-Massenspektrometrie (ICP-MS), zum Nachweis von eventuellen „Seltenen Erden“ sinnvoll wären, da diese durch das EDX-Verfahren in geringen Konzentrationen (z.B. als Spurenelemente) nicht nachzuweisen sind.

\subsection{Schlussfolgerung für die Praxis}

Den Ergebnissen dieser Studie zufolge, ist bei der Entfernung von Zementresten vor erneuter Rezementierung eine Kombination aus manueller und Ultraschallreinigung empfehlenswert. Die gängige Methode des Ausstrahlens der Kronengerüste hat sich in der vorliegenden Untersuchung nicht bewährt und führte zu einer deutlich reduzierten Haftkraft. Generell muss aus klinischer Sicht beachtet werden, dass einerseits zwar eine hohe Retentionskraft wünschenswert ist, andererseits aber auch die Abnehmbarkeit der provisorisch zementierten Suprakonstruktion gewährleistet werden sollte. 


\section{Zusammenfassung}

In der vorliegenden in-vitro-Studie wurden drei verschiedene Reinigungsmöglichkeiten untersucht, um nachweislich aufzuzeigen, welche Methode bei rezementierten prothetischen Implantat-Versorgungen zu einer bestmöglichen Retentionskraft führt:

- manuelle Entfernung der Zementreste

- Säuberung durch Ausstrahlung der Suprakonstruktion mit Aluminiumdioxid (Korngröße: 110 m, 2 bar, 15s Dauer)

- kombinierte manuelle Säuberung und Ultraschallreinigung (Isopropanolbad $99 \%$ ig).

Für den Versuch wurden insgesamt 52 Probekörper mit den drei oben genannten Parametern, sowie eine Kontrollgruppe mit unbehandelten ZirkoniumdioxidKäppchen je 13 Mal einem Abzugsversuch unterzogen. Zur Herstellung der Kronengerüste wurden die Titan-Abutments mit dem Cercon® eye Scanner (DeguDent, Hanau) eingescannt und die Zirkoniumdioxid-Käppchen daraufhin digital mit der CAD-Software Cercon $\circledast$ art modelliert und im Labor der Firma DeguDent, Hanau, gefräst. Anschließend wurden die Kronengerüste auf den Abutments mit TempBond ${ }^{\circledR}$ NE der Firma Kerr (Ratstatt, Deutschland) zementiert und in der Universalprüfmaschine Zwick Z007 (Zwick, Ulm) den Abzugsversuchen bis zur Dezementierung unterzogen. Die Auswertung der Abzüge erfolgte mit der Software „testXpert“. Die Ergebnisse zeigten, dass die Kombination aus manueller Reinigung und Ultraschallbad verglichen mit den anderen Methoden zu statistisch signifikant höheren Retentionswerten führte. Zwischen der reinen manuellen Säuberung und der Reinigung durch Ausstrahlen des Kronengerüstes zeigte sich kein klinisch relevanter und signifikanter Unterschied. 


\title{
Literaturverzeichnis
}

\begin{abstract}
Abke J:
Verbesserung der Biokompatibilität metallischer Implantate durch kovalente Anbindung einer quervernetzten Kollagenschicht.

Nat. wiss. Diss. Regensburg 2003
\end{abstract}

Abrahamsson I, Berglundh T, Wennstrom J, Lindhe J (1996):

The peri-implant tissues at submerged and non-submerged titanium implants.

J Clin Periodontol 26, 600-607

Agar JR, Cameron SM, Hughbanks JC, Parker MH (1997):

Cement removal from restorations luted to titanium abutments with simulated subgingival margins,

J Prosthet Dent $\underline{78}$, 43-47

Aggstaller H, Beuer F, Funk M, Erdelt KJ, Gernet W (2006):

Einfluss der Präparationsgeometrie auf die Bruchfestigkeit von Kronenkappen aus Zirkoniumdioxid.

Dtsch Zahnärztl Z $\underline{61}$, 347-352

Al-Nawas B, Brahm R, Grötz KA, Wagner S, Kann P, Wagner W (2000):

Non-invasive Beurteilung des knöchernen Implantatlagers durch

Ultraschalltransmissionsgeschwindigkeit.

Z Zahnärztl Implantol 16, 116

Al Nawas B, Wagner W, Sakoh J, Wahlmann U, Stender E, Nat R (2006):

Primary stabilitiy of a conical implant and a hybrid, cylindric screw-type implant in vitro.

Int J Oral Maxillofac Implants 21 (4) Jul-Aug, 560-6

Anjard R (1981):

Mayan dental wonders.

J Oral Implantol $\underline{9}$, 423-426

Anneroth G, Ericsson AR, Zetterqvist L (1990):

Tissue integration of AL2O3- ceramic dental implants (Frialit)--a case report.

Swed Dent J 14, 63-70.

Arnaudow M, Gerlichs UA (1972):

Die enossale Implantationsmethode künstlicher Zahnwurzeln.

Zahnärztl. Welt 81, 313

Attia A, Kern M (2011):

Long-term resin bonding to zirconia ceramic with a new universal primer.

J Prosthet Dent 106, 319-327 
Attia A, Lehmann F, Kern M (2011):

Influence of surface conditioning and cleaning methods on resin bonding to zirconia ceramic.

Dent Mater 27, 207-213

Baldissara P, Comin G, Martone F, Scotti R (1998):

Comparative study of the marginal microleakage of six cements in fixed provisional crowns.

J Prosth Dent 80(4), 417-422

Bernal G, Okamura M, Munoz CA (2003):

The effect of abutment taper, length and cement type on the resistance to dislodgement of cement-retained, implantsupported restorations.

J Prosthodont 12, 111-115

Beuer F, Schweiger J, Edelhoff D (2008):

Digital dentistry: an overview of recent developments for CAD/CAM generated restorations.

Br Dent J 204, 505-1100

Bhola M, Neely AL, Kolhatkar S (2008):

Immediate implant placement: clinical decisions, advantages, and disadvantages J Prosthodont 17 (7): 576-81

Bindl A, Mörmann W (2002)

An up to 5 year clinical evaluation of posterior In-Ceram CAD/CAM core crowns.

Int J Prosthodont 15, 451-456

Bowers KT, Keller JC, Randolph BA, Wick DG, Michaels CM (1992):

Optimization of surface micromorphology for enhanced osteoblast responses in vitro, Int J Oral Maxillofac Implants, $\underline{7}, 302-310$

Brägger U, Karroussis I, Persson R, Pjetursson B, Salvi G, Lang NP (2005):

Technical and biological complications/failures with single crowns and fixed partial dentures on implants: a 10-year prospective cohort study.

Clin Oral Impl Res $\underline{16}$, 326-334

Brånemark PI, Adell R, Breine U, Hansson BO, Lindsrom J, Ohlsson A (1969): Intra-osseus anchorage of dental prosteses. I. Experimental studies.

Scand J Plast Reconstr Surg $\underline{3}$ (2), 81-100

Brånemark PI, Breine U, Adell R, Hansson BO, Lindström J, Ohlsson A (1977): Osseointegrated implants in the treatment of the endentulous jaw. Experience from a 10-year period.

Scand J Plast Rec Surg 11: suppl. $\underline{16}$

Bresciano M, Schierano G, Manzella C, Screti A, Bignardi C, Preti G (2005):

Retention of luting agents on implant abutments of different height and taper.

Clin Oral Implants Res $\underline{16}, 594-598$ 


\section{Buchs AU, Levine L, Moy P (2001):}

Preliminary report of immediately loaded altiva natural tooth replacement implants,

Clin Implant Dent Relat Res, $\underline{3}, 97$

Büchter A, Kleinheinz J, Joos U, Meyer U (2003):

Primäre Implantatstabilität bei unterschiedlichen Knochenaufbere.itungstechniken, Eine In-vitro-Untersuchung am Unterkiefer des Minischweins

Int J Oral Maxillofac Implants $\underline{6}$, 351-355

Buser D, von Arx T (2000):

Surgical procedures in partially edentulous patients with ITI implants.

Clin Oral Implants Res 11, 83-100

Buser D, Weber HP, Donath K, Fiorellini JP, Paquette DW, Williams RC (1992): Soft tissue reactions to non-submerged unloaded titanium implants in beagle dogs. J Periodontol, $\underline{63}$, 225-235

Buser D, Belser UC, Schroeder A (1998):

Fortschritte und aktuelle Trends in der oralen Implantologie: Eine

Standortbestimmung.

Schweiz Monatsschr Zahnmed 108, 326-350.

\section{Caesar HH, Ernst S:}

Die Nichtmetalle

In: Grundwissen für Zahntechniker Band II, hrsg. v. Caesar HH, Ernst S

5. Auflage Verlag Neuer Merkur, München 2007, 294-296

Chee W, Felton DA, Johnson PF, Sullivan DY (1999):

Cemented versus screw-retained implant prostheses: which is better?

Int J Oral Maxillofac Implants $\underline{14}$, 137-141

Chong KH, Chai J, Takahashi Y, Wozniak W (2002):

Flexural strength of In-Ceram Alumina and In- Ceram Zirconia core materials. Int J Prosthodont 15, 183-188

Clauss C (2002):

Vollkeramischer Zahnersatz auf Basis von gefrästem Zirkonoxid.

ZMK Magazin für Zahnheilkunde, Management und Kultur $\underline{6}$, 436-442

Cochran DL (1999):

A comparison of endosseous dental implant surfaces.

J Periodontol 무, 1523-1539

Dahlin C, Andersson L, Linde A (1991):

Bone augmentation at fenestrated implants by an osteopromotive membrane technique. A controlled clinical study.

Clin Oral Implants Res 2 (4), 159-165 
De Rouck T, Collys K, Cosyn J (2008):

Single-tooth replacement in the anterior maxilla by means of immediate implantation and provisionalization: a review

Int J Oral Maxillofac Implants. 23 (5): 897-904

\section{Ehrl PA, Müller M:}

Implantatregister.

In: Aktueller Stand der zahnärztlichen Implantologie.

Hrsg .v. H.J. Hartmann, Band 1, Grundwerk, Spittaverlag, Balingen 1993, 156-174

\section{Eichner K (1979):}

Einige klinische Aspekte der Metallkeramik

Dtsch Zahnärztekalender $\underline{38}$, 99-111

\section{Eichner K, Kappert HF:}

Zahnärztliche Werkstoffe und ihre Verarbeitung

6. Auflage Hüthig Verlag, Heidelberg 1996, 326-366

\section{Esposito MA, Koukoulopoulou A, Coulthard P, Worthington HV (2006):}

Interventions for replacing missing teeth: dental implants in fresh extraction sockets (immediate, immediate-delayed and delayed implants).

Cochrane Database Syst Rev 18

Fenske C, Jurren MP, Sadat-Khonsari MR, Jüde HD (1999):

In-vitro-Untersuchung zur Bruchfestigkeit von IPS-Empress-Kronen in Abhängikeit von der Stufenbreite.

Dtsch Zahnärztl Z $\underline{54}$, 732-734

\section{Ferrario V, Sforza C, Zanotti G, Tartaglia GM (2004):}

Maximal bite forces in healthy young adults as predicted by surface electromyography.

J Dent $\underline{32}, 451-457$

Filser F, Lüthy H, Kocher P, Schärer P, Gauckler LJ (2002):

Vollkeramischer Zahnersatz im Seitenzahnbereich.

Quintessenz Zahntech 28, 48-60

\section{Finger W:}

Begriffsbestimmung der Werkstoffprüfung

In: Zahnärtzliche Werkstoffe und ihre Verarbeitung, 7. Aufl.

hrsg. v. Eichner K, Kappert HF

Georg Thieme Verlag, Stuttgart New York 2000, 385-397

Fischer H, Karaca F, Marx R (2002):

Detection of microscopic cracks in dental ceramic materials by fluorescent penetrant method.

J Biomed Mater Res $\underline{61}$, 153-158

\section{Formiggini MS (1947):}

Protesi dentaria a mezzo die infibulazione diretta endoalveolare.

Riv Ital Di Stom II, Marzo. 
Frankenberger R, Kramer N, Sindel J (2000):

Repair strength of etched vs silica-coated metal-ceramic and all-ceramic restorations. Oper Dent 25, 209-15

Galosi T, Güth JF, Beuer F, Edelhoff D (2011):

CAD/CAM - Ein Bestandteil der Digitalisierung

In: Jahrbuch Digitale Dentale Technologien, Ausgabe 1; hrsg. v. Galosi T, Güth JF u.a.; Oemus Media AG, Leipzig 2011, 82-86

\section{Geis-Gerstorfer J:}

Vom Rohstoff zur Dentalkeramik.

In: Vollkeramik Werkstoffkunde-Zahntechnik-klinische Erfahrung, hrsg. v. Kappert HF Quintessenz Verlag Berlin 1996, 43-54

Geurtsen W (1990):

Der Kronen- und Füllungsrand.

Dtsch Zahnärtl Z 노, 380-386

Göbel R, Luthardt R, Welker D (1998):

Experimentelle Untersuchungen zur Befestigung von Restaurationen aus Zirkonoxid und Titan.

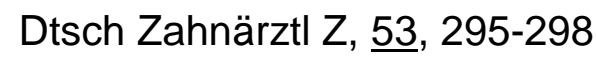

Guazzato M, Quach L, Albakry M, Swain MV (2005):

Influence of surface and heat treatments on the flexural strength of Y-TZP dental ceramics.

J Dent, $\underline{33}$, 9-18

Güth JF, Edelhoff D, Beuer F, Ramberger M, Schweiger J (2009):

Intraorale digitale Erfassung-Der logische Einstieg in die CAD/CAM-Fertigungskette. Quintessenz Zahntechnik $\underline{35}$, Nr. 9

Hahn R, Löst C (1992):

Konventionelle Dentalporzellane versus bruchzähe Hochleistungskeramiken.

Dtsch Zahnärztl Z, 47, 659-664

Hartmann AJ (1891):

Gedanken über die Implantation von künstlichen Zähnen.

Dtsch Mschr Zahnheilkd $\underline{9}, 371$

Hebel KS, Gajjar RC (1997):

Cement-retained versus screw-retained implant restorations: Achieving optimal occlusions and esthetics in implant dentistry.

J Prosthet Dent $\underline{77}$, 28-35

Heine B:

Werkstoffprüfung, Ermittlung von Werkstoffeigenschaften, hrsg. v. Heine B Fachbuchverlag Leipzig im Carl Hanser Verlag Leipzig 2003, 88-90 
Heinemann F, Mundt T, Biffar R (2006):

Retrospective evaluation of temporary cemented, tooth- and implant-supported fixed partial dentures.

J Cranio Maxil-lofac Surg $\underline{34}$, Suppl 2, 86-90

Hellwig E, Klimek J, Attin T (2010):

Einführung in die Zahnerhaltung, 5. Auflage, hrsg. v. Hellwig E, Klimek J, Attin T Deutscher Zahnärzte Verlag Köln, 297-298

Heydecke G, Kohal R, Gläser R (1999):

Optimal esthetics in single-tooth replacement with the Re-Implant system: A case report.

Int J Prosthodont 12, 184-189

Jäger K, Graber G, Schrutt L (1989):

Aufbau und Testung einer Messkette zur Kaukraftmessung.

Schweiz Monatsschr Zahnmed 99(6), 670-675

Jent T, Karlsson S, Hedegart G (1979):

Mandibular movement of young adults recorded by internally placed light emitting diodes.

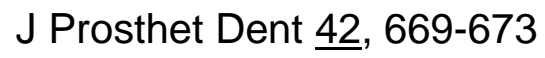

Kaar D, Oshida Y, Andres CJ, Barco MT, Platt JA (2002):

The effect of fatigue damage on the force required to remove a restoration in a cement-retained implant system.

J Prosthodont $\underline{15}$, 289-294

Kappert HF, Altvater A (1991):

Feldstudie über die Paßgenauigkeit und das Randschlußverhalten von In-CeramKronen und -Brücken.

Dtsch Zahnärztl Z $\underline{46}, 151-153$

Kappert HF, Krah M (2001):

Keramiken - Eine Übersicht.

Quintessenz Zahntechnik 27, 668-704

Keller W, Brägger U, Mombelli A (1998):

Peri-implant microflora of implants with cemented and screw retained suprastructures.

Clin Oral Impl Res $\underline{9}, 209-217$

Kern M (2004):

Ist „keramischer Stahl“ das „weiße Gold“?

Jahrestagung der Arbeitsgemeinschaft Dentale Technologie 2004

Quintessenz Zahntech 30, 966-973

Kern M (2011a):

Erfolgreicher Umgang mit Zirkoniumdioxid-Keramik

Quintessenz Zahntech 37, 275-278 


\section{Kern M (2011b):}

Digitaltechnik in Praxis und Labor bietet neue Möglichkeiten

In: Jahrbuch Digitale Dentale Technologien, Ausgabe 1; hrsg v. Kern M; Oemus Media AG, Leipzig 2011, 11-13

Kern M, Bauer HG, Kimmich H (2010):

Das $1 \times 1$ der Zirkonoxid-Behandlung

Zahntech Mag 14, 1/2, 28-32

Kieswetter K, Schwartz Z, Hummert TW, Cochran DL, Simpson J, Dean DD, Boyan BD (1996):

Surface roughness modulates the local production of growth factors and cytokines by osteoblast-like MG-63 cells.

J Biomed Mater Res, 32 (1), 55-63

Kirchoff W (1978):

Untersuchungen über die axiale und horizontale Belastbarkeit verschiedener

intraradikulärer Stiftverankerungen an natürlichen Zähnen. 1. und 2. Teil

Zahnärztl Welt 87, 1014-1063

\section{Kley PA:}

Untersuchung zum Einfluss von Zirkonia-Primern auf die Retentionskraft adhäsiv befestigter Zirkoniumdioxid-Kronen.

Zahnmed. Diss., Rheinische Friedrich-Wilhelms-Universität Bonn 2010

Klink A (2006):

CAD/CAM Restaurationen aus Zirkoniumdioxid.

ZMK, 22, 268-276

Koeck B, Wagner W (2003):

Implantologie

2. Auflage Urband \& Fischer, München Jena, S. 2

\section{Köhler S:}

Allgemeine Grundlagen der Implantologie

In: Implantologie Jahrbuch 01/2011, Oemus Media AG, Leipzig 2011, 10-16

Körber KH, Ludwig K (1983):

Maximale Kaukraft als Berechnungsfaktor zahntechnischer Konstruktionen. dental-labor $\underline{31}, 55-60$

Kohal RJ, Weng D, Bächle M, Klaus G (2003):

Zirkonoxid-Implantate unter Belastung - Eine vergleichende histologische, tierexperimentelle Untersuchung.

Z Zahnärztl Implantol $\underline{19}$, 88-91

Kohal RJ, Weng D, Bächle M, Strub JR (2004):

Loaded custom-made zirconia and titanium implants show similar osseointegration: An animal experiment.

J Periodont, 75, 1262-1268 
Kurbart A, Reichel K (2001):

Cerec inLab - State of the art.

Quintessenz Zahntech, 27, 1056-1074

Lee H, Ercoli C, Funkenbusch PD, Feng C (2008):

Effect of subgingival depth of implant placement on the dimensional accuracy of the implant impression: an in vitro study.

J Prosthet Dent. $\underline{\text { 99, }}$ 107-130

Luthardt R, Musil R (1997):

CAD/CAM-gefertigte Kronengerüste aus Zirkondioxid-Keramik.

Dtsch Zahnärztl Z, 52, 380-384

Luthardt R, Herold V, Sandkuhl O, Reitz B, Knaak JP, Lenz E (1998):

Kronen aus Hochleistungskeramik.

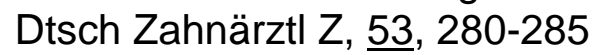

Luthardt R, Rudolph H, Sandkuhl O, Walter M (2001):

Aktuelle CAD/CAM-Systeme zur Herstellung von keramischem Zahnersatz.

ZWR 110 , 747-754, 797-802

Manicone PF, lommetti PR, Raffaelli L (2007):

An overview of zirconia ceramics: Basic properties and clinical applications.

J Dent 35, 819-826.

Mansor A, Ercoli C, Graser G, Tallents R, Moss M (2002):

Comparative evaluation of casting retention using ITI solid abutment with six cements.

Clin Oral Impl Res $\underline{13}$, 343-348

Marx R (1993):

Moderne keramische Werkstoffe für ästhetische Restaurationen - Verstärkung und Bruchzähigkeit.

Dtsch Zahnärztl Z 48, 229

\section{Marx R, Bieniek H:}

Werkstoffeigenschaften von Implantatmaterialien

In: Hartmann HJ: Aktueller Stand der zahnärztlichen Implantologie.

Spitta-Verlag, Balingen 1998

Marxkors R, Meiners H:

Taschenbuch der zahnärztlichen Werkstoffkunde

5. Auflage, Deutscher Zahnärzte Verlag Köln 2005, 79-83, 169-174, 198-199

\section{Mendelin U:}

Die Retention von Kronen in Abhängigkeit von Stumpfhöhe und Befestigungszement. Zahn-Med. Diss. Justus-Liebig-Universität Gießen 2002 
Michalakis KX, Hirayama H, Garefis PD (2003):

Cement-retained versus screw-retained implant restorations: a critical view.

Int J Oral Maxillofac Implants $\underline{18}$, 719-728

Mörmann WH, Bindl A (2001):

3-year Clinical Evcaluation of In-Ceram CAD/CAM Core Crowns.

J Dent Res 80, Spec. Issue: 651 Abst 995

Mörmann WH, Attin T (2008):

Keramik in der Zahnerhaltung - unter dem Aspekt CAD/CAM-Technik.

ZBW-Keramische CAD/CAM-Restaurationen (2008) 02

Nakamura T, Nonaka M, Maruyama T (2000):

In vitro fitting accuracy of copymilled alumina cores and all-ceramic crowns.

Int J Prosthodont, $\underline{13}$, 189-193

Neumeier P:

CAD/CAM ist weiter auf dem Vormarsch

In: Digitale Dentale Technologien Handbuch 2010

Oemus Verlag, Leipzig 2010, 78-80

Niedermeier W, Proano P, Özcan M, Mayer B, Nergiz I, Pfeiffer P (1998):

Enorale Reparaturen mit tribochemischem Verbund.

Zahnärztl Mitt $\underline{88}, 954-7$

Pan YH, Ramp LC, Lin CK, Liu PR (2007):

Retention and leakage of implant-supported restorations luted with provisional cement: a pilot study.

J Oral Rehabil 34, 206-212

Parr GR, Gardner LK, Toth RW (1985):

Titanium: the mystery metal of implant dentistry. Dental materials aspects.

J Prosthet Dent 54, 410-414.

Perry SG (1888):

Mehrere Fälle von Implantationen.

Korr Zahnheilkd 2, 357

Piconi C, Burger W, Richter HG, Cittadini A, Maccauro G, Covacci V,

Bruzzese N, Ricci GA, Marmo E (1998):

Y-TZP ceramics for artificial joint replacements.

Biomaterials $\underline{19}, 1489$

Plein T, Behr M, Rosentritt M, Handel G (2007):

Fracture Resistance of Temporary Cemented Zirconia Crowns on Dental Implant Abutments. 2007 submitted 


\section{Porsche A (1961):}

Die Eignung der Zinkoxid-Phosphatzemente als Befestigungsmittel.

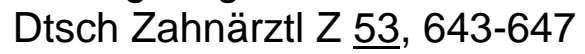

Pospiech P (2002):

Klinische und technische Erfahrungen mit Vollkeramiken.

Dental-praxis, $\underline{9}(10)$, 255-257

\section{Pospiech P, Tinschert J, Raigrodski A:}

Keramik- Vollkeramik,

3M Espe AG, Seefeld 2004

Pröbster L (2001):

Sind vollkeramische Kronen und Brücken wissenschaftlich anerkannt?

Dtsch Zahnärztl Z $\underline{56}$, 575-576

Quaas S, Rudolph H (2007):

Kommunikation ist alles - Schnittstellen der CAD/CAM-Systeme

Digital_Dental.News 1 , 20-23

\section{Raether H:}

Elektroneninterferenzen

In: Handbuch der Physik, Band 32, hrsg. v. Flügge S

Springer-Verlag Berlin, Göttingen, Heidelberg 1957, 443

Ramires PA, Wennerberg A, Johansson CB, Cosentino F, Tundo S, Milella E (2003):

Biological behavior of sol-gel coated dental implants.

J Mater Sci Mater Med 14, 539-545

Rapley JW, Swan RH, Hallmon WW, Mills MP (1990):

The surface characteristics pro- duced by various oral hygiene instruments and materials on titanium implant abutments.

Int J Oral Maxillofac Implants $\underline{5}, 47-51$

\section{Reuling N, Siebert GK (1989):}

Keramische Werkstoffe - Entwicklungsstand und Bedeutung.

Dent Lab 37, 67-71

Rinke S, Jenatschke R (2001):

Neue Perspektiven in der Anwendung vollkeramischer Seitenzahnrestaurationen auf Zirkonoxidbasis.

Quintessenz $\underline{52}, 1151-1159$

Rinke S, Schmidt S, Schliephake H (2008):

Retrospektive Studie zur klinischen Bewährung von Einzelzahnimplantaten im Unterkiefer-Molarenbereich

Z Zahnärztl Impl 24(4), 290-300 


\section{Scheuner B:}

Untersuchung der Abzugsfestigkeit eines experimentellen Zementes zur Befestigung von Implantatsuprakonstruktionen im Vergleich zu zwei bereits genutzten Zementen (eine In-Vitro-Studie).

Med. Diss. Berlin 2002

Schindler HJ, Stengel E, Spiess WE (1998):

Feedback control during mastication of solid foodtextures - a clinical-experimental study.

J Prosthet Dent $\underline{\text { 80, }}$ 330-336

Schlegel KA, Leitenstorfer B, Jakobsen M, Toutenburg H (1994):

Zur klinischen Bruchfestigkeit von Al2O3 Implantaten.

Z Zahnärztl Implantol $\underline{10}, 68-70$

\section{Schmidt M:}

Spezifische Absorption organischer Moleküle auf oxidiertem Titan: „Bioaktivität auf molekularem Niveau“.

Osteologie Band 1, Heft 4, Verlag Hans Huber, Bern, Göttingen, Toronto, Seattle, 1992, 222-235

Schneider GB, Perinpanayagam H, Clegg M, Zaharias R, Seabold D, Keller J, Stanford C (2003):

Implant surface roughness affects osteoblast gene expression

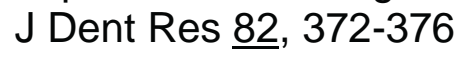

\section{Schroeder A, Stich H, Straumann F, Sutter F (1978):}

Über die Anlagerung von Osteozement an einen belasteten Implantatkörper.

Schweiz Monatsschr Zahnheilkd 요, 1051-1057

\section{Schroeder A, Van der Zypen E, Stich H, Sutter F (1981):}

The reaction of bone, connective tissue and epithelium to endosteal implants with sprayed titanium surfaces.

J Oral Maxillofac Surg $\underline{9}, 15-25$

Schüller KH, Hennicke HW (1985):

Zur Systematik der keramischen Werkstoffe.

Ceram Forum Int 62, 259-263

Schulte W (1983):

Aluminiumoxidkeramik.

Dtsch Zahnärztl Z $\underline{38}, 86-87$

Schwartz R, Davis R, Hilton TJ (1992):

Effect of temporary cements on the bond strength of a resin cement.

Am J Dent $\underline{5}, 147-150$

Schwickerath H (1976):

Kaukraft-Kaudruck-Belastbarkeit

Dtsch Zahnärztl Z 31, 870-873 


\section{Schwickerath H (1994):}

Neue Keramiksysteme unter Dauerbeanspruchung.

Quintessenz Zahntechnik 20, 1495-1499.

Scialom J (1962):

Die „Nadel-Implantate“.

Zahnärztl Welt 16, 565

Schweiger M (2004):

Zirkoniumoxid-Hochfeste und bruchzähe Strukturkeramik.

In: Ästhetische Zahnmedizin 5, 248-257; 2004

\section{Schwenzer N, Ehrenfeld M:}

In: Zahnärztliche Chirurgie

4. Auflage, Georg Thieme Verlag, Stuttgart 2009, 228

\section{Skoog DA, Leary J:}

Instrumentelle Analytik: Grundlagen-Geräte-Anwendungen

übers. v.: Brendel D, Hoffstetter-Kuhn S

Springer Verlag Berlin Heidelberg 1996, 427

\section{Spiekermann H:}

In: Farbantlanten der Zahnmedizin, Band 10: Implantologie; hrsg. v. Rateitschak KH, Wolf HF; Georg Thieme Verlag Stuttgart New York 1994, 1-3

\section{SpiessI B (1989):}

A new method of anatomical reconstruction of extensive defects of the mandible with autogenous cancellous bone.

$\mathrm{J}$ Maxillofac Surg $\underline{8}, 78-83$

Squier RS, Agar JR, Duncan JP, Taylor TD (2001):

Retentiveness of dental cements used with metallic implant components.

Int J Oral Maxillofac Implants 트, 793-798

Starling LB, Cook SD, Anderson RC, Thomas KA (1986):

Materialbelastungen in keramischen Restaurationen

Phillip J $\underline{5}, 207$

\section{Steinebrunner L, Bößmann K, Kern M (2005):}

Implantat-Abutment-Verbindungen - Präklinische Testmethoden.

Implantologie $\underline{13}, 145-160$

\section{Steinemann SG:}

In: Evaluation of Biomaterials., hrsg. v. Winter GD, Leray JL and De Groot K. Wiley, London 1980, 1-34

\section{Steinemann S:}

Werkstoff Titan.

In: Orale Implantologie. Allgemeine Grundlagen und ITI-Hohlzylindersystem hrsg. v. Schroeder A, Sutter F, Krekeler G , 2. Ausgabe, Georg Thieme Verlag,

Stuttgart 1988, 37- 59 


\section{Strietzel R, Lahl C:}

CAD/CAM-Systeme in Labor und Praxis

hrsg. v. Striezel R, Lahl C, 1. Auflage, Verlag Neuer Merkur.

München 2007, 60

Strock AE (1939):

Experimental work on a method fort he replacement of missing teeth by direct implantation of a metal support into the alveolus.

Am J Orthodont Oral Surg 25, 467

Strub JR, Türp JC, Witkowski S, Hürzeler MB, Kern M (1983):

Vollkeramische Systeme

Dtsch Zahnärztl Z $\underline{49}$, 182-187

Strub JR, Türp JC, Witkowski S, Hürzeler MB, Kern M (1999a):

Einführung in die dentale Implantologie.

In: Curriculum Prothetik Band I-III, 2. Auflage, hrsg. v. Strub JR, Türp JC u.a.,

Quintessenz Verlag Berlin 1999, Band III, 1110-1120

Strub JR, Türp JC, Witkowski S, Hürzeler MB, Kern M (1999b):

CurriculumProthetik Band I-III., 2. Auflage, hrsg. v. Strub JR, Türp JC u.a., Quintessenz Verlag, Berlin 1999, 43-61

Sturzenegger B, Fehèr A, Lüthy H, Loeffel O, Filser F, Kocher P, Gauckler L, Schärer $P$ (2000):

Clinical study of zirconiumoxide bridges in the posterior segments fabricated with the DCM- System.

Acta Med Dent Helv $\underline{5}, 131-139$

Suttor D (2001):

Blick in die Werkstoffkunde.

ZWP Spezial 4 , 32-33

Suttor D, Hoescheler S, Hauptmann H, Hertlein G, Bunke K (2001):

LavaTM - Das neue System von 3M Espe für vollkeramische Zirkoniumdioxid-

Kronen- und Brückengerüste.

Quintessenz, ⒉ 805-808

Thomson P, Esposito M, Gretzer M, Källtrop M, Larsen C, Liljenstein E (1999): Interactions between modified titanium implant surfaces and tissues

Oral Impl Res $\underline{10}, 166$

Tinschert J:

Zahnheilkunde in Checklisten

Spitta Verlag Balingen 2002, Grundwerk, Teil 2/4, Kap. 5.5.1., 3-4 


\section{Tinschert J, Natt G, Götzen N:}

Oxidkeramiken

In: Oxidkeramiken und CAD/CAM-Technologien, Atlas für Klinik, Labortechnik und Werkstoffkunde, hrsg. v. Natt G

Deutscher Zahnärzte Verlag, Köln 2007, 8

Torrado E, Ercoli C, Al Mardini M, Graser GN, Tallents RH, Cordaro LA (2004):

Comparison of the porcelain fracture resistance of screw-retained and cementretained implant-supported metal-ceramic crowns.

J Prosthet Dent $\underline{\text { 91, 532-537 }}$

\section{Toumelin-Chemla F, Rouelle F, Burdairon G (1996):}

Corrosive properties of fluoride-containing odontologic gels against titanium.

J Dent 24, 109-115

Volz U (2005):

Der Zirkonstandard in der Implantologie-steht die Revolution bevor?

Industrie report Dent Implantol $\underline{9}$, 42-45

\section{Von Ardenne M, Musiol G, Klemradt U:}

Effekte der Physik und ihre Anwendung, 3. Auflage

hrsg. v. Von Ardenne M, Musiol G, Klemradt U

Verlag Harri Deutsch Frankfurt 2005

\section{Wagner W, Al-Nawas B:}

Implantatmaterialien und Konstruktionsprinzipien der Implantate aus chirugischer Sicht.

In: Implantologie, hrsg. v. Koeck B and Wagner W

2. Auflage, Urban \& Fischer, München Jena 2004, 61-97

\section{Wagner W, Koeck B:}

Einleitung in: Praxis der Zahnheilkunde.

Implantologie Bd. 13; Urban \& Schwarzenberg, München-Wien- Baltimore 2004, 4

\section{Weber W, Rieger W:}

ZrO2-TZP in Dentistry: Materials, Properties and Applications.

In: Key engineering materials. Proceedings of the 13th Int. Symp. on Ceramics in Medicine. Bologna, Italy 22.Nov. 2000.

Trans Tech Publications, Switzerland 2001, 929-932

\section{Wissenschaftliche Dokumentation:}

IPS EMPRESS®. Forschung und Entwicklung. Wissenschaftlicher Dienst 1997

\section{Wohlwend A, Schärer P (1990):}

Die Empress-Technik; Eine neue Möglichkeit Einzelkronen, Inlays und Verblendschalen herzustellen.

Quintessenz Zahntech 16, 966-978 
Wohlwend A, Studer S, Schärer P (1996):

Das Zirkonoxidabutment - ein neues vollkeramisches Konzept zur ästhetischen Verbesserung der Suprastruktur in der Implantologie.

Quintessenz Zahntechnik 22, 364-381.

Wolfart M, Wolfart S, Kern M (2006):

Retention forces and seating discrepancies of implant-retained castings after cementations.

Int J Oral Maxillofac Implants 21, 519-525

Woody TL, Davis RD (1992):

The effect of eugenol-containing and eugenol-free temporary cements in microleakage in resin bonded restorations.

Oper Dent 17, 175-180

Wüstefeld F, von Blackenburg $\mathbf{H}(2007)$ :

Individuelle CAD/CAM-gefertigte Abutments und Kronen aus Zirkoniumdioxid

Digital Dentalnews, 1. Jahrgang, 36-43

Yang B, Barloi A, Kern M (2010):

Influence of air-abrasion on zirconia ceramic bonding using an adhesive composite resin.

Dental Materials Volume $\underline{26}, 44-50$

Zipprich H, Weigl P, Lange B, Lauer HC (2007):

Erfassung, Ursachen und Folgen von Mikrobewegungen am Implantat-AbutmentInterface

Implantologie 15: 31-46

\section{Znamensky NN (1891):}

Implantation künstlicher Zähne.

Dtsch Monatsschr Zahnheilkd 으, 87 


\section{Danksagung}

Mein besonderer Dank gilt Herrn PD Dr. med. dent. Nikolaus Gersdorff für die Überlassung des Dissertationsthemas und die hilfsbereite Betreuung während der Durchführung der Arbeit.

Herrn Dr. Matthias Rödiger gilt ebenfalls mein besonderer Dank für die vielfältige Unterstützung und Hilfsbereitschaft.

Herrn Dr. Sven Rinke danke ich für seine fachliche Unterstützung.

Frau Dr. Kirsten Techmer der Abteilung Kristallographie gilt mein Dank für die Kooperation.

Frau Dr. Katharina Lange der Abteilung Medizinische Statistik danke ich für die Zusammenarbeit.

Bei der Firma DeguDent bedanke ich mich für die Bereitstellung der Materialien. 


\section{Lebenslauf}

Am 21.01.1988 wurde ich, Franziska Pohlmeyer, als erste Tochter von Heinrich Pohlmeyer und Aspasia Pohlmeyer, geb. Mingou, in Itzehoe geboren.

Von 1994 bis 1998 besuchte ich die Grundschule in Burg/Dithmarschen, von 1998 bis 2007 die Meldorfer Gelehrtenschule, an welcher ich meine allgemeine Hochschulreife am 11.06.2007 erlangte. Im April 2008 nahm ich das Studium der Humanmedizin an der Martin-Luther-Universität Halle-Wittenberg bis zum Erhalt des Zulassungsbescheids für Zahnmedizin in Göttingen auf. Zum Sommersemester 2008 begann ich anschließend mit dem Studium der Zahnmedizin an der Georg-AugustUniversität Göttingen, an der ich im März 2009 die naturwissenschaftliche Vorprüfung und im März 2011 die zahnärztliche Vorprüfung ablegte.

Im Sommersemester 2011 begann ich meine Doktorarbeit in der Abteilung Prothetik im Zentrum Zahn-, Mund- und Kieferheilkunde der Universitätsmedizin Göttingen unter der Betreuung von PD Dr. med. dent. Nikolaus Gersdorff.

Voraussichtlich werde ich das Studium der Zahnmedizin Ende des Jahres 2013 mit dem Staatsexamen abschließen. 